\title{
STUDENTS PERCEPTIONS OF INTERACTIONS IN A BLENDED SYNCHRONOUS LEARNING ENVIRONMENT: A CASE STUDY
}

\section{by}

Sheri Lyn Conklin

\author{
A dissertation \\ submitted in partial fulfillment \\ of the requirements for the degree of \\ Doctor of Education in Educational Technology \\ Boise State University
}

May 2017 
(C) 2017

Sheri Lyn Conklin

ALL RIGHTS RESERVED 


\title{
BOISE STATE UNIVERSITY GRADUATE COLLEGE
}

\section{DEFENSE COMMITTEE AND FINAL READING APPROVALS}

\author{
of the dissertation submitted by
}

Sheri Lyn Conklin

Dissertation Title: Students Perceptions of Interactions in a Blended Synchronous Learning Environment: A Case Study

Date of Final Oral Examination: March 17, 2017

The following individuals read and discussed the dissertation submitted by student Sheri Lyn Conklin, and they evaluated her presentation and response to questions during the final oral examination. They found that the student passed the final oral examination.

Jesús Trespalacios, Ph.D.

Chair, Supervisory Committee

Chareen Lee Snelson, Ed.D.

Member, Supervisory Committee

Patrick R. Lowenthal, Ph.D.

Member, Supervisory Committee

The final reading approval of the dissertation was granted by Jesús Trespalacios, Ph.D., Chair of the Supervisory Committee. The dissertation was approved by the Graduate College. 


\section{ACKNOWLEDGEMENTS}

I would like to express my gratitude to my committee. Sincere thanks goes to Dr. Jesús Trespalacios for his support, guidance, and reassurance throughout the entire process. I would also like to thank Dr. Patrick Lowenthal for his support and guidance, in addition to the invaluable corrections he gave me. I was able to expedite the analysis process due to data analysis software recommendations made by Dr. Chareen Snelson. In addition, I would like to thank my husband, Chris for his support throughout this process. This endeavor would not have been possible without his love and encouragement. I would also like to thank Dr. Beth Oyarzun and Dr. Daisyane Barreto for taking the time to read many drafts and being a source of support and encouragement. 


\begin{abstract}
Social presence has been analyzed in online asynchronous environments within higher education. The current study was designed to garner insight into students' perceptions of social presence within the Blended Synchronous Learning Environment (BSLE). This environment is unique since it includes both the face-to-face classroom and an online synchronous classroom in one environment. The research described in the current paper was a case study designed to examine the experiences of graduate students in two blended synchronous classes. Specifically, the research examined students' perceptions of interactions within the BSLE. Analysis included an examination of how students described interactions with their peers, the instructor, designed interactions and social presence. Participants were students taking classes in the BSLE. Observations, interviews, and an open-ended survey were used to collect data.

Findings indicated that students preferred to interact with the instructor during whole class discussion but stated that social presence was an important aspect to their learning. Students also described a process of forming social bonds with their peers in terms of designed interactions, activities designed by the instructor to promote collaboration. The web camera was described by the students as a means for beginning to form relationships through the ability of being able to physically identify their colleagues. Further, students were able to form relationships with their peers through designed interactions such as case studies and ill-structured problems.
\end{abstract}


Based on the results of this study, suggestions for instructors and designer/course developers regarding the design and implementation of class activities are provided.

Future research can build on the findings to investigate how students form relationships through intentionally designed activities that promote collaboration. Additionally, more research is needed to validate instructional strategies specific to the BSLE. 


\section{TABLE OF CONTENTS}

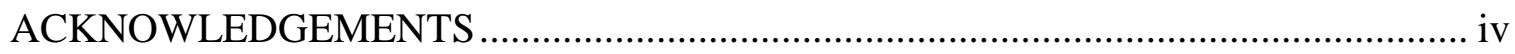

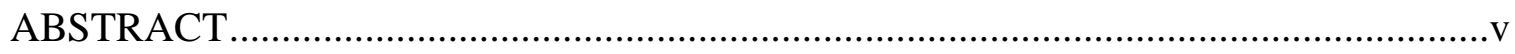

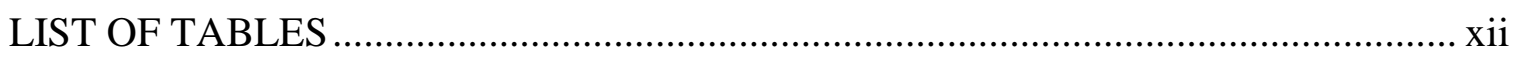

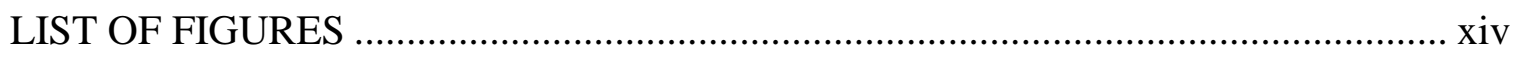

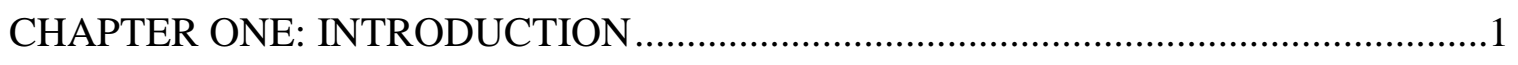

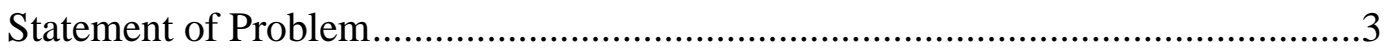

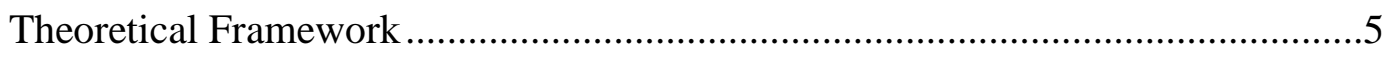

Moore's Transactional Distance ............................................................6

Community of Inquiry and Social Presence ………….............................6

Blended Synchronous Learning Design Framework …….............................8

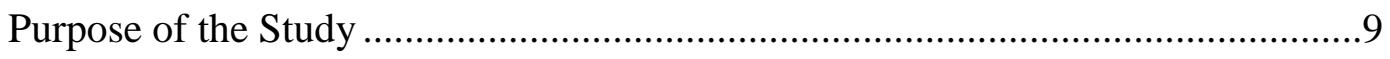

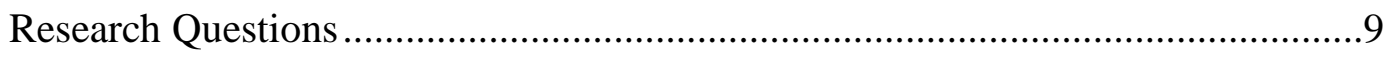

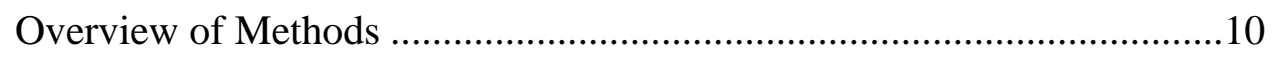

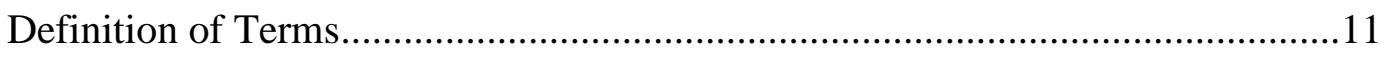

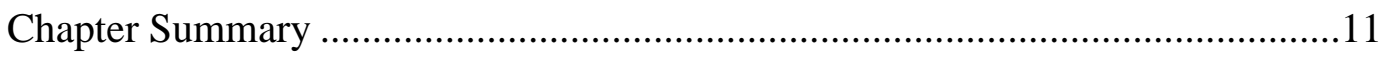

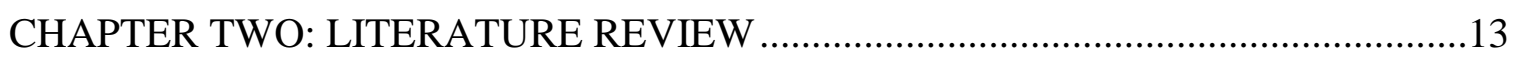

History of Blended Learning Environments ........................................................13

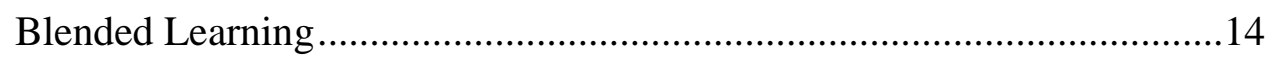

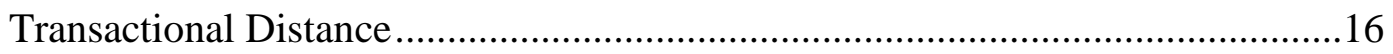


Learner to learner ........................................................................ 17

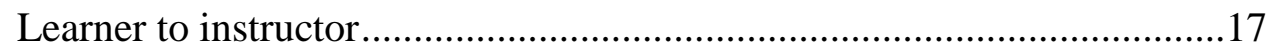

Learner to content ....................................................................... 18

Blended Synchronous Learning Environments ..............................................19

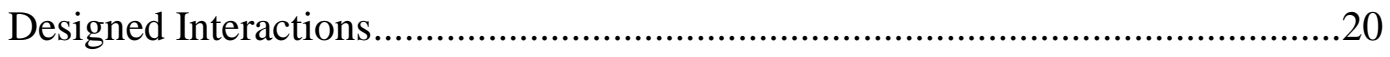

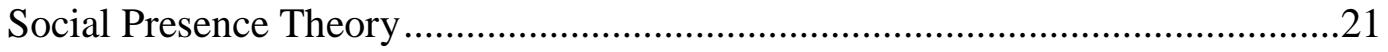

Community of Inquiry ...................................................................21

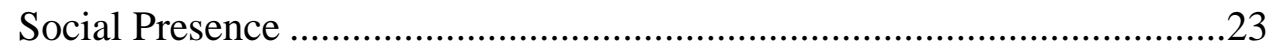

History of Social Presence .............................................................24

Definition of Social Presence............................................................24

Challenges and Opportunities in the BSLE .............................................26

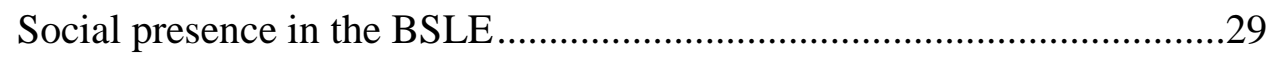

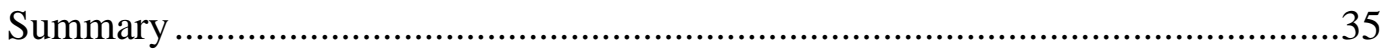

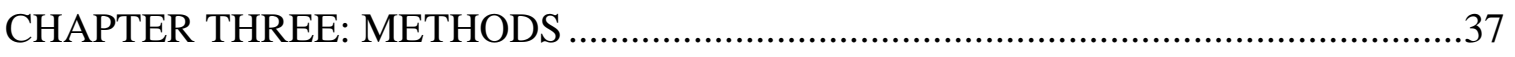

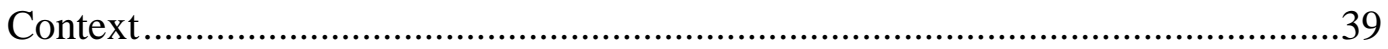

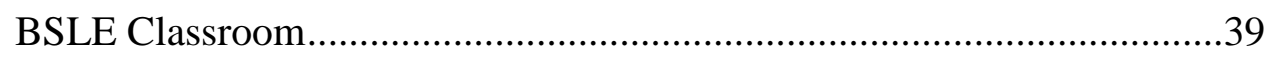

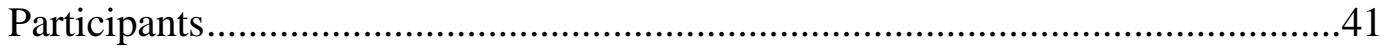

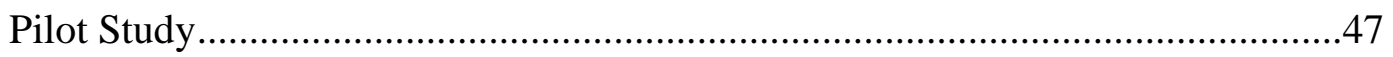

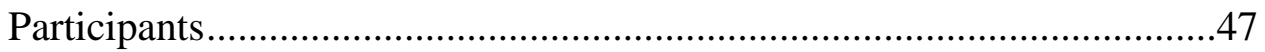

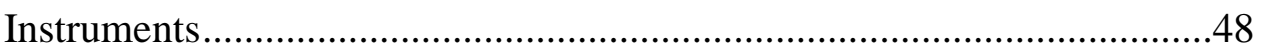

Results of interactions ...............................................................49

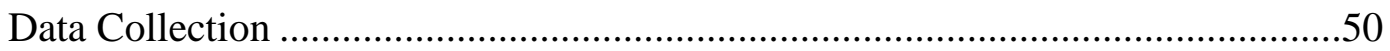

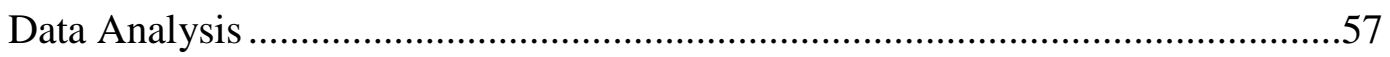


Methods for Trustworthiness Validation ....................................................62

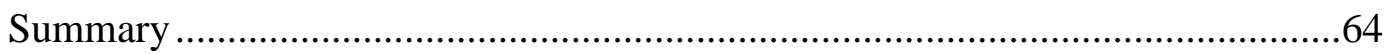

CHAPTER FOUR: RESULTS AND FINDINGS ...................................................65

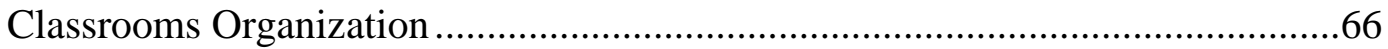

Instructional Technology classroom ...............................................66

Leadership Theory Classroom ............................................................68

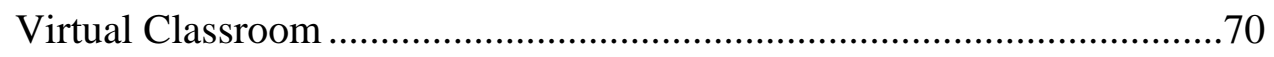

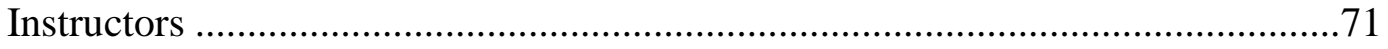

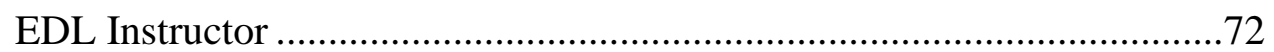

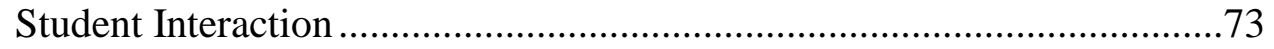

MIT Instructor ........................................................................ 76

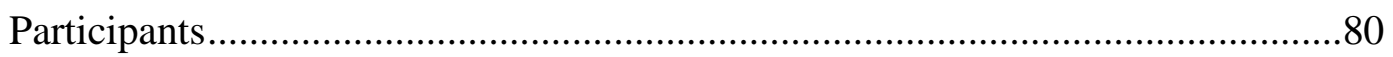

Research Question One .......................................................................... 81

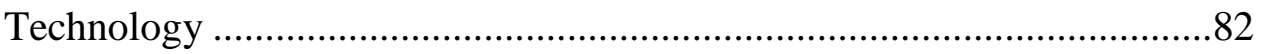

Instructor Knowledge with Technology .............................................85

Summary for Question One ......................................................... 86

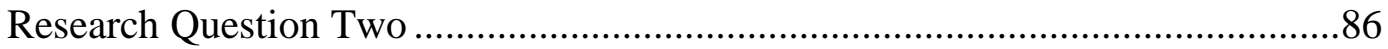

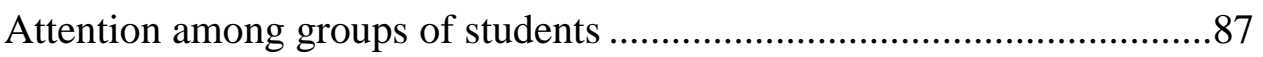

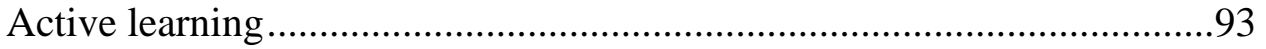

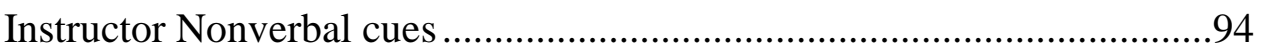

Summary for Question Two..........................................................96

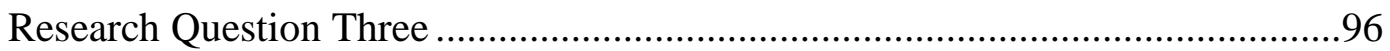

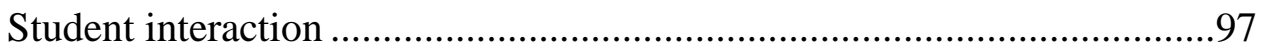


Group activities

Research Question Three Summary................................................101

Research Question Four ..........................................................................101

Research Question Four Summary ..................................................104

Research Question Five ................................................................... 104

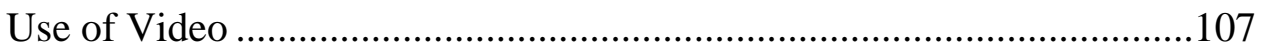

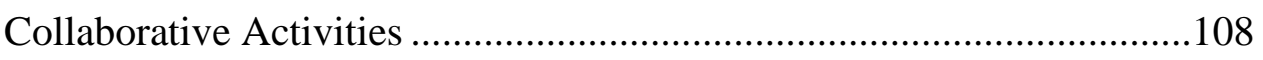

Grouping Students for In-Class Work .............................................109

Research Question Five Summary ................................................111

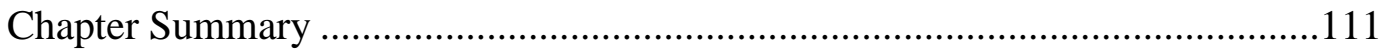

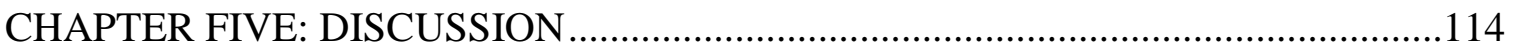

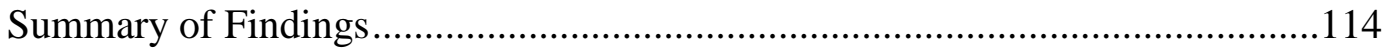

Research Question \#1: What are Students' Experiences in Within the Live

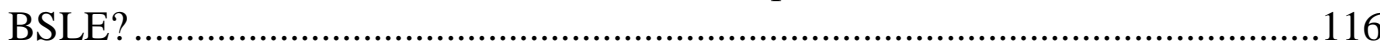

Research Question \#2: How Do Students Describe Interactions (Student and Instructor) Within the Live BSLE? ............................................................119

Research Question \#3: How Do Students Describe Interactions (Student and Student) Within the Live BSLE?

Research Question \#4: How Do Students Describe Designed Interactions Within

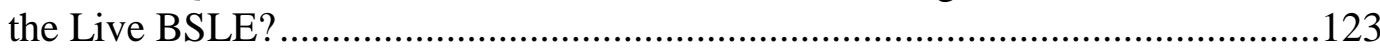

Research question \#5: How Do Students Describe Social Presence Among the Face-to-Face and Online Students Within The BSLE? ....................................125

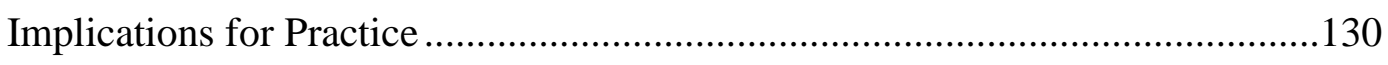

Blended Synchronous Framework ..................................................130

Social Presence ..........................................................................132

Additional Practices Based on this Case Study Project .........................133 
Implications for Research ...............................................................136

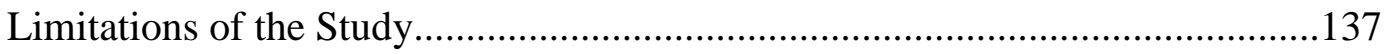

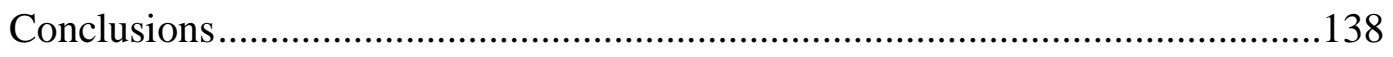

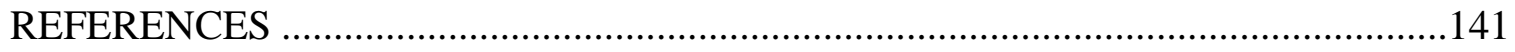

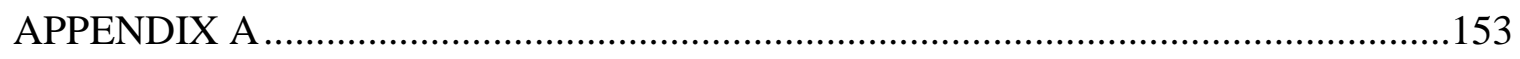

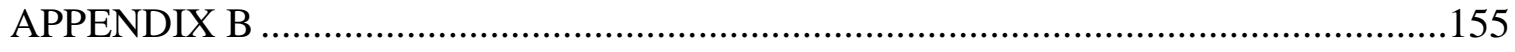

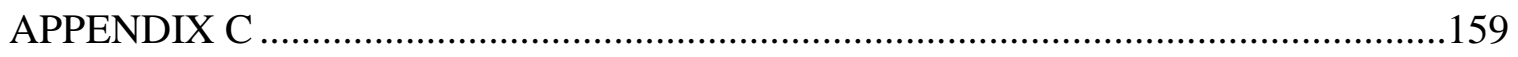

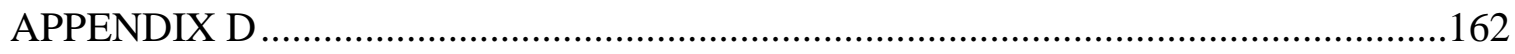

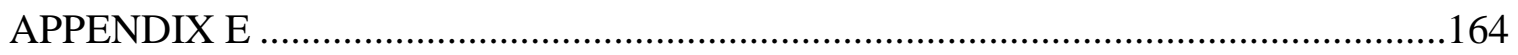

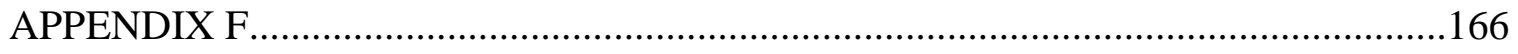

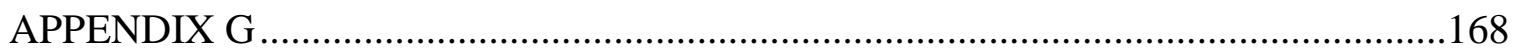

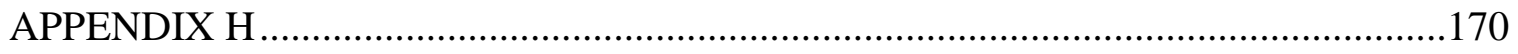




\section{LIST OF TABLES}

Table 1 The various blended synchronous learning environments explored by Hastie, Hung, Chen, and Kinshuk (2010)................................................. 15

Table 2 Number of students registered and classification for MIT 500 and EDL 601 students.

Table 3 Number of students who attended online and face-to-face for MIT 500 throughout the observation period ............................................................ 46

Table $4 \quad$ Number of students who attended online and face-to-face for EDL 601 throughout the observation period ......................................................... 46

Table 5 The overall mean of instructor, environment, and interaction................... 50

Table 5 Research questions and methods of data collection to address each question

Table 6 Data collection methods and timeline MIT 500: Instructional Design: Theory and Research.............................................................................. 51

Table 7 Data collection methods and timeline for EDL 601: Leadership Theory. 52

Table $8 \quad$ Data collection methods and method for trustworthiness.......................... 62

Table 9 Table depicting the age range of the students who completed the electronic

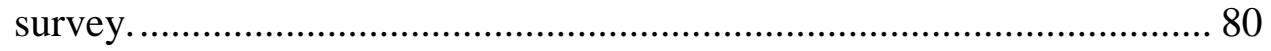

Table $10 \quad$ Student preference for attending class in the BSLE. ................................ 81

Table 11 Technical questions from MIT and EDL students................................... 84

Table 12. Frequency of interactions by class......................................................... 89

Table 13 Average number of students attending the EDL and MIT classes in the online and face-to-face environment.

Table 14 Interactions between the instructor, class, face-to-face students and online students in the Leadership Theory class (EDL). 
Table 15 Interactions between the instructor, class, face-to-face students and online students in the Instructional Technology class (MIT).

Table 16 Student interaction from both the MIT and EDL classes (10 class sessions).

Table 17 Student perceptions of social presence based on webcam, and collaborative activities. 106

Table 18 The Blended Synchronous Learning Design Framework with the practices used in this study bolded. 118

Table 19 The Blended Synchronous Design Framework with additional recommendations from this case study research project. Additional recommendations are in bold. 


\section{LIST OF FIGURES}

Figure 1. Various definitions and degrees of social presence. ............................ 26

Figure 2. The bounded cased of the BSLE and the embedded units which are the individual classes who volunteered for this case study research. Both classes are introduction core classes. ................................................ 40

Figure 3. The Instruction Technology Blended Synchronous classroom for Instructional Technology. Cisco telepresence was used to outfit the classroom including the instructor's station, classroom cameras, microphones (located on each table), and projection screen. WebEx is a web-based software that is used on the instructor's station computer and projected onto the projection screen so the face-to-face students can see the online students

Figure 4. $\quad$ MIT program organizational chart................................................... 44

Figure 5. EDL Program organization chart...................................................... 45

Figure 6. Example of operational diagram use to move from first cycle coding to second cycle coding ................................................................. 58

Figure 7. Example of codebook from first cycle coding with categories................ 61

Figure 8. Screenshot from Nivio 11 depicting the nodes or themes that emerged... 61

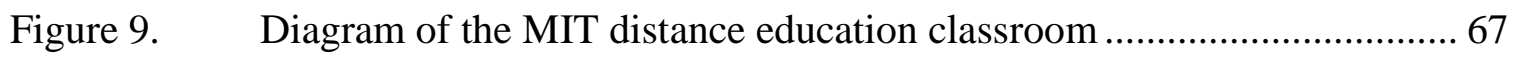

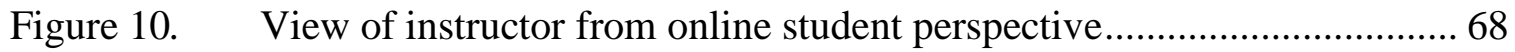

Figure 11. View of the face-to-face student table with microphone from online

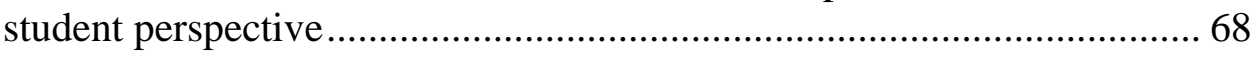

Figure 12. Diagram of the Leadership Theory classroom .................................... 70

Figure 13. View of the EDL classroom from the online student's perspective ........ 70

Figure 14. Social presence process as described by the students .......................... 106 


\section{CHAPTER ONE: INTRODUCTION}

Online course enrollments have continued to increase over time (Allen \& Seaman, 2015). Online course offerings are also growing to accommodate diverse nontraditional student audiences such as deployed military or other working adults (Schornack \& Beck, 2016).

Online learning environments can take many forms (Szeto \& Cheng, 2014). For instance, there are online learning environments that use asynchronous tools such as discussion boards, synchronous tools such as Skype, and blended forms of communication technologies. In learning environments using asynchronous communication technologies, students and the instructor(s) usually do not meet online or face-to-face at the same time; instead, they use a variety of communication media, such as email and discussion boards, to correspond with one another. In synchronous environments, on the other hand, students and the instructor(s) are separated by distance, but not time. The instructor and students gather as a whole at a certain time of day through the use of synchronous communication technologies (e.g., Cisco WebEx, Adobe Connect, Blackboard Collaborate). Finally, there are learning environments, often called blended or hybrid learning environments, that incorporate both synchronous or asynchronous tools in face-to-face learning environments to reduce time in the face-toface environments (Osguthorpe \& Graham, 2003). 
Blending learning environments are growing in popularity and have been adopted by an increasing number of educational institutions in order to offer flexibility to students (Christensen \& Evamy, 2011; Pelliccione \& Broadley, 2010). Higher education is no longer defined by physical boundaries. Keppell, Souter, and Riddle (2012) have suggested that instructors facilitating instruction in technology enriched environments be aware of the benefits and constraints of the various technologies and how these technologies can be utilized to positively affect student learning. Blended learning environments can take many forms. The most popular form is where asynchronous communication technologies are used to reduce face-to-face classroom meetings. Another type of blended learning environment is the blending of online and face-to-face students within one classroom; this type is often called the Blended Synchronous Learning Environment (BSLE) (Osguthorpe \& Graham, 2003).

BSLEs combine the face-to-face environment with synchronous technologies or virtual classrooms where students can participate in one class together. For instance, students can opt to attend class in the physical classroom environment or they can attend via virtual classroom. This environment provides the face-to-face and online students an opportunity to interact with one another and the instructor. BSLE allows for flexibility for students at a distance who prefer live interaction with the instructor and peers. It also allows those students who live in the proximity of the face-to-face environment to attend class physically. Convenience has been cited as a reason for students to participate in the blended synchronous environment as many work full time, have to tend to children, or are ill (Norberg, 2012). In the blended synchronous environment distance students can participate with face-to-face counter parts which can create an enhanced social presence 
among all students (Bower et al., 2015). Interaction among students and instructors can happen through both audio and/or text chat. Students and instructors use microphones to talk so students in the virtual environment can listen. Classrooms should be equipped with speakers so face-to-face students can also hear the online students. Typically, virtual classrooms contain a text chat option which allows students to also communicate with the instructor and peers in a text-based format.

\section{Statement of Problem}

With the growth of distance education, universities are experimenting with various types of blended learning that will enable students at a distance to have a similar experience as attending a face-to-face class. The BSLE presents a unique environment where students are both face-to-face and at a distance concurrently. The BSLE allows for students locally and at a distance to participate in engaging activities with the instructor and their peers in real time. The BSLE is different from both the face-to-face

environment and online synchronous environment since it combines the face-to-face and online synchronous environment in one setting.

Although, blended synchronous learning environments have been around since early 2000's, there has been little research conducted on students' experiences in these environments, specifically in terms of instructor-student and student-student interaction and especially between those in the face-to-face environment and those at a distance (Bower et al, 2015; Szeto \& Cheng, 2014; Szeto, 2015). Some researchers have analyzed the patterns of interactions within the BSLE to determine how these interactions affect the students' and instructors' experiences (Rasmussen, 2003; Szeto, 2015; Szeto \& Cheng, 2014). As useful as this initial research has been, many of these studies focused 
only on the frequency of interactions and not the quality of interactions. For instance, Szeto and Cheng (2014) analyzed a BSLE class to determine the frequency of pedagogic interactions. They used a coding framework based on the Community of Inquiry (CoI), developed for asynchronous learning environments (see Garrison \& Anderson, 2003; Ice et al, 2007; Rourke et al., 2001); therefore, these codes may not be the best way to analyze interaction in blended synchronous learning environments. The codes developed for the asynchronous learning environments may not translate well to a synchronous environment. Rasmussen (2003), on the other hand, analyzed the frequency of interactions based on Moore's three types of interactions (i.e. learner-learner, learnercontent, learner- instructor). Rasmussen, however, did not delve deeper into how interactions affected students' educational experiences. By elaborating on students' experiences, one can ascertain on whether these types of interactions are beneficial to student learning and how the interaction contributed to creating social presence among students.

Other researchers have done some initial research into strategies for conducting a class in the BSLE and the impact on both students' and instructors' experiences (Bower et al., 2015; Cunningham, 2014). Bower et al. (2015) conducted a comprehensive research project that analyzed seven cases of classes taught in the BSLE in order to develop a pedagogic framework for practitioners: Blended Synchronous Design Framework. This framework guides instructors through best practices before, during and after implementation. They postulated that activities should be well designed prior to implementation and technology should be thoroughly tested. Students should also be versed in the technologies being utilized. The researchers also discovered that 
implementing active learning strategies will assist with students reaching the intended learning outcomes, increase student satisfaction, and increase social presence.

Although these studies provide insight into the BSLE, research on how interactions shape both the students' and instructors' experiences is lacking. This is important because many educators are not versed in teaching in the BSLE. These educators, and even many with experience teaching in BSLE, need more research on how best to organize and manage a class to facilitate student learning and interaction in order to achieve intended learning outcomes and student satisfaction (Bower et al., 2015).

\section{Theoretical Framework}

In past decades, researchers have explored how social presence, or the extent to which students connect with other students in the course, affects the students' educational experiences particularly in the asynchronous environment (Anderson et al., 2001; Garrison, Anderson, \& Archer, 2000; Gunawardena, 1995; Gunawardena \& Zittle, 1997; Lowenthal, 2009; Picciano, 2002; Richardson \& Swan, 2003). The ability to create cohesive social groups among learners has been heavily researched particularly in asynchronous environments where there is a physical distance among learners (Anderson et al., 2001; Garrison et al., 2000; Gunawardena, 1995; Gunawardena \& Zittle, 1997; Lowenthal, 2009; Picciano, 2002; Richardson \& Swan, 2003). Social presence has shown to improve learning and student satisfaction (Garrison et al., 2000; Gunawardena, 1995; Richardson \& Swan, 2003). In the BSLE, learners are both face-to-face and at a distance which creates a unique environment (Bower et al, 2015; Cunningham, 2014; Szeto, 2015). Therefore, three major theoretical perspectives, Moore's Transactional Distance, social presence and blended synchronous learning design framework, will be used to 
analyze how interactions in the BSLE can contribute or hinder the ability to create a cohesive group among learners.

Moore's Transactional Distance

Transactional distance is a pedagogical concept that emerged in 1972 that describes the instructor to learner relationship in terms of being physically separate, which affects structure, dialogue, and autonomy (Moore, 1993). Transactional distance theory proposes that distance in online courses is transactional not spatial. Structure (learner-content) refers to course design or in the case of the BLSE, the design of the environment in terms of activities, assignments, and planned interactions. Dialogue refers to the communication between and among the instructor and students. Moore (1989) identified learner-instructor interactions within dialogue construct. Finally, autonomy is a technique used by learners to manage learning as self-reliant manner (Moore, 1989). According to Moore (1993), transactional distance is reduced when there is an increase of interaction between the student and instructor. Moore (1989) went on to define three core types of interaction: learner-learner, learner-instructor, and learner-content. These types of interactions will be the basis for understanding the patterns of interactions that occur during the BSLE.

\section{Community of Inquiry and Social Presence}

Community of Inquiry (CoI) is a theoretical framework used for the research and practice of online learning. There are three overlapping essential elements to CoI: social, cognitive, and teaching presence (Garrison, 2009). Grounded in specific philosophical and epistemological assumptions from Dewey's (1938) practical inquiry, CoI aims to encourage higher order cognitive processing through a collaborative/constructivist 
environment (Garrison, 2011). The framework suggests that the online experience happens at the intersection of the three constructs. Social, cognitive and teaching presence if designed in balance, create a collaborative environment of a community of learners (Akyol, Garrison, \& Ozden, 2009). This study will focus on social presence. There is no one agreed upon definition of social presence as researchers continue to redefine social presence. Social presence refers to the degree to which people are perceived as real when using Computer Mediated Communications (CMC) (Picciano, 2002) or the ability to project themselves (Garrison et al., 2000). Social presence initially was researched in text-based asynchronous environments. Research has also used social presence in the web-enhanced blended and synchronous environments (Garrison \& Anderson, 2003; Rourke et al., 2001; Szeto, 2015; Szeto \& Cheng, 2014).

A sense of group commitment where students see themselves as part of a whole rather than an individual is described as group cohesion. The construction of group cohesion typically uses conversational strategies such as humor and joking banter (Garrison, Anderson, \& Archer, 1999). This category is important as students have a sense of belonging, which is important to sharing personal meaning and developing discourse. The development of discourse through information sharing is essential to knowledge construction (Garrison et al., 1999; Swan \& Shih, 2005).

Picciano (2002) postulated that interactions alone do not create social presence among the class; one also needs to consider the quality of interactions. The organization and design of effective interactions is essential to the success of creating a cohesive class among the face-to-face, online students and instructor while lessening instructor cognitive and affective load during teaching (Bower et al., 2015; Teng, Chen, \& Leo, 
2012). Therefore, it is essential to continue to explore designed interactions in the BSLE as well as social presence and hence student's perceptions and rationale for their perceptions on designed interactions and social presence.

\section{Blended Synchronous Learning Design Framework}

Bower et al. (2015) developed the Blended Synchronous Learning Design

Framework. This framework is developed for instructors and is divided into three stages: presage, process, and product. Each stage consists of three categories: pedagogy, technology, logistic/setup. The presage reviews components to be complete prior to classroom instruction. The process stage consists of activities to be completed during class time, and the product are the outcomes of following the framework.

The blended synchronous learning design framework encourages instructors to clearly define learning outcomes and grouping strategies prior to conducting class. During class instruction, use of active learning strategies is encouraged as well as encouraging regular student contributions and distributing attention between remote and face-to-face students. Active learning is a broad term for pedagogies that focus on student activity and engagement (Chickering \& Gamson, 1987). Active learning strategies that engage students to collaborate with one another will be defined for the purpose of this study as designed interactions. Designed interactions emphasize active engagement between both peers and the instructor (Parker, Maor, \& Herrington, 2013). Overall, use of these strategies will allow for more active learning for both the distance and face-to-face students, enhance sense of communication and increased student satisfaction (Bower et al., 2015). 


\section{Purpose of the Study}

The purpose of this study was to investigate students' perceptions of designed interactions, interactions that are intentionally created by the instructor to provide students an opportunity to collaborate, among the instructor and students within the BSLE. The researcher applied Moore's three types of interactions, social presence theory, and the blended synchronous design framework to evaluate how designed interactions may influence social presence within the virtual classroom. Moore's types of interactions were used to frame the frequencies of interactions. The frequencies of interactions were compared to student responses to validate student responses and perceptions. The various definitions of social presence theory were applied to student responses and analyzed to determine how students described social presence. The suggested strategies from the blended synchronous design framework were analyzed according to the data collected. The suggestions from the blended synchronous design framework insinuated that if the methods are employed students will have a positive experience in the BSLE and as a result, there will be an increase in social presence among the students. Subsequently, in the end, this study was to gather student perceptions of designed interactions and social presence in the BSLE. Furthermore, students' perceptions towards these types of interactions were studied, and recommendations for best practices in the BSLE were evaluated based on the blended synchronous design framework.

\section{Research Questions}

\section{Central question:}

How do students perceive the various interactions that take place within the BSLE?

\section{Sub Questions:}


- What are students' experiences within the live BSLE?

- How do students describe interactions (student and instructor) within the live BSLE?

- How do students describe interactions (student and student) within the live BSLE?

- How do students describe designed interactions within the live BSLE?

- How do students describe social presence within the BSLE?

Overview of Methods

The research utilized a qualitative case study approach to understand how interactions affect student perceptions of social presence and rationale for student perceptions. This case study approach employed a single case study with embedded units of two classes within the BSLE. Multiple methods of data collection were used (e.g. observations, interviews, and open-ended surveys). Semi-structured observations were a method for the researcher to gain firsthand knowledge of the phenomenon (Creswell, 2012). Since there were pre-determined categories, the observations were semistructured. During observations, frequencies of interactions were also recorded to triangulate data from the observations, surveys, and interviews (Merriam \& Tisdell, 2015). Semi-structured interviews were conducted with both instructors and students. The instructor interviews informed the researcher of their pedagogical approaches to teaching within the BSLE. The student interviews were used to gather additional information regarding the student experience. Finally, an open-ended survey was sent out to both classes to gather initial information on students' perceptions of interactions and social presence within the BSLE. The data from the observations, interviews, and survey was coded for patterns, and a rich description is provided to support the findings. Further detail of the methods is found in Chapter Three. 


\section{Definition of Terms}

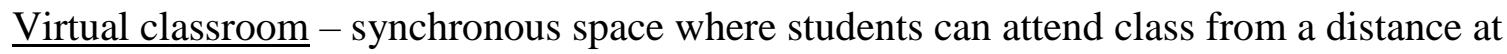
a certain time (e.g. WebEx, Bb Collaborate, Adobe Connect).

$\underline{\text { Social presence }}$ - degree of salience of the other person in the interaction and the consequent salience of the interpersonal relationship (Short et al., 1976).

Blended Synchronous Learning Environment - one class where students can attend virtually through a virtual classroom or physically face-to-face simultaneously.

Designed Interactions - interactions that are intentionally created by the instructor to provide students an opportunity to collaborate.

\section{Chapter Summary}

Social presence has been at the forefront of research for the last two decades with regards to distance education. The landscape of distance education continues to change over time from correspondence courses, asynchronous, synchronous, and blended learning. The Blended Synchronous Learning Environment is a unique environment that combines the face-to-face classroom with the synchronous environment. With little research on the BSLE with regards to social presence, this study contributed to existing literature on best practices for conducting classes to encourage students to meet intended learning outcomes, enhance social presence and increase student satisfaction. In the following chapter, BSLE, Moore's transactional distance, social presence, and blended synchronous design learning framework are further defined, and research on the BSLE will be analyzed to determine the gaps in the literature. Chapter Three explains the methods of data collection and data analysis. Chapter Four contains the results of the data 
analysis including a thick description from student/instructor interviews, observations, and survey analysis. Chapter Five discusses the results through the existing literature as well as implications of the results. 


\section{CHAPTER TWO: LITERATURE REVIEW}

The purpose was to discover students' perceptions of designed interactions in the Blended Synchronous Learning Environment (BSLE). The purpose of this review is to define the BSLE and examine the underlying aspects that support interactions in this environment such as Moore's Transactional Distance, social presence, and blended synchronous design framework. Levels of interaction will be identified, social presence will be discussed to highlight the importance of interactions, and finally, a framework for blended learning design will be discussed.

\section{History of Blended Learning Environments}

Distance education, a concept that has been around since the late $19^{\text {th }}$ century, was originally developed around one-way communication. At first, distance education consisted of correspondence courses which relied on the postal service for exchanging communication, however, as radio and television became more prominent in the 1950's more college credit courses began to be offered via broadcast television (Simonson et al., 2014). One drawback of one-way communication was the amount of time needed to create interaction between the student and instructor (Porter, 1994). As new innovative technologies emerged such as the Internet, blended learning began to take shape with the combination of face-to-face and online environments. The success and satisfaction of blended learning has been attributed to the interactive capabilities of Internet communication technology (Garrison \& Cleveland-Innes, 2003). The advent of Internet communication technologies with the rich dynamic, fast-paced, spontaneous verbal 
communication increased educational possibilities including blended learning environments (Garrison \& Kanuka, 2004).

Blended Learning

The term "blended learning" is used in academic journals and conferences frequently however often this term can be used to describe a myriad of different environments (Osguthorpe \& Graham, 2003; Reece \& Lockee, 2005; Picciano, 2006). Many definitions have emerged to describe blended learning and include: an environment with more than one delivery mode (Singh \& Reed, 2001), a mix of instructor led training with technology based learning (Bielawski \& Metcalf, 2005), and a mix of traditional training and innovative technologies (Thorne, 2003). Quinn et al. (2012) identified three levels of blended learning: (1) the blending of instructor expertise and approaches, (2) mode of delivery (3) inter-institutional collaboration. Blended learning can take on many forms ranging from the blending of activities, students, model of interaction, and instructors.

Osguthorpe and Graham (2003) analyzed blended learning to define the various types blended learning that can occur. Osguthorpe and Graham (2003) analyzed the learning activities, students, and instructors to develop three models of blended learning that can occur: (1) blending of online and face-to-face activities, (2) the blending of online and face-to-face students in one environment, and (3) the blending of multiple instructors either face-to-face or from a distance. The blending of online and face-to-face activities refers to the blending of activities. For example, students may participate in inclass activities and then have another activity such as an online discussion. In the case where a course has multiple instructors who team teach would be an example of blending 
online and face-to-face instructors when one instructor is online and the other is face-toface. Model two, the blending of online and face-to-face students will be the learning environment of this study's focus.

Hastie et al., (2010) explored a variety of blended learning environments that involved students and instructors connecting through multiple combinations of the virtual and physical classrooms to engage in educational collaborations (Table 1).

Table 1 The various blended synchronous learning environments explored by Hastie, Hung, Chen, and Kinshuk (2010).

\begin{tabular}{lll}
\hline Learning Environment & Instructor & Student \\
\hline Mode 1 & Online only & Physical and online classrooms \\
Mode 2 & Physical classroom only & Online classroom only \\
Mode 3 & Physical classroom only & Physical and online classrooms \\
Mode 4 & Online classroom only & Physical classroom only \\
Mode 5 & Physical and online classroom & None \\
Mode 6 & Physical and online classroom & Physical only \\
Mode 7 & Online only & Physical and online classrooms \\
Mode 8 & Physical and online classrooms & Online only \\
Mode 9 & Physical and online classrooms & Physical and online classrooms \\
\hline
\end{tabular}

Through this case study research, Hastie et al. (2010) coined the term blended synchronous learning environment (BSLE) to describe the various models for combining face-to-face and online instruction. For this study, the focus will be Mode 3, which combines the face-to-face and online environments in a way that students can attend a live class either in person or from a distance. Bower et al. (2015) defined this type of environment as "Learning and teaching where remote students participate in face-to-face classes by means of rich-media synchronous technologies such as video conferencing, 
web conferencing, or virtual worlds" (p. 1). The BSLE combines two or more learning settings in one flexible environment and includes audio/visual technologies, whiteboard, chat, and desktop sharing that resemble a face-to-face classroom (Hastie et al., 2010; Oyarzun \& Martin, 2013). Both the face-to-face students and the online students have the ability to interact with the instructor and their online and face-to-face peers. This type of environment gives students who are unable to attend class due to a geographical distance the opportunity to take part in live class sessions.

\section{Transactional Distance}

Moore (1989) laid the groundwork for interaction through this transactional distance theory and it is defined as a pedagogical concept that describes the instructor to learner relationship in terms of being physically separate which affects structure, dialogue, and learner autonomy which represents the psychological distance of space and time between the instructor and the students (Moore, 1993). Structure refers to the course's rigidity or flexibility in terms of educational goals, instructional strategies, assessment, and addressing individual needs. Dialogue refers to the communication between and among the instructor and students. Autonomy is a technique used by learners to manage learning in a self-reliant manner. According to Moore, (1993) transactional distance is reduced when there is an increase of interactions between the student and instructor. Moore (1989) then suggested three types of interaction dyads: (1) learner to learner (2) learner to instructor (3) learner to content. These dyads are further defined in the following sections.

Wagner (1994) has offered a broad definition stating that interaction is "reciprocal events that require at least two objects and two actions. Interactions occur when these 
objects and events mutually influence one another" (p. 8). Interactions have continued to be analyzed with the increase of distance education courses and information and communication technologies (ICT). Moore's (2013) Transactional Distance theory emerged as a prevalent theory for defining distance education as a type of transaction, and the distance between the learning and teachers as psychological rather than physical.

\section{Learner to learner}

Learner to learner interaction is an exchange and collaboration between individual and/or groups of students (Moore, 1989). This can occur within instructor designed activities or within learner created activities without instructor knowledge (Anderson et al., 2000). Instructors often provide students with the opportunity for learner to learner interaction in online classes through group projects and threaded discussion boards. Collaborative projects of this nature encourage students to analyze various cases or prompts in order to build new knowledge (Ravenna, Foster, \& Bishop, 2012). Through learner to learner interaction, students are able to share in the knowledge creation process. Moore (1993) referred to the shared learning experience between and among students as "collective intelligence" which he further described as the most advanced form of the instructional process (Medeiros et al., 2014). Student to student interactions has been linked to increased student satisfaction with the online environment (Akyol et al., 2009; Arbaugh \& Benbunan-Fich, 2006; Garrison \& Akyol, 2013; Richardson \& Swan, 2003).

\section{$\underline{\text { Learner to instructor }}$}

Learner to instructor interaction is established through the structure of the course content and the instructor presence within that content (Baker, 2010). Learner to 
instructor interaction may add emotional or motivational support which assists in stimulating students' interests in course content (Moore, 1989). Adding a synchronous component such as audiovisual calls or chats increases instructor presence since the students typically have direct interaction with the instructor (Baker, 2010). In asynchronous systems, the instructor may use discussion boards and emails to communicate direct instruction or clarification and additionally interject personality and humor (Moore, 1989). Learner to instructor interaction has been linked to student satisfaction (Wise et al., 2004), sense of community, and increased instructor presence (Shea, Li, \& Pickett, 2006).

\section{$\underline{\text { Learner to content }}$}

Learner to content refers to how the student interacts with the course content to construct meaning. Learner to content interactions can include course readings, watching videos, interacting with computer based instruction or simulations. It can also include searching for materials and completing projects/assignments (Bernard et al., 2009). The learner to content interaction facilitates the perspective and cognitive structure of the student (Moore, 1989).

Moore (2013) has postulated that interactions can reduce the transactional or psychological distance between the learners and instructor. Yet, Picciano (2002) stated that interactions alone do not create social presence: the interactions must be designed to facilitate collaborative learning. Increased satisfaction in online courses has been reported by both instructors and students depending on the quantity and quality of interactions (Shea et al., 2001). 


\section{Blended Synchronous Learning Environments}

Many terms have been associated with the blending of face-to-face and online students in one environment. Oyarzun and Martin (2013) dubbed this environment multimodal course delivery. This is the combination of face-to-face and simultaneous synchronous online delivery with asynchronous materials. Bower, Cram \& Groom (2010) defined the combination of the physical and virtual environment as blended reality. This combination included participants in both the physical and virtual space simultaneously. Hastie et al. (2010) coined the term blended synchronous learning environment (BSLE). The BSLE consists of five components: a teacher, physical classroom, cyber classroom, and a number of classrooms and/or participants.

Blended synchronous learning environments are created using an array of technologies such as room-based video-conferencing systems, desktop web-conferencing platforms such as Skype (Cunningham, 2014), web-based conferencing platforms such as Cisco WebEx (Oyarzun \& Martin, 2013), or chat rooms with video feeds. Oyarzun and Martin (2013) state that students must have the ability to chat with their peers both publicly and privately. All students, face-to-face and virtual, should be logged into the virtual classroom for face-to-face and online peer interactions to occur. The classroom should be outfitted with two cameras, one for the instructor(s) and content and the other camera to capture the classroom. The purpose of the secondary camera is to capture the face-to-face students and instructor, which increases social presence and awareness in the learning environment (Bower et al., 2015; Oyarzun \& Martin, 2013). The BSLE must be equipped to allow interactions between face-to-face and online students and their 
instructor. (Oyarzun \& Martin, 2013). These interactions can assist with the facilitation of creating social presence among the students and instructor.

\section{Designed Interactions}

Designed interactions emphasize active constructive and reciprocal engagement between both peers and instructors (Parker et al., 2013). Pallof and Pratt (2007) suggested that students will experience meaningful learning in a participatory learning environment which will assist the students with developing social presence. Designed interactions are beneficial since it encourages students to actively construct new meanings related to the course content (Lehman \& Conceicao, 2010). Examples of designed interactions include active learning strategies.

Active learning is an umbrella term for pedagogies focusing on student activity and engagement (Chickering \& Gamson, 1987). Teaching methods that support active learning strategies are those that engage students in doing things and thoughtful participation that emphasize the learning outcomes (Ritchhart, Church, \& Morrison, 2011). Active learning methods require students to utilize higher order thinking skills and are typically collaborative in nature. Zayapragassarazan and Kumar (2012) referenced four broad categories for active learning: individual activities, paired activities, informal small groups, and cooperative student projects. These methods may employ various activities such as brainstorming, collaborative writing, case-based instruction, cooperative learning, and peer teaching.

Synchronous environments have been acknowledged for active learning due to the ability to incorporate immediate feedback and dynamic interaction (Bower et al., 2015; Chen, Ko, Kinshuk, \& Lin, 2005; Marjanovic, 1999; Park \& Bonk, 2007). Bower et al. 
(2015) found that technology enabled instructors to design active learning which included collaborative evaluation tasks, group report activities, collaborative problem solving activities, and class discussions. They also stated that for active learning to occur, tasks needed to include student participation. The addition of active learning tasks increase student satisfaction (Bower et al, 2015; Richardson \& Swan, 2003).

\section{Social Presence Theory}

\section{Community of Inquiry}

The Community of Inquiry (CoI) is a framework developed as a critical thinking model for online courses (Garrison et al., 2000). CoI is used to achieve higher order critical thinking skills and create a community of students and instructors. There are three essential elements to CoI: social, cognitive, and teaching presence (Garrison, 2009). Grounded in specific philosophical and epistemological assumptions, and learning theories, CoI aims to encourage higher order cognitive processing through a collaborative/constructivist environment (Garrison, 2011). Social, cognitive and teaching presence, if designed in balance, create a collaborative environment of a community of learners who will achieve deep and meaningful learning (Akyol \& Garrison, 2008).

Social presence is the extent to which students feel connected with other students in the course (Garrison et al., 2000). Creating social presence within online courses requires deliberate planning on the part of the instructor to ensure the learning environment promotes probing questions, skepticism, and the contribution of ideas. The social environment should develop naturally and progressively. Once students begin to identify with a group and a purpose, they become more productive through the development of personal and affective relationships (Garrison, 2009). Studies have 
shown a link between social presence and student satisfaction (Akyol et al., 2009; Arbaugh \& Benbunan-Fich, 2006; Garrison \& Akyol, 2013; Richardson \& Swan, 2003). Teaching presence is directly related to both social and cognitive presence through the design and organization, facilitation and encouragement, and materials and learning activities. Through these three categories students can reach meaningful and educational outcomes (Anderson, et al., 2001). Design and organization refers to the macro level structure. Both the design and the delivery are interrelated and require effective responsiveness to developing needs and events. Facilitating reflection and discourse develops cognitive understanding in a positive environment and involves pedagogical, interpersonal, and organizational skills. Through reflection, students construct personal meaning of the content and confirm a mutual understanding. Direct instruction contradicts being a "guide on the side" but is needed to diagnose misconceptions and brings expertise to the class (Garrison \& Akyol, 2013). Teaching presence is important for perceived learning and satisfaction (Akyol et al., 2009; Richardson \& Swan, 2003; Swan \& Shih, 2005) and the development of a community (Ice et al., 2007; Shea et al., 2006). As defined by Garrison and Akyol (2013), “Teaching presence is the unifying force in CoI" (p. 113).

Cognitive presence is the intellectual engagement with course content and the ability to create meaning out of ideas and facts (Garrison et al., 2000) and is formed when meaning is constructed and confirmed through reflection and discourse. Cognitive presence is guided by the Practical Inquiry (PI) model which has its origins in Dewey's (1959) phases of reflection. The PI model has an interplay of both public and private worlds that includes two dimensions of inductive/deductive and divergent/convergent 
processes of critical thinking (Figure 3). The PI model which is an influence on cognitive presence has four phases: triggering events, exploration, integration, and resolution (Anderson et al., 2001). Students need to move through all four phases to reach higher order cognitive skills and should be aware of the inquiry process. Students need to conceptualize a problem (triggering) which should be a well thought out plan to generate students' curiosity. The next phase, the students begin searching for information such as an explanation for the problem (exploration). Next, students must construct meaning of the problem through critical discourse. Finally, finding a solution (integration) and testing the solution through implementation (resolution) (Garrison \& Akyol, 2013; Garrison \& Anderson, 1993).

The underlying tenant in $\mathrm{CoI}$ is all three presences work in tandem to create a community of inquirers. Garrison and Arbaugh (2007) postulate that a community begins with social presence, followed by the integration of teaching presence which then produces cognitive presence. The CoI has been employed as a theoretical framework to understanding the complexities of technology enhanced learning environments to emphasize critical thinking (Garrison \& Akyol, 2013). As seen in Figure 2, the educational experience is created in an environment which is supportive both socially and intellectually, under the guidance of a knowledgeable instructor, where students engage with course content to develop meaningful, deep learning (Garrison et al., 2000).

\section{$\underline{\text { Social Presence }}$}

Learning is a social process and therefore has been used to describe how people interact and learn in online environments (Swan \& Shih, 2005; Tu, 2000). Research has determined that social presence can affect student learning outcomes as well as instructor 
and course satisfaction (Gunawardena, 1995; Gunawardena \& Zittle, 1995; Richardson \& Swan, 2003). Thus, educational environments should be able to foster learning through social practices (Shea et al., 2001). In the next section, the history and definition of social presence will be reviewed.

\section{History of Social Presence}

Many researchers credit Short, Williams, and Christie (1976) with the initial definition of social presence to explain the effect of communication media can have on communication. They defined social presence as the "degree of salience of the other person in the interaction and the consequence salience of the interpersonal relationships . ..” (p. 65). They argued that social presence was a critical factor in person-to-person communication and the medium can affect perceptions of immediacy and intimacy. As the popularity of communication media grew in the late 1980's and early 1990's, social presence began to be heavily researched (Garrison, et al., 2000; Gunawardena, 1995; Gunawardena \& Zittle, 1997; Swan, 2002; Walther, 1996). Researchers began to question whether the attributes of a communication medium determined its social presence or if it was the ability of the user to project their persona defined social presence. In the following section, the various definitions of social presence will be discussed.

\section{Definition of Social Presence}

In the late 1990s, there was a shift from focusing on communications media to online learning. With this shift, researchers began to re-conceptualize the definition of social presence theory. Gunawardena (1995) questioned whether social presence was an attribute of communication media or whether users' perceptions of media altered their behavior. Based on her experience and research, she stated that students were able to 
project their identities through a communication media and build an online community through the use of interaction skills and techniques. Gunawardena and Zittle (1997) went on to state that users project their presence by developing skills to incorporate their personality. The characteristics of communication media did not determine the social presences levels; it is the student perceptions of the social presence created by both the instructor and the students. Thus, she argued the ability of the participants to project their "self" through a communication media creates social presence. Other researchers such as Picciano (2002) defined social presence in an online course as "a student's sense of being in and belong in a course and the ability to interact with other students and an instructor" (p. 22). Picciano (2002) went a step further and the person is not just able to project their “self” but also feel a sense of belonging.

Since the late 1990 's, the definition of social presence has continued to change over the years and researchers continue to redefine the definition (Lowenthal, 2009). Thus, many definitions have emerged. As seen in Figure 2, the definitions can vary from students having the ability to project themselves in an environment (Garrison et al., 2000) to creating positive interpersonal and emotional connections (Lowenthal, 2009). The difference in the definitions ranges from student's perceptions of their belonging to creating actual emotional connections with others (Garrison et al., 2000; Picciano, 2002; $\mathrm{Tu}, 2000)$. At the other end of social presence definitions, Garrison et al. (2000) and Picciano (2002) defined social presence as the students' perceptions of being able to project themselves or their sense of belonging. Lowenthal (2009) stated that definitions of social presence tend to fall on a continuum. At one end, students make connections with others such as Tu's (2000) definition of the ability to feel access to the intelligence 
and sensory impression of others. At the other end of the continuum, students are merely projecting themselves (Garrison et al., 2000) Although this is not a comprehensive overview of all the definitions that have emerged, it provides an indication of the range of social presence definitions.

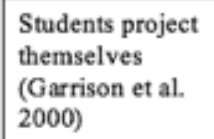

Low social/emotional presence

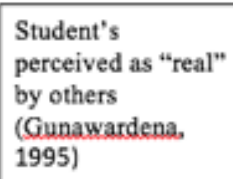

Feel access to intelligence and sensory impression of others $\mathrm{Tu}$. 2000)
Positive interpersonal and emotional connection (Lowenthal, 2010)

Figure 1. Various definitions and degrees of social presence.

Throughout the years, social presence has been linked to student satisfaction (Gunawardena, 1995; Gunawardena \& Zittle, 1995; Richardson \& Swan, 2003), increased interaction ( $\mathrm{Tu}, 2000)$, and perceived learning (Picciano, 2002; Wise et al., 2004). Thus, it is necessary for instructors and instructional designers to recognize the importance of intentionally designed activities to facilitate social presence in an online educational environment (Pallof \& Pratt, 2007).

\section{Challenges and Opportunities in the BSLE}

There is a range of practical, educational, and economic benefits to incorporating blended synchronous learning environments. Schools have the ability to reach greater audiences and new populations. This type of environment allows students who are geographically isolated or unable to attend the physical classroom to obtain an equitable education (White et al., 2010) and provides students with immediate access to support (Bower et al., 2014). Moreover, this type of environment allows opportunities for social interaction, peer/teacher support and knowledge sharing (Park \& Bonk, 2007). Students 
who have a demanding life outside of their educational studies have stated that the convenience of being able to attend class either face-to-face or online as well as have the ability to review the class recording at a later time has contributed to student satisfaction of this environment (McCue \& Scales, 2007). The ways in which the blended synchronous tools are configured may vary. Students may be connected from one location to another, point-to-point, or multipoint, where students at multiple locations stream to one location such as a classroom. As a result, the blended synchronous environment allows for a flexible education environment.

One of the main advantages of the blended synchronous learning environment is the enhanced notion of creating social presence among both face-to-face and online learners. It has been hypothesized that participants in the blended synchronous learning environment experience high levels of social presence which may be attributed to the immediacy that real-time communication offers joined with the dynamic and spontaneous nature of interactions it supports (Cunningham, 2014; Park \& Bonk, 2007). The heightened sense of social presence may be attributed to the ability to form a larger cohort of students that can bring a variety of perspectives and expertise (Bower et al., 2015).

Many educators are not versed in teaching in the blended synchronous learning environment, therefore it is imperative to understand what the blended synchronous learning environment is and how to organize and manage a class to facilitate student learning and interaction (Bower et al., 2015). Organization and design of effective interactions are imperative to the success of creating a cohesive class among the face-toface and online students and lessening instructor cognitive and affective load during 
teaching (Teng et al., 2012). During the implementation of the lesson, instructors need to engage students to keep them involved with the course content and each other (Bower et al., 2015; Szeto \& Cheng, 2014), and balance the contributions of the students between the face-to-face group and the online students (Bower et al, 2015; Szeto \& Cheng, 2014; Szeto, 2015). For this reason, the design of lessons and planning on the instructor's part is essential.

Research has identified many challenges associated with the blended synchronous learning environment such as technology (Szeto 2014; Szeto \& Cheng, 2014), promoting interaction between the face-to-face and online students (Stewart, Harlow, \& DeBacco, 2011), and the ability of the instructor to give equal attention to both the online and faceto-face students (Cunningham, 2014, Szeto, 2014; Szeto \& Cheng, 2014). Both Ramussen (2003) and Szeto and Cheng (2014) found that student to instructor interaction was unequally distributed between the online and face-to-face students. Ramussen (2003) found the face-to-face students had a much higher interaction frequency with the instructor whereas Szeto and Cheng (2014) found the online students had a much higher interaction frequency with the instructor. Both Ramussen (2003) and Szeto and Cheng (2014) found that there was also a much higher frequency of interactions within groups. The students preferred to interact with their peers who were in the same learning environment. For example, face-to-face students interacted with their face-to-face peers.

Technology is also an important aspect of the blended synchronous learning environment, and professional development is essential for the instructor and students (Szeto, 2015). Both online and face-to-face students should become familiar with the technology used in the blended synchronous learning environment as it is the platform for 
communication between the two groups of students and the instructor. Students can be resentful when technology fails and the instructor takes class time to assist online students (Cunningham, 2014). Other researchers have noted that audio lags can be detrimental to group cohesion due to the interference it can cause for group activities (Bower et al., 2015; Szeto \& Cheng, 2014). Both face-to-face students and the instructor also need to be aware of the camera and microphones in the room to ensure the online students are able to view and hear the class discussion (Cunningham, 2014). With this in mind, it is important for the instructor to consider the type of technologies utilized as well as incorporating student training into the design of the course.

\section{$\underline{\text { Social presence in the BSLE }}$}

With social presence being such a predominant factor in education to foster collaboration and higher-order thinking (Garrison et al., 2000), researchers have been interested with how the dynamics of teaching students in dual modes, face-to-face and online, affects interactions and social presence. The quantity of interactions between the instructor, online students, and face-to-face students have been analyzed (Ramussen, 2003), as well as the interactions between the face-to-face and online students (Cunningham, 2014; Szeto \& Cheng, 2014; Szeto, 2015). Often the quantity of interactions has been established to determine a pattern to then support additional findings through qualitative methods such as observations and interviews (Ramussen, 2003; Szeto \& Cheng, 2014).

Ramussen (2003) conducted a multiple case study and based the quantity of interactions on Moore's three types of interactions and developed eight groups: distancedistance, distance-face-to-face, distance-instructor, distance-technical assistant, face-to- 
face-face-to-face, face-to-face-instructor, face-to-face-technical assistant, and instructortechnical assistant, under four categories: administrative, content, social, and technical support. He found that the use of text chat connected the distance students but did not connect the distance students with the face-to-face students. It was also noted that students preferred audio interactions when the interaction was content related and used text chat when the interaction was social. In this study, the chat tool was only available for the distance students in case one. In case two, the chat tool was integrated for all students. Once the chat tool was integrated for the face-to-face students, the number of interactions dropped between the online students and increased among the face-to-face students.

Szeto and Cheng (2014) also conducted a case study and used Moore's three types of interactions to determine a pattern. They classified the interactions into three participant groups: online students, face-to-face students, and instructor. Within each group were student-student, student-instructor, student-content. Under the instructor group, interaction types were classified as instructor-student and instructor-content. They suggested there is much higher intra-group interactions (student to student) for the faceto-face group but the online group had much high inter-instructor interactions (student to instructor). The face-to-face group was more apt to seek consultation from their peers whereas the online students preferred to consult with the instructor. Student-student interactions did not happen outside their immediate vicinity (Szeto \& Chang, 2014). Although these studies findings contrast one another, they are similar with regards to low interactions among the face-to-face and online students. Thus, demonstrating the two groups remain separate with low collaboration. 
Bower et al. (2015) researched the design and implementation of teaching in the blended synchronous learning environment and how that influenced the quality of instruction, which included social presence of the students using a multiple case study approach. Pedagogy was the focus of this study to determine successful collaborative strategies for the BSLE. All cases included collaborative activities such as group work or whole class collaboration. Instructors used various techniques for collaboration. Some instructors preferred to establish grouping strategies prior to class while others allowed students to self-group. During instructor interviews, many of the instructors stated that preparation was essential for successful classes including, pre-loading materials and creating clear instructions. Also important is the ability to direct students to answer questions through the use of names. Face-to-face students were also strongly encouraged to be logged into the distance environment in order to contribute to chat conversations with their online peers. Overall, providing active learning strategies enabled students to collaborate and engage with one another.

\section{BSLE strategies}

Interactions have been a subject of study in the blended synchronous environment (Cunningham, 2104; Szeto \& Cheng, 2014; Szeto, 2015), and have been heralded as a significant component of pedagogy to obtain intended learning outcomes (Ravenna et al., 2012). Furthermore, these interactions can facilitate peer rapport between online and face-to-face students. Yet, interactions alone are not enough for learning attainment and the blended synchronous learning environment offers new forms of interaction. Moore (1993) postulated three types of interaction that can occur: student to student, student to instructor, and student to content. In the blended synchronous learning environment, four 
additional types of interactions can also occur: face-to-face student-face-to-face student, face-to-face student-online student, instructor-face-to-face student, and instructor-online student. It is these types of interactions that can influence the social presence and group cohesion of the class and thus attaining intended learning outcome (Swan, 2004).

Interactions between face-to-face and online students does not happen spontaneously; therefore, attention to the design of in-class activities is essential as well as stimulating meaningful communication and collaboration between both groups (Bower et al., 2015; Szeto, 2015; Szeto \& Cheng, 2014). Interactions in the blended synchronous environment can happen in many ways through audio, text, and visual cues. Grouping strategies such as grouping online students with face-to-face could potentially "level the playing field" and creating more interactions between the online and face-to-face students (Bower et al., 2015).

The instructor has to be aware of both groups of students and ensure equal attention is given. This can cause cognitive overload for the instructor; therefore, instructors should design lessons for active learning (Bower et al., 2015). Szeto (2015) found the face-to-face students felt neglected due to the instructor focusing on the online students for skill demonstration. Some students reported that it is difficult to hold an audio conversation with the online students due to audio delay which resulted in interruptions (Stewart et al., 2011). In order to incorporate both online and face-to-face students and reduce cognitive load for both instructor and students, instructors can employ various strategies. First instructors can direct communication to one mode (e.g. audio, text). For example, when the instructor asks a question, they can direct the students to type their answer in via chat. Another strategy to reduce cognitive load is to employ a 
student to monitor the chat and ensure questions are answered, or comments are made aware to the whole class (Bower et al., 2015). Overall, the instructor must be aware of any potential audio lags and ensure equal attention is given to both the online and face-toface students.

$\underline{\text { Blended synchronous learning design framework }}$

In order to overcome the many challenges of the BSLE, Bower et al. (2015) developed the Blended Synchronous Learning Design Framework which offers pedagogical, technological and logistical recommendations. The framework is designed around three constructs: presage (design), process (implementation), and product (outcomes). The premise for the development of the framework is to compile innovative practices and tool selection to create a media-rich environment for collaborative learning experiences (Bower et al., 2015).

During the presage or design stage of conducting a blended synchronous class, the instructor should determine the learning outcomes for the class and design activities for active learning. At this stage, the instructor should determine student groupings (e.g. group students according to location, mix face-to-face students with online students). The technologies used during class need to match the lesson requirements and need to be setup and tested in advanced. Logistically, the instructor should have all materials organized prior to class instruction. If group work will be required, any supplementary materials need to be provided to the students either prior to class or via a Learning Management System (LMS). Students need to be informed of any technical requirements for their computer or technologies needed such as a webcam or microphone. Through preparation for both the students and instructor, the class will be able to focus on course 
concepts and collaborative activities rather than navigating the technology (Bower et al., 2015).

During the process or implementation of the class, instructors need to continually monitor students while being aware of any potential technology issues. Some pedagogical recommendations offered include distributing attention among the face-to-face and online students, encourage regular contributions from students, and to be flexible and adaptive. Some students may have technology difficulties during class, therefore, the instructor needs to have knowledge of troubleshooting techniques. Finally, start class ten minutes early to ensure the technology works for all students (Bower et al., 2015).

The recommendations for pedagogy, technology, and logistics set forth by Bower et al. (2015), will lead to more active learning for both face-to-face and online students while at the same time enhancing the sense of community among learners. Overall, this will lead to student satisfaction and achievement of learning outcomes (Garrison et al., 2000; Gunawardena, 1995). The Blended Synchronous Learning Design Framework was developed based on previous literature and a comprehensive research case study project, yet, the framework needs to be validated and refined through future research.

Social presence has been linked to student satisfaction (Gunawardena, 1995; Gunawardena \& Zittle, 1995; Richardson \& Swan, 2003) and perceived learning (Richardson \& Swan, 2003). Social presence is an integral part of the blended synchronous learning environment yet, it has been noted that although students are perceived as real through webcams. Interaction between online and face-to-face students is typically short and transactional (Bower et al., 2015; Szeto \& Cheng, 2014; Szeto, 2015) and there is a need to develop deliberate strategies to enhance the creation of a 
community of learners (Szeto \& Cheng, 2014) and validate the Blended Synchronous

Learning Design Framework (Bower et al., 2015). Further research needs to be conducted to validate and develop strategies that increase social presence in the blended synchronous environment.

\section{Summary}

This chapter described the important components of the BSLE as well as the research findings and issues related to this type of learning environment. Research pertaining to the BSLE is just beginning to scratch the surface. Several studies offer insight into creating one community of learner within two separate learning environments through the analysis of interactions between the students and the students and instructor. While research has shown that there has been a disproportionate number of interactions between the instructor and online and face-to-face students as well as between groups of students, many of the studies have been unable to develop strategies to level the interactions or if it is even necessary to increase social presence among students in both learning environments.

Research in social presence abounds (Anderson et al., 2001; Garrison et al., 2000; Gunawardena, 1995; Gunawardena \& Zittle, 1997; Lowenthal, 2009; Picciano, 2002; Richardson \& Swan, 2003), a review of the literature reveals that research of social presence within the BSLE is minimal. Additionally, while the literature includes studies addressing the benefits of learning interactions within the BSLE, many of the studies lack rigor and thus requires additional exploration before educators can draw conclusions. Much of the research focuses on the frequency of interactions based on Moore's three types of interactions and on the Community of Inquiry (Ramussen, 2003; Szeto \& Cheng, 
2014). As Picciano (2002) stated, it is not just the interactions that create a sense of community but the design of the interaction. Bower et al. (2015) focused on active learning pedagogy to enhance the BSLE and create a community and increase student satisfaction to obtain learning objectives. This research is relatively new and therefore needs to be validated.

This study seeks to build on previous research to examine important constructs through a qualitative design incorporating multiple types of data collection based on Moore's three types of interactions, social presence, and blended synchronous design framework. By incorporating the additional construct of active learning strategies to determine if designed interactions can facilitate social presence across the various learning environments. Finally, this study seeks to explore student perceptions of the BSLE and examine students' rationales for their perspectives. 


\section{CHAPTER THREE: METHODS}

This study investigated students' perceptions of interactions within a Blended Synchronous Learning Environment (BSLE). Research suggests that there is often an imbalance of interactions between the instructor, distance students, and face-to-face students in BSLE classes (Bower et al, 2015; Szeto \& Cheng, 2014). However, little if any research has investigated students' perceptions of this imbalance and the implications it has on perceptions of social presence. Given this gap in the literature, this study investigated students' perceptions of designed interactions in a Blended Synchronous Learning Environment (BSLE) classroom. The methodology employed to address this problem is outlined in this section. The following chapter is divided into the following sections: (1) context (2) participants (3) data collection, and (4) data analysis.

Qualitative research is a means for studying social or human problems in a realworld setting. It assists with constructing meaning and understanding of the world or understanding a phenomenon which can include multiple forms of data such as interviews, observations, and documents (Creswell, 2012; Merriam, 2009; Patton, 2002). The researcher, who is the primary instrument, uses complex reasoning throughout the data collection and analysis process to develop themes either using inductive or deductive reasoning (Creswell, 2012; Merriam, 2009). Finally, qualitative research provides a rich description to the audience in the form of words and pictures rather than numbers to convey the findings of the phenomenon (Merriam, 2009). 
This study took place in a natural environment and utilized multiple forms of data collection (i.e., observations and interviews) to investigate patterns of interactions and student perceptions of interactions and social presence in the BSLE. Therefore, a case study that utilized qualitative methods of data collection was optimal for this study. The researcher was interested in understanding how the students made sense of their educational environment and their experiences (Merriam, 2009). Case study research is a type of qualitative research which studies a real-world phenomenon that utilizes a variety of methods such as interviews, direct observation, and document analysis (Creswell, 2012; Yin, 2014). Case study is conducted when an investigator is answering "how" or "why" questions in a real-world situation where the behaviors cannot be manipulated (Yin, 2014).

The unit of analysis for this study was interactions that occur within the BSLE during class time (Merriam, 2009). Within the BSLE, the interactions between students and instructors during class time were the phenomenon being researched. This included both verbal and text chat. The ability to predict or control interactions in a live classroom is difficult, therefore qualitative research in the form of case study was the best method (Yin, 2014).

An embedded, single case study approach was utilized for this research. Embedded approach is when subunits within the case are also included in the analysis. Figure 3 depicts the case study design. A single case embedded approach is justified since this case is limited to classes within the BSLE. This common case was the academic programs using the BSLE and the subunits are the individual classes within the programs (Yin, 2014). The BSLE was utilized by two programs during the Fall semester, 
Master of Instructional Technology and Educational Leadership, therefore, this is a common case.

\section{Context}

\section{$\underline{\text { BSLE Classroom }}$}

The Instructional Technology and Educational Leadership programs use a Cisco Telepresence system along with WebEx for their BSLE (Figure 4). The Cisco Telepresence system provides high definition video of the classroom and quality audio feeds to allow the face-to-face and online students to feel as if they are in the same room. The classroom is equipped with an instructor station computer that can be projected on to a screen. The face-to-face students have access to laptops in the classroom. Cisco telepresence is integrated into the distance education room and includes the instructor station, cameras, and microphones. The instructor uses the web-based software of WebEx on the instructor's station computer to connect peer-to-peer with the online students. The peer-to-peer connection allows the students to access the instructor from any location as long as they have a computer and Internet access. The Cisco telepresence then allows the face-to-face students to see and communicate with the online students through the microphones and projector screen. 


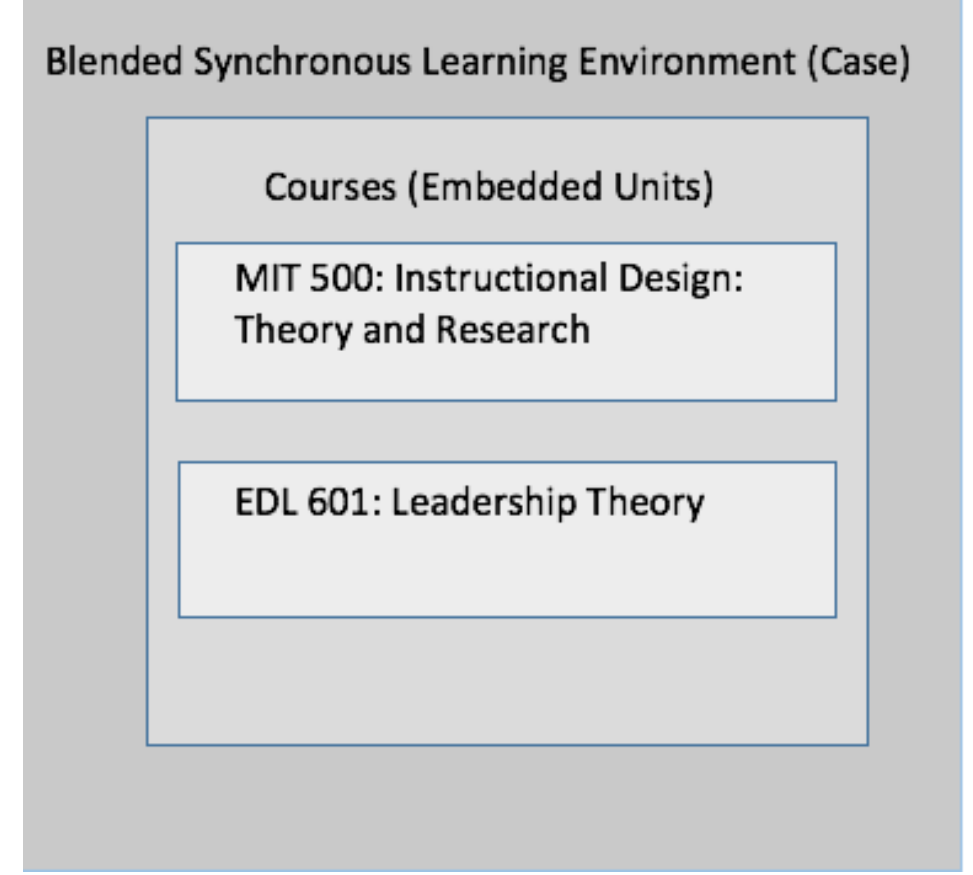

Figure 2. The bounded cased of the BSLE and the embedded units which are the individual classes who volunteered for this case study research. Both classes are introduction core classes.

A virtual classroom needs to have the following features: ability to archive, application sharing, use of e-board, conduct text chat, use audio and video interaction, ability to create online groups for collaboration, share content, emoticons, and polling tools (Oyarzun \& Martin, 2013). WebEx is used for the virtual synchronous environment. From the instructor station, the instructor logged into WebEx environment. Once logged into the WebEx software, students were able to join from any geographical location. The WebEx environment was projected onto the classroom screen where the face-to-face students can view the content and the online students. The students and instructor had the ability to interact with one another through the use of both audio and text chat. The text chat was located within the WebEx environment. 


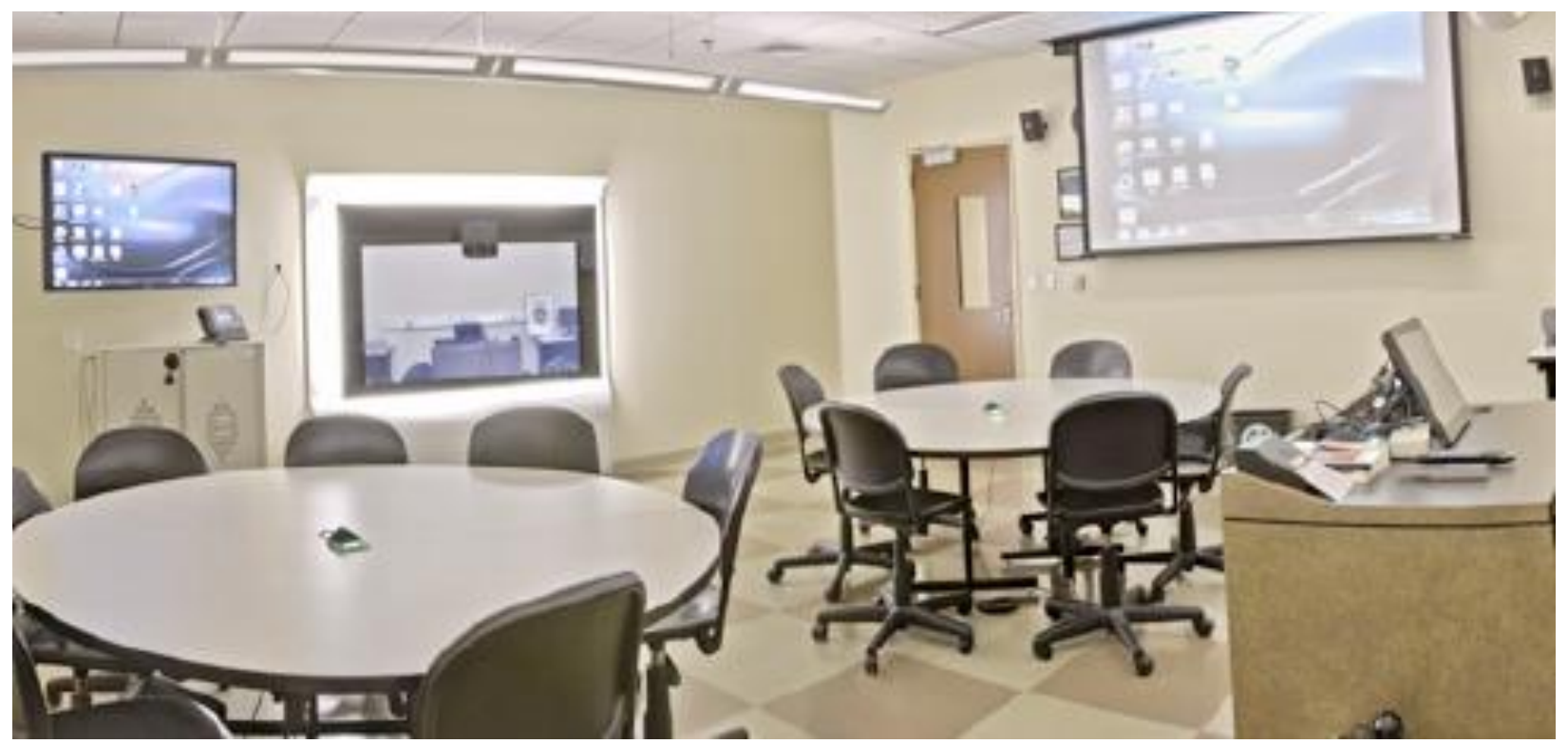

Figure 3. The Instruction Technology Blended Synchronous classroom for Instructional Technology. Cisco telepresence was used to outfit the classroom including the instructor's station, classroom cameras, microphones (located on each table), and projection screen. WebEx is a web-based software that is used on the instructor's station computer and projected onto the projection screen so the face-toface students can see the online students.

\section{Participants}

Purposive sampling was used to identify participants for the study. Purposeful sampling allowed the researcher to select the courses/participants that would provide rich information regarding the phenomenon and lead to an in-depth understanding of the case (Creswell, 2012; Patton, 2002). This study took place during Fall 2016 at a mid-sized southern university. There were seven Master of Instructional Technology and ten Educational Leadership courses being offered in Fall 2016 that utilized the BSLE. The embedded units of this study consisted of two classes: one in the Master of Instructional Technology program and one in the Doctorate of Educational Leadership program. One course from each program was chosen to prevent having the same students in two different classes from participating in the study. The courses chosen for this case study were MIT 500: Instructional Design: Theory and Research and EDL 601: Leadership 
Theory. These courses were chosen since both courses were the introduction core class for their respective programs and most of the students would have minimal exposure to this type of environment. For this reason, students were not overexposed to the environment to the point where they have formulated opinions based on previous instructors. Yet, since the students are new to the environment, it also may take time for them to develop opinions of the educational environment. Overall, twenty-seven students and two instructors were part of the study. MIT 500: Instructional Design: Theory and Research had five female students and three males. EDL 601: Leadership Theory had twelve females and seven males. Students who live within the vicinity of the university campus have the choice of attending either face-to-face, online, or a combination throughout the duration of the semester (see Table 2).

MIT 500: Instructional Design: Theory and Research is a core class and also the introduction course for the program. This class met weekly and had fourteen meetings throughout the Fall semester. Students in the MIT program had taken two or more classes while students in the EDL program had taken one or none. EDL 601: Leadership Theory was also a core introduction class therefore; the students were new to the program and were also new to this type of learning environment. Due to program design, EDL 601 had six live meeting times during the Fall semester. The Educational Leadership program combines asynchronous and synchronous environments where students also have to participate in asynchronous discussions during the weeks they do not meet synchronously. Both courses are pre-requisite courses for the remainder of the core courses. 
Table 2 Number of students registered and classification for MIT 500 and EDL 601 students.

\begin{tabular}{lllll}
\hline & \multicolumn{2}{l}{$\begin{array}{l}\text { MIT 500: Instructional Design: Theory } \\
\text { and Research }\end{array}$} & EDL 601: Leadership Theory \\
\hline Gender & $\begin{array}{l}\text { Face-to-face } \\
\text { students }\end{array}$ & $\begin{array}{l}\text { Distance } \\
\text { education students }\end{array}$ & $\begin{array}{l}\text { Face-to-face } \\
\text { students }\end{array}$ & $\begin{array}{l}\text { Distance } \\
\text { education students }\end{array}$ \\
\hline Male & 2 & 1 & 3 & 4 \\
Female & 1 & 4 & 4 & 8 \\
\hline
\end{tabular}

Each course had a different instructor. MIT 500: Foundations of Distance

Education was taught by an instructor who founded the Master of Science in Instructional Technology program. She was a tenured faculty who had taught in the BSLE since the inception of this learning environment at the university ten years ago. The instructor for EDL 601: Leadership Theory was also a tenured faculty and had taught in the BSLE for the past four years.

The Master of Science in Instructional Technology program is housed under the College of Education. This graduate program requires 36 credit hours (Figure 5). The program is divided into core classes, focus classes, individual inquiry and thesis. Core classes and individual inquiry classes are offered only during full fifteen week terms. Focus classes are offered both during full terms and during summer sessions. The program has been offering classes in the BSLE since the 2005-2006 academic year. 


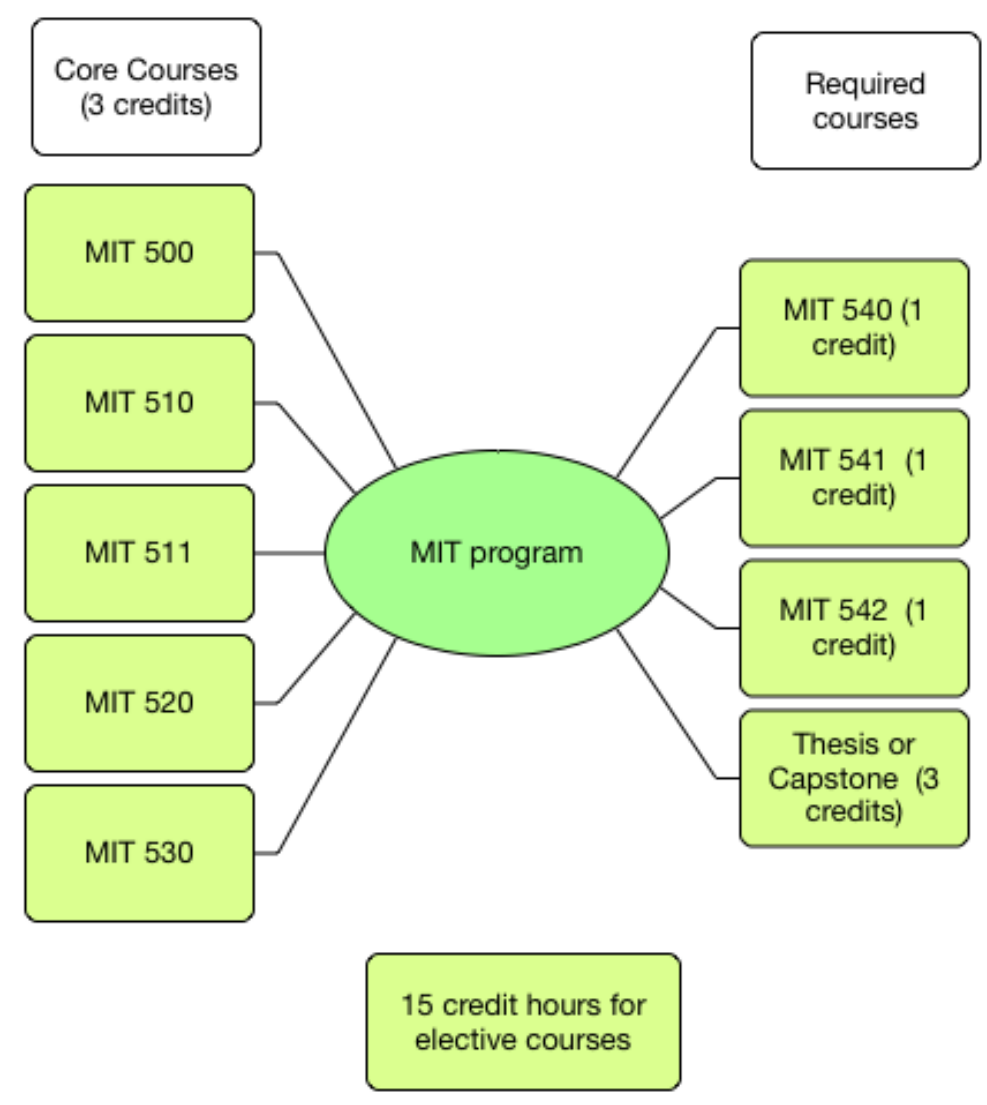

Figure 4. MIT program organizational chart.

The Educational Leadership program is under the College of Education as well. This doctorate program requires 60 credit hours. The program is divided into core classes and three program concentrations: Leadership in Educational Administration, Leadership in Curriculum and Instruction, and Leadership in Higher Education (Figure 6). Each concentration requires 36 credit hours. The program has been offering classes in the BSLE since the inception of the program in 2007. 


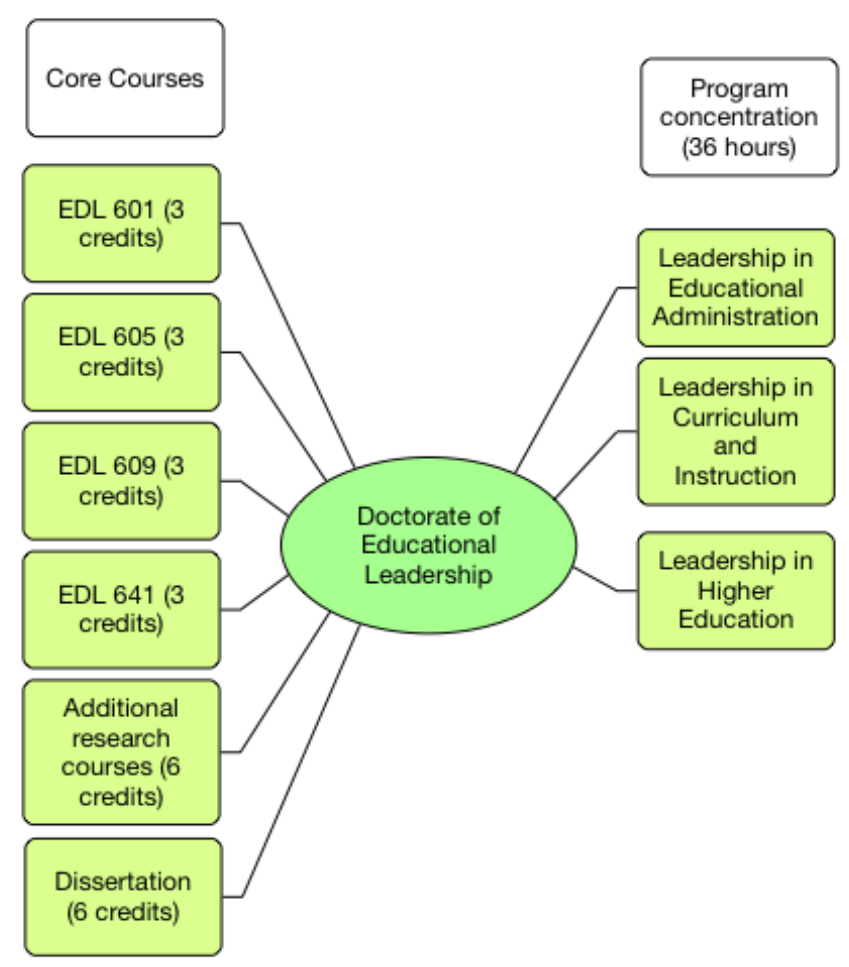

Figure 5. EDL Program organization chart.

MIT 500: Instructional Design: Research and Theory and EDL 601: Leadership Theory were offered during the Fall semester from August $17^{\text {th }}-$ December $8^{\text {th }}$. MIT 500: Instructional Design: Research and Theory met every Wednesday from 5:30 - 8:15. EDL 601: Leadership Theory met on certain Mondays from 5:00 - 7:15. The class days the students met were determined by the program coordinator. The instructors volunteered to participate in the study which entailed in-class semi-structured observations, and an instructor interview. Students were informed during the initial class that participation is optional and will remain anonymous if students chose to volunteer. Students who volunteered were given an opportunity to sign a consent form electronically (Appendix A). Students were informed that their real names will not be used during this study. Online and face-to-face participants. Each course consisted of two section. Students who live locally and could attend campus classes as well as use campus resources registered 
for the on-campus section (e.g. 001). Students who lived at a distance (e.g. outside of Wilmington) registered for the distance education section (800). Although students may live outside of the Wilmington area and registered for the distance section, if they chose to, the student may drive to campus to attend class face-to-face. The on-campus students could also choose whether they attend on-campus or online. The designation of distance education student means that those students do not have the opportunity to use the oncampus resources and thus have reduced tuition. None of the distance education students opted to attend the face-to-face sessions during the observation period. In MIT 500, three of the face-to-face students decided to attend class online starting in week three (Table 3). Two students moved to the online environment in EDL 601 for the third class (Table 4). The motivations for students to attend online ranged from medical reasons, moving overseas, and overall preference for attendance.

Table 3 Number of students who attended online and face-to-face for MIT 500 throughout the observation period

\begin{tabular}{ccccc}
\hline $\begin{array}{l}\text { Class observation } \\
\text { (CO) }\end{array}$ & Male & Face-to-face & Male & Online \\
\hline CO 1 & 2 & 2 & 1 & Female \\
CO 2 & 2 & 2 & 1 & 3 \\
CO 3 & 0 & 1 & 3 & 4 \\
CO 4 & 0 & 1 & 3 & 4 \\
CO 5 & 1 & 1 & 2 & 4 \\
CO 6 & 0 & 2 & 3 & 3 \\
CO 7 & 0 & 1 & 3 & 4 \\
\hline
\end{tabular}

Table 4 Number of students who attended online and face-to-face for EDL 601 throughout the observation period

\begin{tabular}{lcccc}
\hline $\begin{array}{l}\text { Class observation } \\
\text { (CO) })\end{array}$ & Male & Face-to-face & Male & Online \\
\hline CO 1 & 4 & 6 & 3 & Female \\
CO 2 & 3 & 4 & 4 & 6 \\
CO 3 & 3 & 2 & 4 & 9 \\
\hline
\end{tabular}




\section{Pilot Study}

A pilot study was conducted during Summer and Fall 2015 to begin to understand student perceptions of the BLSE. This exploratory study explored the phenomenon of the BSLE and used quantitative and qualitative data that was collected from a single instrument (i.e., survey). A 34-item survey (Appendix B) was used to examine the perceptions of graduate students enrolled in BSLE courses. Likert questions and openended questions were designed into the survey. This pilot study was included as part of the methods since it addresses some of the gaps in the BSLE environment as well as addresses an overview of student perceptions of the BSLE.

\section{$\underline{\text { Participants }}$}

This study took place at the same mid-sized southern university. Participants were graduate students enrolled in courses that utilized the Blended Synchronous Learning Environment. A variety of graduate programs were included in this study such as Instructional Technology, Business Administration, Social Work, and Educational Leadership in a southeastern university. Students were sent a survey via email at the end of the semester during Summer and Fall 2015 semesters.

During these two semesters, approximately sixty students received the survey with thirty students completing the entire survey (50\%). The students' ages ranged from under 20 to 59 with a majority (49\%) being within the age range of 20-29 years old. For a majority of the students, this was their first semester taking blended synchronous classes (29\%), $23 \%$ were in their second semester, and $26 \%$ were in their third semester. Students were in a variety of programs such as Educational Leadership (56\%), Business Administration (9\%), Instructional Technology (9\%), and Social Work (26\%). Students 
have the ability to choose how they attend live if they live within range of the face-toface classroom. For example, $14.3 \%$ of the students attended class online, $51.4 \%$ attended face-to-face, and $34.3 \%$ preferred to alternate between the face-to-face and online environment.

$\underline{\text { Instruments }}$

An observational instrument (Appendix D) was developed, based on Rasmussen's (2003) observation instrument, to ascertain types of interactions in the BSLE. Rasmussen (2003) categorized interactions by the following (a) distance student - distance student, (b) distance student - face-to-face student, (c) distance student - instructor, (d) distance student - technical assistant, (e) face-to-face student - face-to-face student, (f) face-toface student - distance student, (g) face-to-face student - instructor, (h) face-to-face student - technical assistant. Since these classes do not have a technical assistant, the categories of distance student - technical assistant and face-to-face student - technical assistant were dropped. After piloting the observational instrument with one class, it was noted that often there were whole class interactions, therefore, distance student - whole class, face-to-face - whole class, and instructor-whole class were added to the observational instrument.

A survey tool (Appendix A) was developed to ascertain students' perceptions of the BSLE, the instructor, and interactions between the face-to-face and online students. This tool was developed from Sahin and Shelley (2008) and O’Malley and McCraw (1999). The survey was divided into three sections: environment, instructor, and interactions. The environment section contained twelve Likert questions, the instructor section contained ten Likert questions, and the interaction section contained eight Likert 
questions. These items used a five-point response scale (1=strongly disagree to $5=$ strongly agree). After each section, there is an open-ended question allowing participants to elaborate on their answers in the Likert section. A pilot study was conducted in the summer and Cronbach alpha reliability of the survey tool was 0.873 .

\section{$\underline{\text { Results of interactions }}$}

As seen in Table 3, interactions overall ranked the lowest with $\bar{X}=3.67$. Each section (Two statements within the twelve questions ranked low for students. The introductions enabled me to form a sense of community had a mean 3.30 and Discussions are more impersonal in this environment had a mean of 3.13. One student stated,

There is a lot of interaction with the students who are in the face-to-face class, but it is hard/impossible to form individual classmate relationships with online peers. Sometimes we do breakout sessions with online peers, which is productive, but it often is somewhat difficult technologically.

Another student commented, "if there is a class and a student chooses to use WebEx to attend the class, I feel they are more of an observer than a participant in class compared to their in-person classmate(s)." (Conklin et al., 2016). Overall, students were satisfied with the BSLE, interactions, and the instructor. Based on the comments from the students, the instructor and the technology can greatly affect satisfaction of the BSLE. The low mean scores relating to the instructor creating a sense of community and unifying the class could be a result of cognitive overload of the instructor attempting to give equal attention to two groups of students in two environments (Bowers et al., 2015; Szeto \& Cheng, 2014; Szeto, 2015). Based on the students' comments, there is a 
disconnect between the face-to-face and online students. Based on this data, the question arises of why there is a disconnect between the students and how can this be resolved? Table 5 The overall mean of instructor, environment, and interaction.

\begin{tabular}{lccccc}
\hline $\begin{array}{l}\text { Survey question } \\
\text { section }\end{array}$ & $N$ & Range & Minimum & Maximum & Mean \\
\hline Interaction mean & 30 & 1.75 & 2.83 & 4.58 & 3.6694 \\
Instructor mean & 29 & 1.40 & 3.60 & 5.00 & 4.3241 \\
Environment mean & 29 & 2.13 & 2.88 & 5.00 & 3.8276 \\
\hline
\end{tabular}

\section{Data Collection}

Data collection for this study included an open-ended survey, semi-structured observations, text chat transcripts, and interviews. These forms of data were used to answer the following research questions posed in this study: (a) how do students perceive the various interactions that take place within the BSLE, (b) what are students' experiences within the live BSLE, (c) how do students describe interactions (studentstudent) within the live BSLE, (d) How do students describe interactions (studentinstructor) within the live BSLE, (e) how do students describe interactions within the live BSLE, and (f) How do students describe social presence within the classroom experience? After each question, the method of data collect used to answer the question along with the analysis utilized. Table 6 outlines the research questions and the data collection methods used to address each question. Table 7 addresses the timeline for data collection for Instructional Design: Research and Theory and Table 8 address the timeline for the data collection for Leadership Theory. 
Table 5 Research questions and methods of data collection to address each question.

\begin{tabular}{|c|c|c|}
\hline Research questions & Data collection & Data Analysis \\
\hline $\begin{array}{l}\text { Central Question: How do } \\
\text { students perceive the various } \\
\text { interactions that take place within } \\
\text { the BSLE? }\end{array}$ & $\begin{array}{l}\text { Semi-structured observation (live } \\
\text { and recorded) } \\
\text { Text chat transcript } \\
\text { Interviews } \\
\text { Survey }\end{array}$ & $\begin{array}{l}\text { Frequency } \\
\text { Pattern matching } \\
\text { Memoing }\end{array}$ \\
\hline $\begin{array}{l}\text { Question 1A: What are students' } \\
\text { experiences in within the live } \\
\text { BSLE? }\end{array}$ & $\begin{array}{l}\text { Semi-structured observation (live } \\
\text { and recorded) } \\
\text { Text chat transcript } \\
\text { Interviews } \\
\text { Survey }\end{array}$ & $\begin{array}{l}\text { Frequency } \\
\text { Pattern matching } \\
\text { Memoing }\end{array}$ \\
\hline $\begin{array}{l}\text { Question 1B: How do students } \\
\text { describe interactions (student and } \\
\text { instructor) within the live BSLE? }\end{array}$ & $\begin{array}{l}\text { Semi-structured observation (live } \\
\text { and recorded) } \\
\text { Text chat transcript } \\
\text { Interviews } \\
\text { Survey }\end{array}$ & $\begin{array}{l}\text { Frequency } \\
\text { Pattern matching } \\
\text { Memoing }\end{array}$ \\
\hline $\begin{array}{l}\text { Question 1C: How do students } \\
\text { describe interactions (student and } \\
\text { student) within the live BSLE? }\end{array}$ & $\begin{array}{l}\text { Open ended survey } \\
\text { Interviews }\end{array}$ & $\begin{array}{l}\text { Pattern matching } \\
\text { Memoing }\end{array}$ \\
\hline $\begin{array}{l}\text { Question 1D: How do students } \\
\text { describe social presence within } \\
\text { the classroom experience? }\end{array}$ & $\begin{array}{l}\text { Open ended survey } \\
\text { Interviews }\end{array}$ & $\begin{array}{l}\text { Pattern matching } \\
\text { Memoing }\end{array}$ \\
\hline $\begin{array}{l}\text { Question 1E: How do students } \\
\text { describe designed interactions } \\
\text { within the live BSLE? }\end{array}$ & $\begin{array}{l}\text { Text chat transcript } \\
\text { Interviews } \\
\text { Survey }\end{array}$ & $\begin{array}{l}\text { Pattern matching } \\
\text { Memoing }\end{array}$ \\
\hline
\end{tabular}

Table 6 Data collection methods and timeline MIT 500: Instructional Design: Theory and Research

\begin{tabular}{ll}
\hline Data collection methods & Timeline \\
\hline Semi-structured observations & August 17 - October 17 \\
Text chat transcripts & August 17 - October 17 \\
Interviews (students) & September 28 - October 26 \\
Interviews (instructors) & September 28- October 26 \\
Open ended-survey & October 5 - October 12 \\
\hline
\end{tabular}


Table 7 Data collection methods and timeline for EDL 601: Leadership Theory

\begin{tabular}{ll}
\hline Data collection methods & Timeline \\
\hline Semi -structured observations & August 17 - October 10 \\
Text chat transcripts & August 17 - October 10 \\
Interviews (students) & September 28 - October 26 \\
Interviews (instructors) & September 28- October 26 \\
Open ended-survey & October 5 - October 12 \\
\hline
\end{tabular}

Before data collection began, written consent from the Office of Research Compliance from the university and Boise State University was granted to conduct the study (IRB\# 16-0385). The data collection was divided into three overlapping phases: observation, survey, and interview. At the beginning of the first observation of each class, students were informed of the study and emailed an observation consent form that could be electronically signed. During this phase, the researcher took analytic annotations of interactions that occurred during the class sessions and student reactions. During the second phase, students were asked to volunteer to complete an open-ended survey. Students had two weeks to complete the survey. The survey elicited more in-depth student perspectives of the BSLE, interactions within the BSLE and social presence. Finally, during the third phase, students were asked to volunteer for a one-on-one interview. Students who volunteered for the interview were asked to complete an interview consent form. The interview questions were semi-structured with additional questions added based on the observations and survey results.

\section{Observations.}

A commonly used data collection method for qualitative research is the use of observations (Creswell, 2012). Observations are a way to represent a firsthand encounter with the phenomenon and were utilized to triangulate emerging findings which was used 
to provide knowledge of the context and also used as reference points for subsequent interviews (Merriam \& Tisdell, 2015). Through this type of data collection method, the researcher had the ability to describe the environment and activities within the settings. Observations also offer the opportunity for the researcher to be open and inductive and finally allow the researcher to gain insight and learn things participants might not discuss in an interview (Patton, 2002). Detailed notes were taken during the observations and then analyzed according to social presence theory and suggestions from the blended synchronous design framework. Finally, interactions were tallied according to Moore's categories of interactions.

Semi-structured classroom observations were used to identify various patterns of interactions yet impose a structure upon the method of data collection which in this case includes pre-defined categories (Treanor, 2010). I was a non-participant/observer as participant where I was physically in the classroom but an outsider taking notes and not participating in the class activities. (Patton, 2002). I attended seven sessions from MIT 500 since the class met fourteen times throughout the semester. The EDL 601 class met six times throughout the semester, therefore, I attended three class sessions. Semistructured observations of the live class and class recording were conducted first, which allowed the researcher to refer to actions that occurred in the classroom when conducting the interviews. The semi-structured observations were used to record classroom interactions along with annotations where extensive detailed field notes were taken during the observation period.

All classes were recorded for review by the students or those students who were unable to attend class. The researcher reviewed the recordings to note frequencies of 
interactions throughout class time using a semi-structured observation form (Appendix E). The recording reviews were conducted after the data collection period ended.

\section{Text chat transcripts.}

Within the WebEx environment participants had the ability to use the text chat area to communicate with one another throughout the class. During the semi-structured observations, the researcher noted interactions that occur verbally. Since verbal and text interactions can happen simultaneously, the instructor was asked to save the text chat transcript at the end of each class for the researcher to review at a later time for text interactions. The text chat only archives those chats that occurred in the general chat area or privately with the instructor. The archives did not include any types of interactions that may have occurred privately between students.

\section{Survey.}

Open-ended surveys are designed to allow the respondent to express an opinion (Foddy, 1994). There are many advantages to the use of open-ended surveys such as spontaneous responses without bias which may occur in closed-ended questions or interviews. However open-ended questions need extensive coding. Nevertheless, deploying the survey after a month of class allowed the students to provide insightful information on how they perceived the BSLE.

Students received an electronic open-ended survey via email (Appendix C) a month into the semester along with a consent form which was embedded within the survey (Appendix B). The survey consisted of seven demographic questions and four open-ended questions regarding how students interact with each other. The questions were developed based on the data from a pilot study (Appendix C) as well as 
recommendations from Lowenthal and Dunlap (2014) regarding social presence. For example, students were asked about how they interact with one another and whether they feel an emotional connection to their peers. The survey data and the observations provided a baseline for the interviews and assisted with establishing trustworthiness. The survey was available for two weeks, and students received three reminders to complete the survey with a $70 \%$ completion rate.

\section{Interviews.}

The use of interviews in case study research is a popular method for collecting data (Creswell, 2012). It is an efficient data collection strategy for collecting rich, empirical data (Eisenhardt \& Graebner, 2007). Interviews are useful for asking participants sensitive questions or going beyond initial questions (Creswell, 2012). The researcher asked a series of broad questions which were based on the research questions (Runeson \& Höst, 2009).

Near the end of the observation period, students were asked to volunteer for semistructured interviews via email. Students who opted to participate in the interviews received a consent form (Appendix F) either electronically if participating from a distance or paper if the interview was in person. Semi-structured interviews included guided questions to ensure all the topics were covered but the wording and order were flexible (Merriam, 2009). Eight students and two instructors participated in the interviews. Three were online students, four were face-to-face students, and one student participated in both face-to-face and online environment. Both instructors were physically located at the school. The focused interview was conversational in nature but followed a prescribed set of questions (Appendix G) (Yin, 2014). A set of design-based 
questions were part of the protocol in order to keep the researcher on task and ensure the conversation flows in the direction of the research questions (Stake, 1995). These questions were based on the research questions, the data from the open-ended survey, and field notes from the observation period. The students' interviews were guided by the following topics:

- Experience in a blended synchronous classroom

- Preferred method of interactions and reasons for the preference

- Opinions of in-class work

- Feelings and level of comfort toward classmates

- Level of comfort towards instructor

The instructors from each program were asked to participate in the interview process (Appendix H). Instructors were asked to participate in the interview process so the researcher could gain insight into the instructors' pedagogical approaches. The background information was used to frame the students' experiences of the BSLE. The instructors' interviews were guided by the following topics:

- Knowledge and experience teaching

- Level of comfort with technology

- Professional development

- Facilitation of discussion methodology and reasons guiding the type(s) of instruction

- Preference of eliciting responses from students - Distance Education or face-toface

- Opinion of class cohesion 
Topics were chosen for the instructors based on the Blended Synchronous Design Framework specifically with regards to comfort level with technology, facilitation of discussion and pedagogy. Social presence theory influenced questioning regarding how instructors chose to facilitate class discussions.

Interviews took place in the face-to-face environment, online environment, or phone call depending on the interviewees' preferences and ranged from 20- 40 minutes. All interviews were recorded using audacity which is a free audio recording software program with the students' permission. The interview recordings were transcribed by a third party and all documentation was stored in Google Drive then imported into Nvivo 11.

\section{Data Analysis}

The data collection and data analysis occurred concurrently throughout the research process (Miles \& Huberman, 1994). Multiple forms of data analysis were employed to analyze the data such as structural coding, memoing, frequency analysis, and pattern coding (see Table 7). Structural coding was used as a first-round coding process as a categorization technique. Structural coding allowed the researcher to apply a content based or conceptual phrase that represented a topic to a segment of data that related to specific research questions (Saldaña, 2015). Analytic memoing was also used throughout the first-round coding process. An operational diagram was used as a transition to second-round coding process in order to organize the themes from structural coding. Figure 7 depicts an example of the operational diagram. 


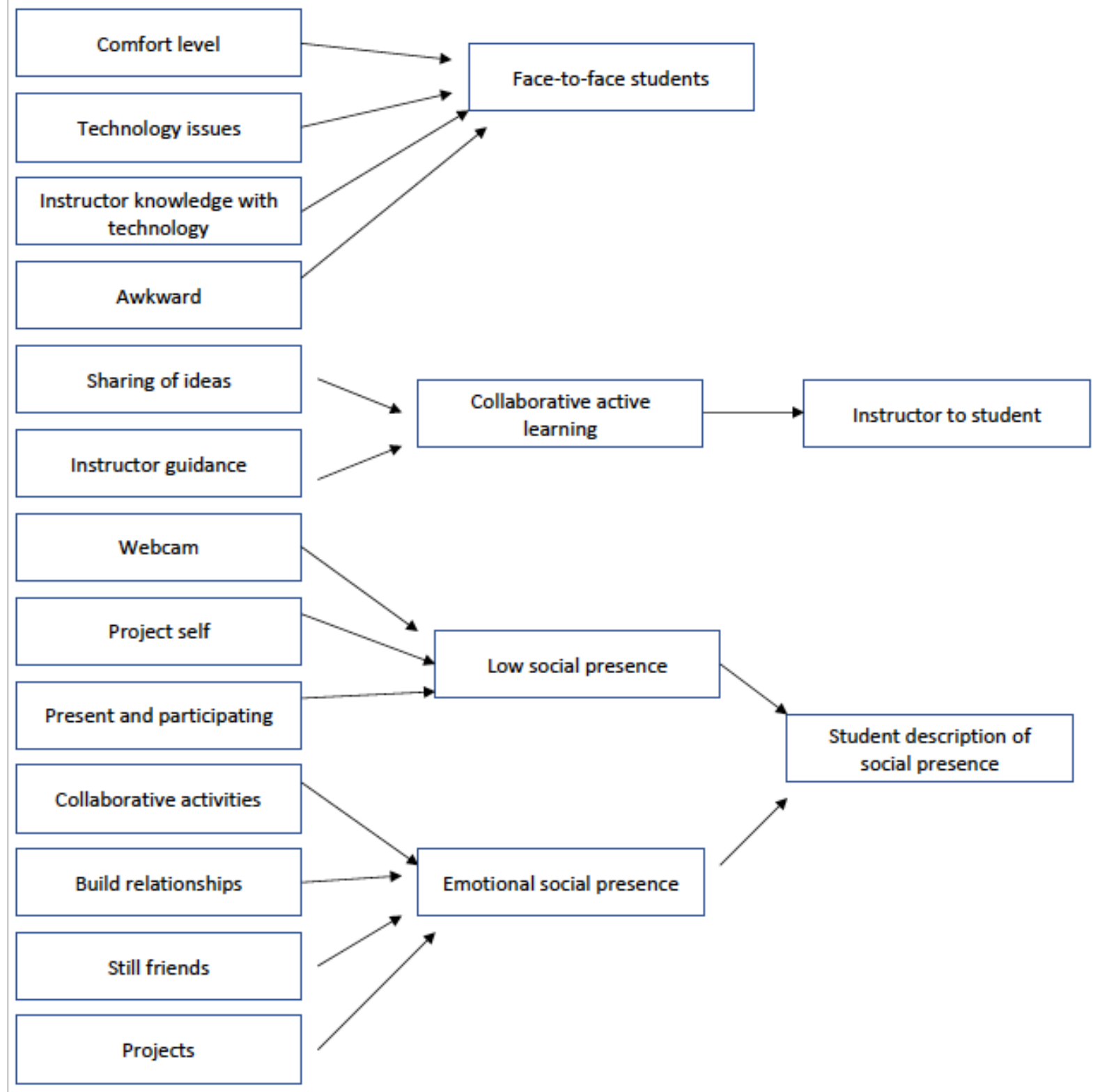

\section{Figure 6. Example of operational diagram use to move from first cycle coding to second cycle coding}

Pattern coding was used to develop categories to interpret the data from the observations, interviews, and surveys. Pattern coding allowed the researcher to group or cluster emerging themes. Analytic memos were recorded throughout the process on emerging patterns or themes throughout the data collection and analysis after each 
observation and interview (Miles \& Huberman, 1994). Frequencies of interaction were determined from the guided observation form and from the recorded class sessions and were supplemented with field notes. These data were compared to the surveys and interviews to determine consistency. All information was imported into Nvivo 11 for data analysis.

\section{Coding scheme.}

The initial coding scheme began with the semi-structured observations and text chat. The frequency of interactions was based on Moore's three types of interactions (Moore, 1989) with modifications based on Ramussen's (2003) study and Conklin et al. (2016) study. Eight pairs of interactions were identified of having the opportunity to interact: face-to-face student-face-to-face student, online student-online student, face-toface student-online student, online student-whole class, face-to-face student-whole class, instructor-whole class, instructor-face-to-face student, instructor-online student. The interactions were classified under four categories: administration, social, content, and technical. The categories were based on Ramussen's (2003) study. Administrative interactions are defined as exchanges dealing with matters from the syllabus, assignments, papers, tests class breaks, due dates, etc. Social interactions are defined as exchanges of a personal nature including questions and statements regarding personal events, jokes, stories, or side comments. Content interactions are those associated with course topics. Technical interactions revolved around the Learning Management System or the virtual classroom. These four categories are predefined based on a review of literature pertaining to the BSLE (Ramussen, 2003). Analytic memos were taken during 
the semi-structured observations regarding the various interactions and pre-coding with additional categories took place during fieldwork (Saldaña, 2015).

\section{Coding process.}

During the data collection phase, the researcher analyzed the data and began open coding and writing of analytic memos. Open coding is a means for conceptualizing the data and identifying or conceptualizing the data which allowed the researcher to begin to see patterns (Strauss \& Corbin, 1990). Open coding was achieved by analyzing phrases and repeating parts of it in a descriptive manner. During this process, the researcher began categorizing the data by developing a draft codebook (Figure 8).

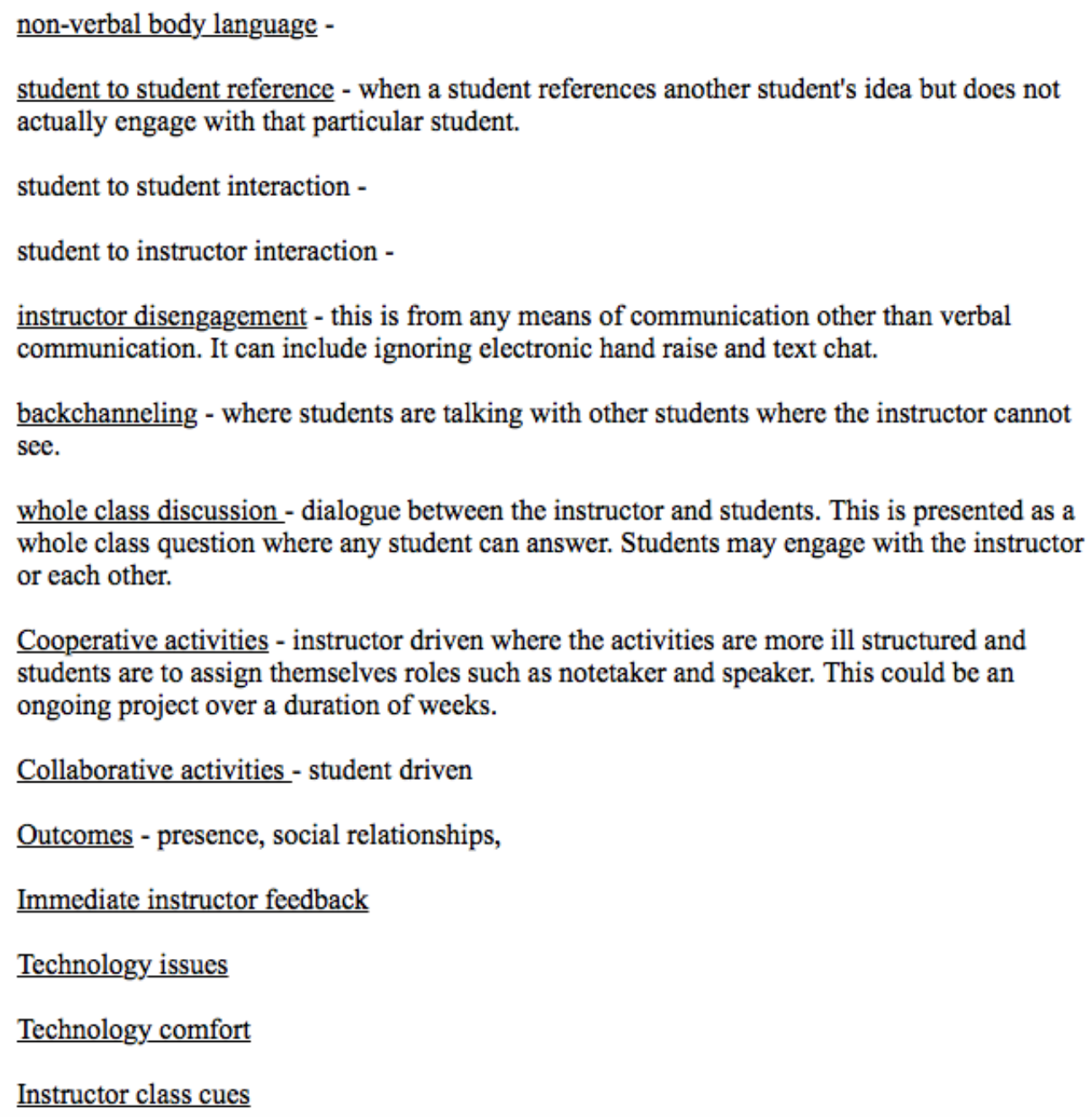




\section{Figure 7. Example of codebook from first cycle coding with categories}

Next, pattern coding was utilized to begin to group the themes into categories

(Miles \& Huberman, 1994). Nvivo 11 was used to group or cluster categories with the creation of nodes. Figure 9 depicts the Nvivo 11 node screen. At the top of the figure are

a list of sub-nodes associated with the BS Framework node. All of the data (interviews, surveys, observations) were coded and associated with corresponding sub-nodes. For example, all of the data associated with 'distributing attention' is listed below the nodes.

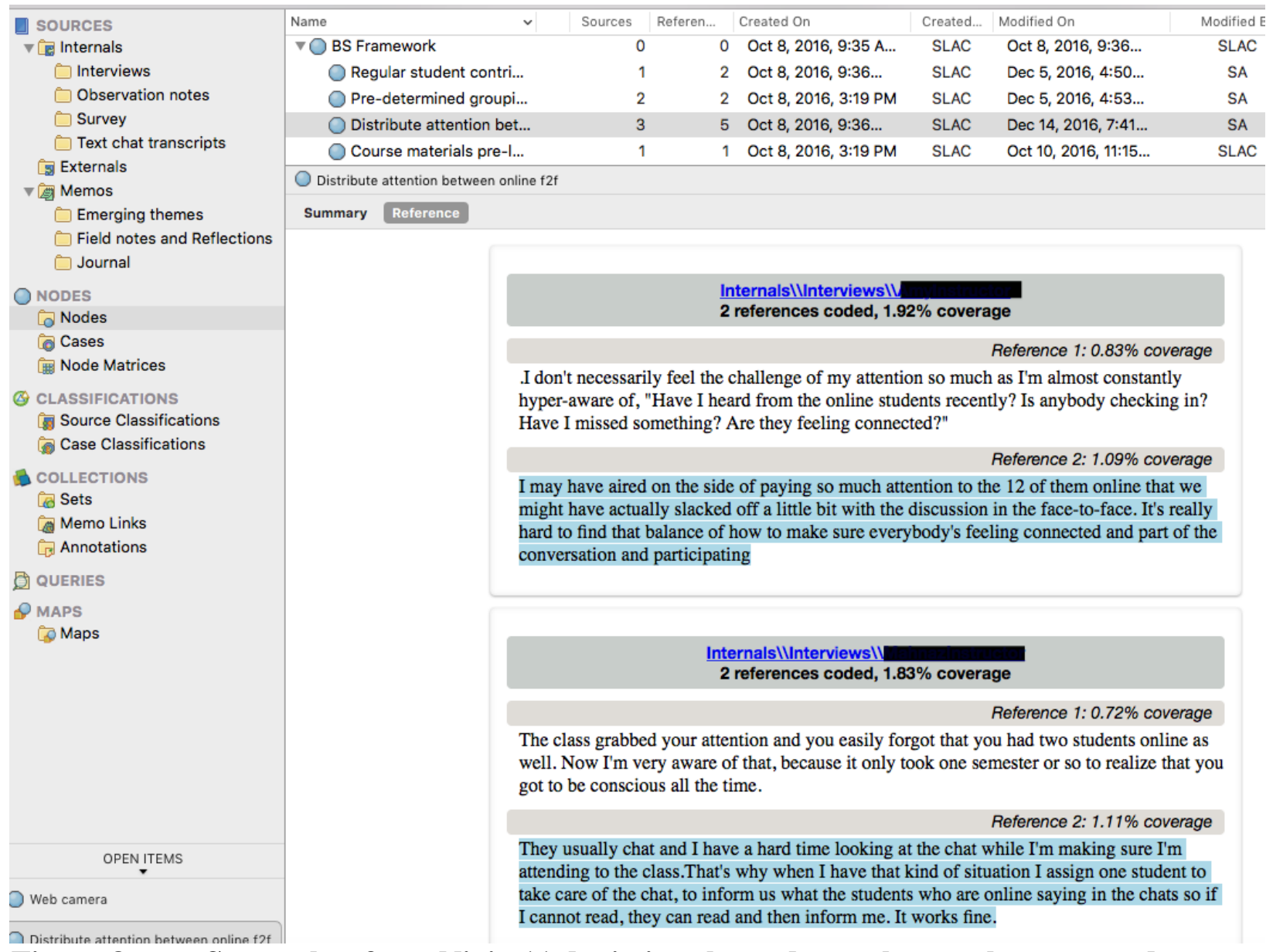

\section{Figure 8. Screenshot from Nivio 11 depicting the nodes or themes that emerged.}

Memoing was utilized throughout the process as a sense-making tool which assisted with the conceptualization of themes and clustering categories (Miles \& Huberman, 1994). 
The semi-structured observations were tallied using a frequency count which were compared to field notes, survey data, and interview data to determine consistencies.

\section{Methods for Trustworthiness Validation}

The establishment of trustworthiness is a critical component of qualitative research. Trustworthiness is also referred to as validity and reliability (Yin, 2014). Trustworthiness establishes confidence to the audience in the methods used to gather the data as well as the results (Lincoln \& Guba, 1985). To ensure the study's findings are authentic the following methods were utilized: persistent observation, triangulation, and member checks. During the coding process three methods were utilized to ensure trustworthiness: 1) check initial interpretations with the participants, 2) initially code during interview transcription, 3) maintain a reflective journal with analytic memos (Ezzy, 2002). Table 9 depicts the data collection strategy and the type of method for trustworthiness to ensure validity and credibility.

Table 8 Data collection methods and method for trustworthiness

\begin{tabular}{ll}
\hline Data collection method & Method for trustworthiness validation \\
\hline Observation & $\begin{array}{l}\text { Persistent observation } \\
\text { Triangulation }\end{array}$ \\
Text chat transcript & Triangulation \\
Survey & Triangulation \\
Interview & Member Check \\
& Triangulation \\
\hline
\end{tabular}

Persistent observation.

Persistent observation added salience to the observations. The purpose of persistent observation is to identify characteristic and element in the setting that are most relevant to the problem being studied (Lincoln \& Guba, 1985). To obtain the necessary scope and depth for effective results, I attended seven of the fourteen class sessions in 
MIT 500 and three of the six class sessions in EDL 601. This also allowed the researcher to learn the culture and document the multiple influences that affect the study (Lincoln \& Guba, 1985).

\section{Triangulation.}

Triangulation is a method of collecting multiple sources and using multiple methods of data collection were used. The methods of open-ended surveys, observations, and interviews were used to answer the research questions from a qualitative perspective. These multiple sources were then used to converge the data to determine if there is consistency in the findings (Yin, 2014). Patton (2002) defined four types of triangulation: methods triangulation, triangulation of sources, analyst triangulation, and theory/perspective triangulation. For this study, methods triangulation was employed. Methods triangulation verifies the consistency of findings generated through the various data sources (Lincoln \& Guba, 1985; Patton, 2002).

Member checks.

Informal member checking was performed specifically with regards to the interviews. Member checks is a crucial technique for establishing credibility. Data, interpretations and conclusions are tested with those participants from whom the data was collected (Lincoln \& Guba, 1985). Informally, during the interview I restated and confirmed what the interviewee was communicating. Informal member checking served several purposes: ensured the respondent's intent, gave the respondent an immediate opportunity to correct errors, provided an additional opportunity to volunteer additional information, and provided an opportunity to summarize (Lincoln \& Guba, 1985). 


\section{Summary}

This qualitative embedded case study approach employed multiple methods of data collection to gain a holistic view of the BSLE and examine student perceptions of interactions within the BSLE. Data collection included observations, open-ended surveys, and interviews which were triangulated to ensure trustworthiness. During the observations, frequencies of interactions were tallied but not used for statistical analysis. This data was utilized to support the analytic notes from observations and students and instructor interviews. The open-ended survey was also used to support analytic memos and interview data to validate the findings. Finally, it is the hopes that the data from this research will contribute to existing literature of best practices for teaching within the BSLE. 


\section{CHAPTER FOUR: RESULTS AND FINDINGS}

The purpose of this case study was to examine students' experiences of interactions in a Blended Synchronous Learning Environment (BSLE). Data was collected using ten semi-structured observations, eight interviews, and an open-ended survey with nineteen participants. This chapter presents the key findings obtained from the analysis of all the data. Three major findings emerged from this study:

1. Students described a process of forming social relationships among their peers based on designed interactions.

2. Technology can be a major contributor to the formation of relationships among students or it can obstruct relationships based on technology knowledge and skills.

3. Pedagogical strategies suggested in the blended synchronous framework contributed to the formation of social presence.

The initial section of this chapter reports on the findings by first giving an overview of the BSLE and the instructors' teaching styles from classroom observations and instructor interviews. Next, student demographics are reviewed. Then each sub research question is discussed by building explanations from the data and identifying emerging themes that work toward answering the central research question: how do students perceive the various interactions that take place within the BSLE?

\section{Central question:}

How do students perceive the various interactions that take place within the BSLE?

\section{Sub Questions:}


1. What were students' experiences within the live BSLE?

2. How did students describe interactions (student and instructor) within the live BSLE?

3. How did students describe interactions (student and student) within the live BSLE?

4. How did students describe designed interactions within the live BSLE?

5. How did students describe social presence within the BSLE?

\section{Classrooms Organization}

Each of the two classes observed were located in two different distance education classrooms. Although both classrooms were outfitted for synchronous connectivity, each classroom had a different configuration. Both classes included an instructor station and two projector screens. One screen projected the instructor's computer screen while the other projected the virtual classroom which displayed the online students' cameras through the WebEx environment. Each instructor wore lapel microphones and additional microphones were located throughout each classroom to capture what students attending face-to-face might say. The locations and types of microphone varied per room. The differences in each room configurations which impacted online learners are addressed in the following sections.

$\underline{\text { Instructional Technology classroom }}$

The Master of Instructional Technology (MIT) classroom was equipped with three cameras, one for the instructor and one additional camera for each of the two tables where the students sat in the class (see Figure 10). 


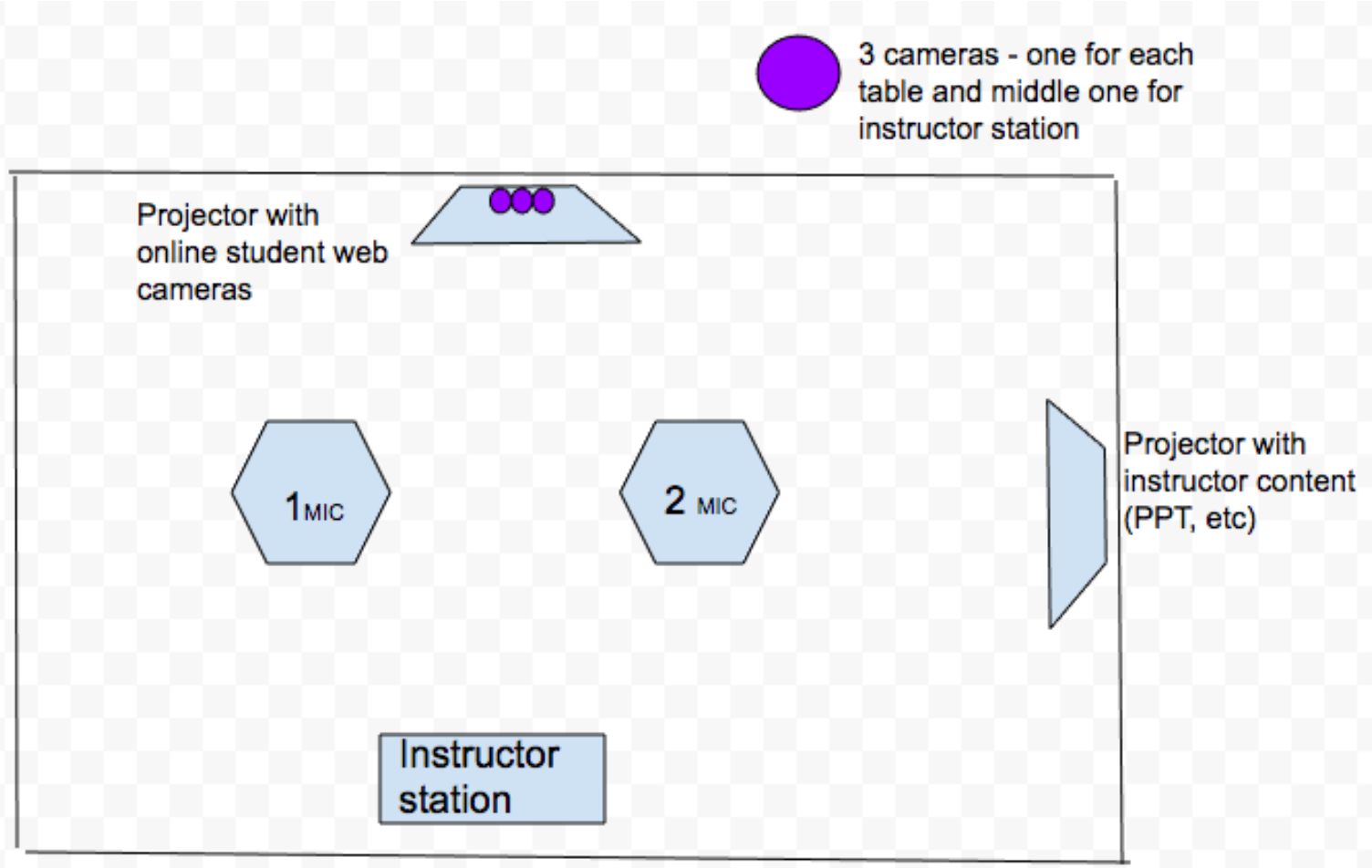

Figure 9. Diagram of the MIT distance education classroom

The middle camera followed the speaker and when the students spoke, the two side cameras displayed those face-to-face students speaking so the online students could see the face-to-face students. As seen in Figure 11, students in the classroom could also easily view the online students when they spoke in addition to viewing the content on the instructor's screen. Due to the location of the instructor station and the seating arrangement in the room, the online students saw the side or back of the face-to-face students most of the time. 


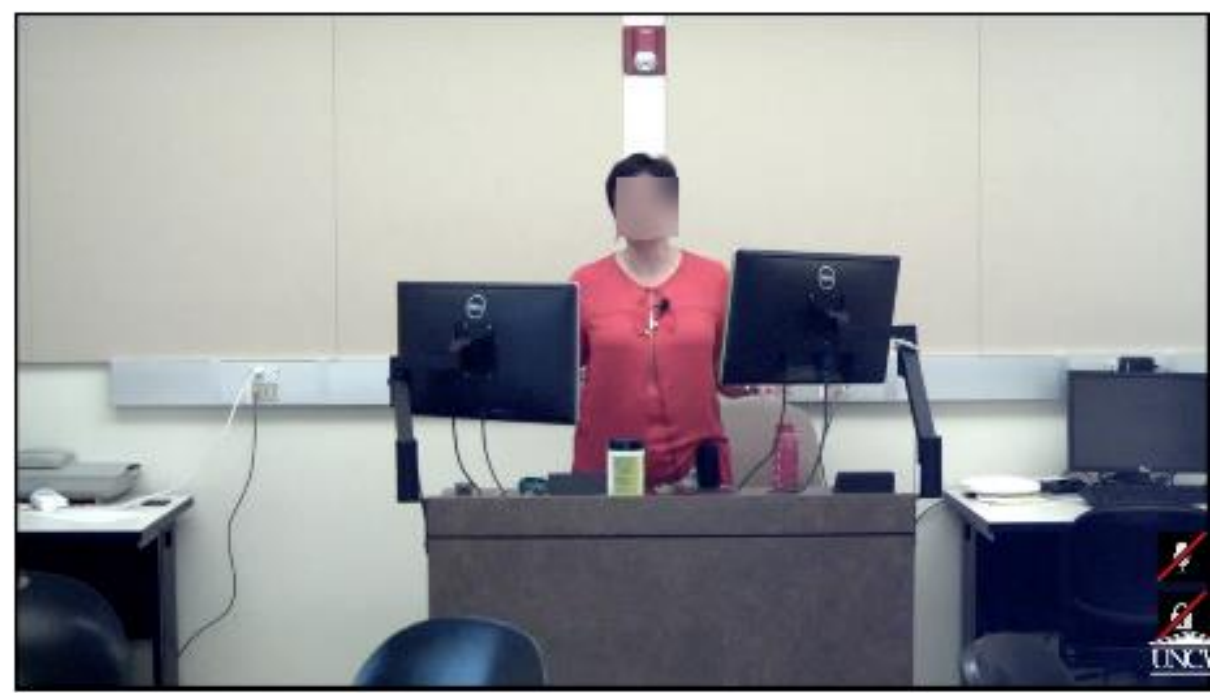

Figure 10. View of instructor from online student perspective

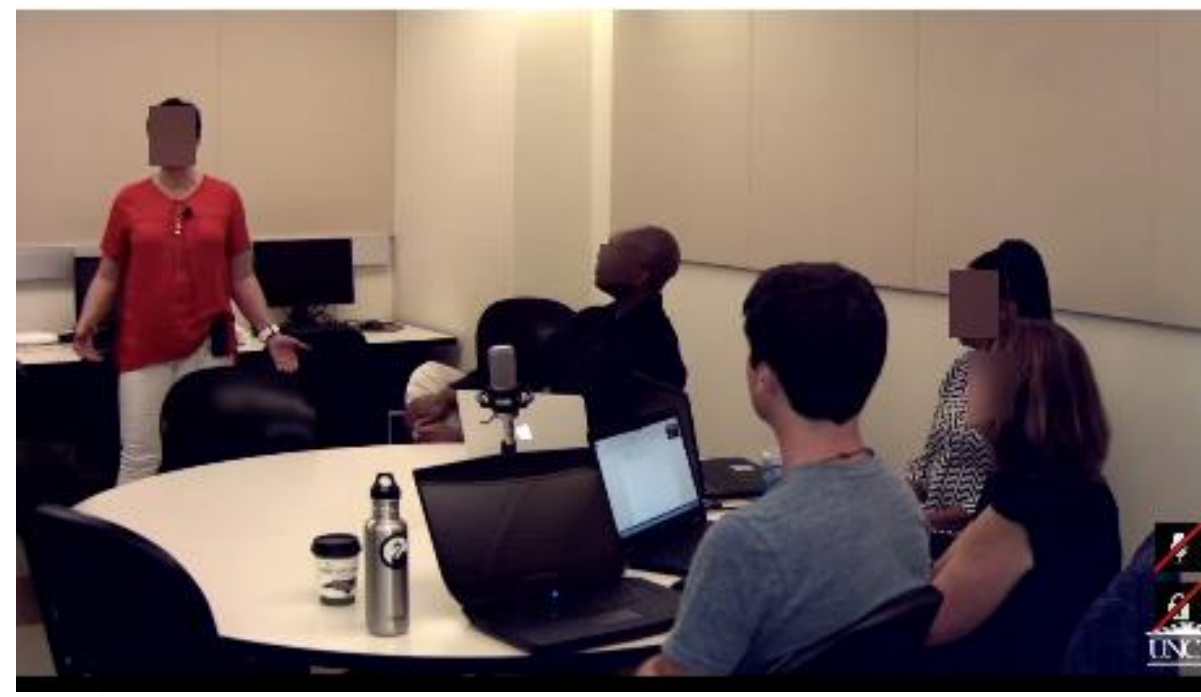

Figure 11. View of the face-to-face student table with microphone from online student perspective

\section{Leadership Theory Classroom}

The Educational Leadership (EDL) classroom, contained one camera at the back of the room that displayed the class to the online students (Figure 12). The setup of the camera allowed the online students to view the instructor easily but they only saw the back or side of face-to-face students. The classroom camera did not capture the whole 
classroom, only two of the five tables. (see Figure 13). The projector screens were placed so the face-to-face students had to sit at a certain angle to view the online students.

However, sitting in this position required the students to adjust head angles to engage with the instructor. The instructor wore a lapel microphone to improve quality and clarity for the online students. The classroom was equipped with two additional drop microphones that hung from the ceiling above two of the tables (see figure 14). These microphones allowed the online students to clearly hear the face-to-face students. However, the placement of the microphones created the potential for classroom disruption because it enabled the online students to hear conversations between the faceto-face students. The face-to-face students sometimes engaged in side conversations while the instructor or other students were speaking, causing the online students to have to distinguish between the information being presented and disruptive side conversations.

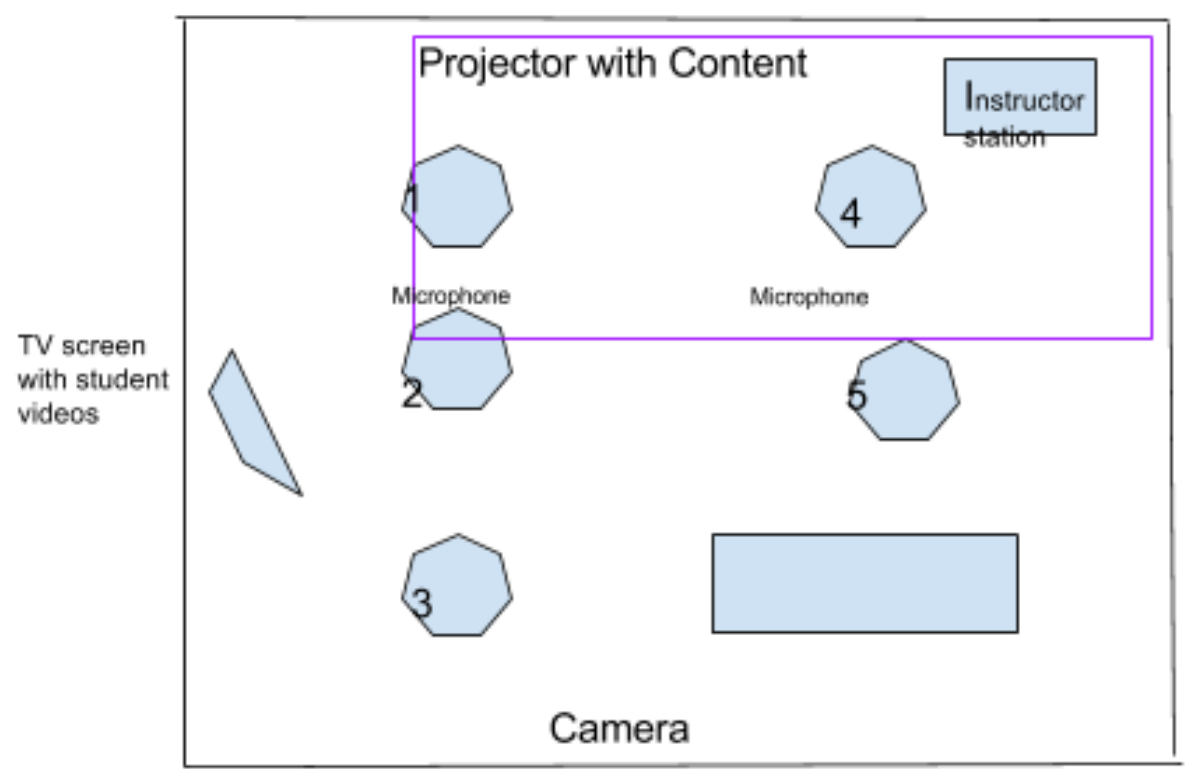

Purple box is the camera range for the online students. 


\section{Figure 12. Diagram of the Leadership Theory classroom}

The microphones are hanging from the ceiling above the tables. The students on the right are looking at the screen with the online students' videos.

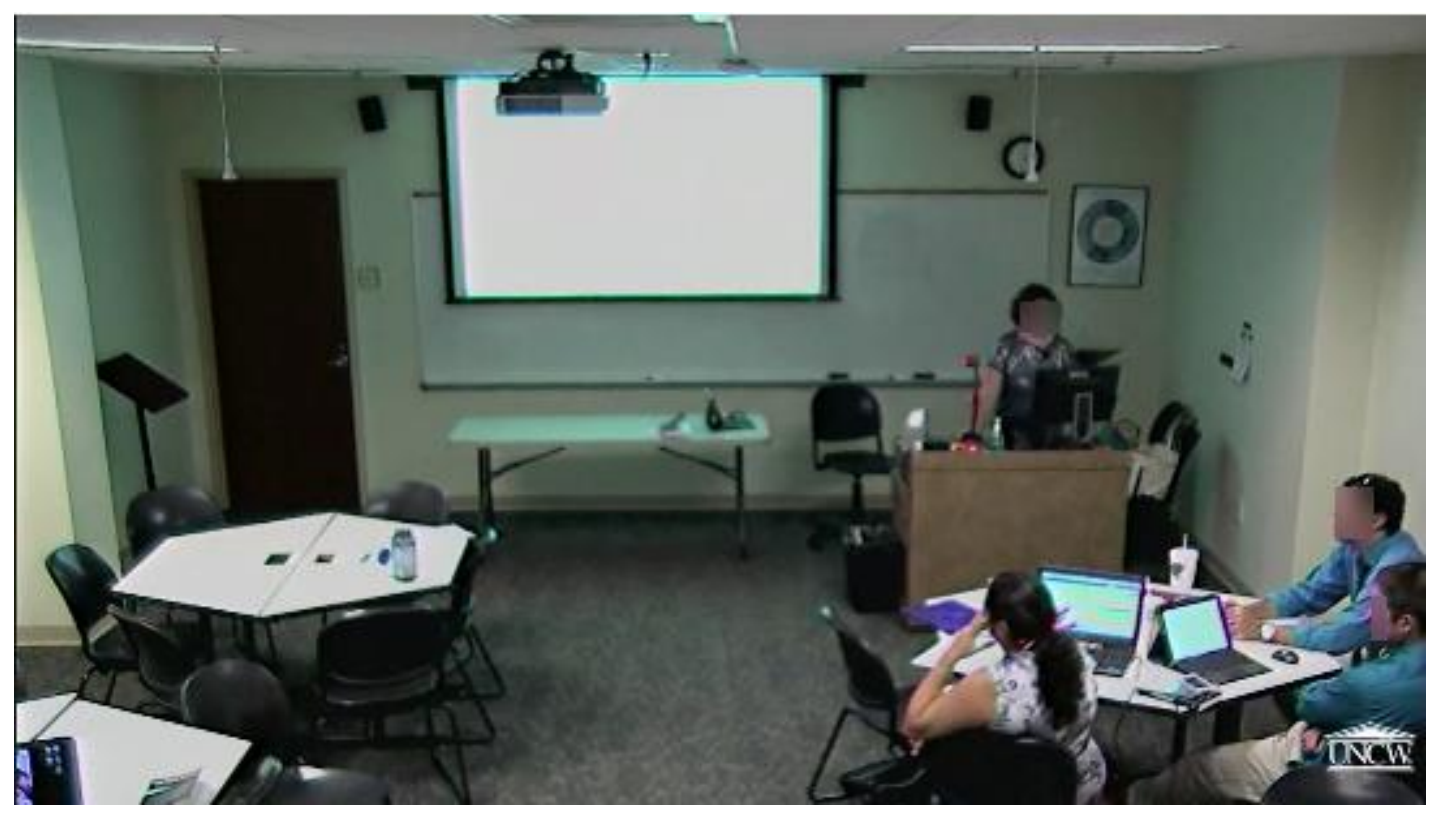

Figure 13. View of the EDL classroom from the online student's perspective

\section{$\underline{\text { Virtual Classroom }}$}

The MIT and EDL virtual classrooms both utilized Cisco's WebEx video conferencing software which allowed for the use of multiple student cameras to be used simultaneously with the classroom camera. The WebEx software allowed the instructor to enable desktop sharing capabilities and present polling questions. Students answered polling questions nonverbally by choosing a "check" to agree or an " $\mathrm{X}$ " to disagree. Additionally, the software allowed instructors to create breakout rooms where students could collaborate and share desktop displays in small groups. WebEx displays the instructor camera within the video feed of the person who is speaking. Below the main area, participant videos are displayed. The WebEx software allows for five participant 
cameras to be displayed at one time, so the instructor and students had to scroll back and forth to view additional participants.

\section{Instructors}

The instructors were interviewed to gather additional information on their experience with the BSLE and their teaching pedagogy. The interviews served three main purposes: (1) to understand how the instructor designed interaction (2) gain insight into the instructors' experiences in the BSLE which could potentially affect the student experience, and (3) garner insight into the instructors' underlying pedagogical underpinnings and classroom strategies. The instructors were asked the following (1) to explain their background and experience in the BSLE, (2) their pedagogical approach, and (3) grouping strategies. Since the interviews were semi-structured, the instructors were also asked questions based on observations and were specific to each class.

The two instructors who participated in this study had never received formal training on the technology used in the BSLE. Active learning strategies that involved both instructors asking frequent questions were used throughout the class, and both instructions used very little direct instruction. The MIT instructor stated that she felt lecturing in this type of environment is not a good strategy since the use of non-verbal cues for immediate feedback of student understanding is difficult to ascertain particularly with the online students. Online students in both BSLE settings were required to enable their webcams to validate participation; however, based on the observations, neither instructor strictly enforced this procedure. Therefore, there were approximately one to two students per class that did not enable their camera for most of the class. The 
following section will discuss the individual teaching styles and backgrounds of each instructor.

$\underline{\text { EDL Instructor }}$

When asked about the instructor's background, the EDL instructor stated her area of research included social presence therefore she stated she was knowledgeable and applied the social presence model within the class. She stated when I say "social presence model" about different ways to actually, truly build instructional practices that will hopefully lead to social presence, because social presence then we learn and experience, leads to certain satisfaction which of course would help lead to achievement, or at least stay in our class.

She also stated that she was almost "hyper-aware" of ensuring that all students have a voice in the class. Her comments regarding voice are as follows, "Have I heard from the online students recently? Is anybody checking in? Have I missed something? Are they feeling connected?"

She additionally stated this was the first semester where many of the students attended class online. Previously, she had a majority of face-to-face students and two-three students online. This semester (Fall 2016) she had twelve students consistently attending online. With so many students online for the first time, she felt that she had difficulty finding a balance to ensure everyone was feeling connected and may focus more of her attention to the online students. She stated the following:

I may have erred on the side of paying so much attention to the 12 of them online that we might have actually slacked off a little bit with the discussion in the faceto-face. It's really hard to find that balance of how to make sure everybody's feeling connected and part of the conversations and participating. 
She does not require the face-to face students to bring computers and log into the virtual environment but sometimes the face-to-face students do have to use their computer to collaborate for class activities.

\section{$\underline{\text { Student Interaction }}$}

When asked about grouping strategies, the instructor prefers to randomly group the students so not only do online students work with face-to-face, but more importantly to the instructor, students with varied backgrounds are working with one another. In order to achieve the randomness, the instructor pulls names from a hat to group the students during class time. She stated that she does want the face-to-face students to be able to talk with the online students but felt that it was cumbersome given that the students will have brought a computer and headsets to class. She was still trying to work out the logistics to create in-class groups composed of online and face-to-face students and stated,

It's a little cumbersome because they're gonna have to bring laptops, they're gonna have to bring headsets. Then we're gonna have to break out and move to other places. It probably will work easier now that there's just six of them in the face-to-face setting because I can send two out to an area with one laptop and they don't even need to have headsets necessarily if it's quiet enough. I can send two out to this area, and two can stay in the room. They can be joined with breakout groups with the online people. I have to think about that.

It was noted in the observations that in most class activities, the students were grouped by location often asking the online students if they wanted the instructor to group them or if they wanted to work independently. The instructor also employed additional technologies, TitanPad, for student collaboration. During the interview she stated, 
What can I do?, and she [instructional designer] said Google Docs. I'm like, Yeah, but they complain about tech as it is. I don't want them to have to log into anything, so she [instructional designer] showed me TitanPad and we played with it for like five minutes, and I thought, Okay, this will work. I had just had that conversation with her the previous week, so when I was thinking about, Oh, a TitanPad would work, I'll do that! I tried that with them in class to have them all connect at the same time right in the TitanPad. I guess I'm always thinking about ways to make the connect, and I'm always thinking about having them discuss.

From the observations, the researcher noted that the instructor was proficient with the basic features of the virtual classroom. One of the advanced features of the WebEx software is its capability to create breakout rooms. This feature allowed the instructor to break the class into small groups for an activity. When the instructor attempted to use the breakout feature, she stated that she had not created online groups in over two years. This was evident from the observations. She was not able to seamlessly direct students how to get started in the group rooms. Also, some of the students did not get placed into the group rooms, which required the instructor to spend additional time trying to redirect the students to the online group room.

When asked about her teaching strategies, the instructor stated that she did not prefer direct instruction but liked to engage the class in the discussion using probing. This was evident from the observations. The instructor frequently engaged the class by asking whole class questions. Although she asked the class questions, she did use non-verbal skills that elicited responses from particular groups. For instance, the instructor asked a question and looked at the face-to-face students, therefore the face-to-face students dominated the conversation. Then other times, she asked a question and looked at the screen with the student videos, these nonverbal cue-elicited responses from the online students who then dominated that conversation. She stated that she realized that sometimes she talked to the screen instead of the camera because seeing the students 
made a connection for her and then she realized what she was doing and tried to look to the back of the room at the camera. She also stated that she wished the room infrastructure was set up differently so that when she looked at the screen with the student videos, she simultaneously looked at the camera. However, she noted that when she looked at the screen, the online students answered her questions. The instructor also noted that she was aware that she would turn her back to the camera when she would refer to the projector screen with instructional content. She stated that she looked at the screen and then realized her back was turned towards the online students and turned around to ensure the online students had a frontal view.

During observations, it was perceived that the instructor preferred to ask the whole class questions rather than call on individual students. She reflected, during the interview, on the students who had not participated in answering the questions. In her reflections, she mentioned that she believed a student dropped the class but realized that was not the case. The student was connected online but not participating. This resonated with her since she did not know what this student looked like but could name the other online students as well as the background she typically would see in the student's video. She stated she thought about emailing to ask this student to try to speak up during class but had not reached out to that student at the time of the interview. The instructor's probing methods consisted of continually questioning throughout the class. She brought up a classroom concept and then ask the students to elaborate and provide examples of the concept. This method allowed the students to develop the content knowledge rather than the instructor providing the content knowledge. 


\section{$\underline{\text { MIT Instructor }}$}

The MIT instructor stated she had previously conducted research in the design of the distance education rooms and was an integral part of the creation of this distance education classroom. During the observations, the researcher observed that the instructor was able to use WebEx with ease. She easily moved students into small groups or breakout sessions and was able to assist students on how to navigate the group rooms within WebEx.

From the observations, it was noted that this instructor also used probing to engage both online and face-to-face students. The method of probing for the MIT instructor was more systematic. She began class by asking each student to recap their learning from the previous week. She then probed students to elaborate on their thoughts or answer any questions giving additional examples of the concepts. During class time, students participated in small group activities after which she prompted each group to reflect on the activity. When the instructor discussed concepts during the class, she also discussed a topic then asked if there were any questions once she finished reviewing the concepts. Finally, prior to the end of class, she again asked each student to reflect on concepts from the class that evening and then again elaborated on student answers giving additional examples. Therefore, the instructor was the primary concept knowledge provider asking the students to provide additional examples to ensure the students understand the concepts.

When asked about grouping strategies, the instructor explained that there are two types of teams. One is specifically for in-class activities which are mini problems and solved during class time and then discussed with the whole class and instructor. The other 
team is for the project which is a class project that the students determine and work outside of class time. The project teams are not predetermined and are based on student interest therefore, students group themselves. These teams worked on a long-term project outside of class time during a majority of the semester. The instructor used predetermined grouping strategies for the class activity teams because she wanted to ensure that there would be a mixture of online and face-to-face students with varied backgrounds. The class activities were mini problems that were solved during the class time. The grouping was based on the instructor's prior knowledge of each student according to classroom experience, resumes, and other documentation. The instructor also wanted to ensure that students did not group themselves with only familiar people. Through observing the interactions of students while collaborating in groups, the instructor found that changing group members affected student performance; therefore, the same groupings were utilized over the course of the entire semester. The instructor felt it was important for students to establish a "norm" which takes time. She stated,

Originally I changed them [groups] every four weeks but their performance got affected by norming. Some of them are online, some of them live, and they have to communicate at a distance. Establishing the norm for the group to work takes time. Once they know each other and they know how they can work together, the performance becomes much better and they get to the depths of the issue faster and easier. Then, when they have to figure out who the new members are, or get to know, it takes about a week or two at the minimum to get to know themselves and be able to get to the point that it can really focus on the problem rather than focus on the problem rather than focus on who's idea it is? What is your background? A lot of norming happens, so I decided to not change the class activities teams because it appeared that helps greatly.

The instructor also offered teams instruction on group work by reminding them to establish a leader and recorder as well as reminding them to rotate role assignments for 
each class activity. Each class contained at least one group activity which lasted for about 30 minutes for students to collaborate.

Often the group activities were solving ill structured problems so the groups typically needed to finish the assignment outside of class. When the instructor was asked about why class time is given to work on team activities, she stated,

Over time they [students] have said to me that feedback is the most important thing that they have learned from the class, because feedback is so specific to what they are doing and what they are thinking, is much more powerful than anything else that they do.

Providing students with class time to work on team activities also allows the instructor to identify any student misconceptions or issues. Furthermore, students who previously completed the same course stated that the immediate feedback was essential to their performance on the problem-solving activities. Based on those students' comments, the instructor made sure to provide class time for working on team activities.

When asked about whether she felt there was a cognitive overload for her having to divide her time between two environments, she stated,

It's not an overload as much as it's an awareness that you have a group of people that are not in front of you. I learned that over time, because particularly when I had more student in class than I had online that could easily happen. The class grabbed your attention and you easily forgot that you had two students online as well.

It was easy for the face-to-face students to grab the instructor's attention. She also stated,

The thing I still cannot handle, and most of the time have a student handle that for me, when I have more student in class and then a couple online. They usually chat and I have a hard time looking at the chat while I'm making sure I'm attending to the class. That's why I have that kind of situation I assign one student to take care of the chat, to inform us what the students who are online saying in the chats so if I cannot read, they can read and then inform me. 
However, during the observations it was noted that the instructor did not employ this strategy. She also stated student videos helped with the awareness of the online students. The instructor further stated, "it really requires a lot of consciousness and a style of teaching as well."

As for the MIT instructor's teaching style, she stated that she used an interactive style including discussion, problem solving, and hands-on activities since those will keep all students on task, and she can stay informed of how the students are doing. The instructor felt this was particularly important for the online students since they are in more distracting environments such as homes where there are children. The instructor provided the online students with additional tips for minimizing distractions such as using headphones with built-in microphones to reduce outside audio interference and choosing an appropriate location to connect and participate in class. The use of probing also keeps students on task as she stated she will hone in on students she either has not heard from during that class or students she feels are losing attention. This was confirmed through observations. Often, she would ask a question and then follow up by saying "Who have I not heard from yet?"

The small MIT class size (eight students) allowed the instructor to check for understanding of the material being discussed both at the beginning and end of class. Each student was asked to reflect on knowledge gained throughout the week and to ask any additional questions. She stated that she keeps the class capped at fifteen in order to maintain this type of activity. During the class when asking questions, she also deliberately incorporated long pauses. If the question was a yes or no question, she would ask both types of students to use the virtual environment to answer. If one student did not 
use the "check" or " $X$ " feature in the virtual environment, she would call on that student to ensure they were still present and attentive.

\section{Participants}

Participants for this study came from two blended synchronous classes which are part of the Instructional Technology program and the Educational Leadership program. The two classes consisted of twenty-seven students and two instructors. The EDL classroom had nineteen students and the MIT had eight students. Of those students, eighteen completed the survey, with a $67 \%$ response rate. Six students were from the MIT program (75\%) and twelve students were from the Educational Leadership program (63\%). The ages of the participants ranged from 20 - 59 with a majority falling in the 3039 range (Table 10$)$.

Table 9 Table depicting the age range of the students who completed the electronic survey.

\begin{tabular}{ll}
\hline Age range & Number of students \\
\hline Under 20 & 0 \\
$20-29$ & 4 \\
$30-39$ & 7 \\
$40-49$ & 5 \\
$50-59$ & 2 \\
Over 60 & 0 \\
\hline
\end{tabular}

From this group, twelve were females and six males. Although many of the participants were registered for either the online or the face-to-face section, some of the face-to-face students opted to attend class online. Notice in Table 11, six students stated they prefer to alternate between the online and face-to-face classes. 
Table 10 Student preference for attending class in the BSLE.

\begin{tabular}{ll}
\hline Mode for attending class in BSLE & Number of students \\
\hline Online in WebEx & 8 \\
Face-to-face on campus & 4 \\
I prefer to alternate between face-to-face and online & 6 \\
\hline
\end{tabular}

Eight students opted to participate in the one-on-one interview. Of those eight, three were online students, four were face-to-face students, and one student went between the face-to-face and online class. Both instructors also participated in one-on-one interviews.

\section{Research Question One}

For research question one, I analyzed students' experiences within the BSLE. This data was gathered from multiple sources including observations and one-on-one interviews. Students were asked to describe their experience in the BSLE in terms of interactions. From the interview, many students alluded to the BSLE being a positive environment. Only two of the eight interviewees shared negative comments regarding the BSLE classroom format. Both students were face-to-face students. The online students' experiences overall were positive. This potentially is due to the ability for students to gain access to their desired education due to location or another barrier that may have prevented them from attending the program. The students who continually attended classes in the face-to-face format felt the environment was uncomfortable and had a more adverse viewpoint to the BSLE. The main finding was students' comfort level with technology dictated students' perspectives to this type of environment. 


\section{$\underline{\text { Technology }}$}

The BSLE is heavily dependent upon communication technology. Online students attend class through a virtual classroom, in this case, through Cisco's WebEx virtual platform. For face-to-face and online students to interact with one another, the face-toface students had to log into the virtual classroom which was a requirement in the MIT class but not the EDL class. With this technology, there was a small lag in audio, therefore, it took the online students a few seconds longer to answer questions. Within the WebEx environment, the instructor can move students into small group sessions called breakout rooms. These rooms allow students to privately talk amongst themselves. The EDL classroom also employed a collaborative tool in addition to the virtual classroom, TitanPad, for students to create a collaborative document. TitanPad was chosen by the instructor for this class since students did not need to have an account to access and edit the document. TitanPad is a free text editing tool that allowed multiple users to edit the text simultaneously.

Technology was a common theme among the face-to-face students. Many face-toface students were less comfortable with the WebEx technology which made the BSLE more difficult to navigate. Students who regularly attended face-to-face described their lack of comfort with technology which also made it difficult for them develop relationships with their online peers. Students in the MIT and EDL classes both had the option of attending a program orientation. Students in MIT were introduced to the technologies used during the orientation whereas the students in the EDL class did not have an introduction to the technologies during their program orientation. The lack of a 
technology orientation could be a possible reason for the lack of comfortability with technology.

Overall, the face-to-face students had more difficulty developing relationships outside the classroom mainly due to being uncomfortable with the WebEx technology. Face-to-face students felt comfortable in the face-to-face environment and collaborating with their respective peers. The students felt that the course was set up in a manner that allowed students to reach out to their online peers but those same students neglected to take advantage of the technology due to comfort issues. One student stated,

Well one of the things that I think hurts us a little bit is the technology. I don't hate the technology, that while it's definitely better at the [university] class than I think I've seen anywhere else, it's still a little unfamiliar maybe to me, so it makes it a little bit more uncomfortable. Not only do I have to struggle to learn the content, but I have to struggle with the way the content is presented.

When asked about collaborating with online students, a second student stated, "I think the course is set up in such a way that the opportunity is there. I would say that it's probably more me that just doesn't take advantage of it, it's more my comfort level."

A third face-to-face student stated,

I'm not a huge fan of this model to be perfectly honest. If we were all online it would be one thing, if we were all in the class it would be something different. Trying to combine them, even being in the class is a little uncomfortable at times, because it's a little awkward interacting with people online.

Issues related to the level of comfort for using technology could be based on the fact that many of the face-to-face students do not have to use technology to access the instructor and other students. Although technology was a barrier for some of the face-to-face students, overall they enjoyed the environment. One face-to-face student stated,

I enjoy the hybrid experience. I really kind of require that socialization. Completely online classes are a little difficult for me and make me feel a little un- 
tethered. I like to have a little bit of face-to-face time to come back and then off of that face-to-face time, at least for me, makes me more comfortable.

Furthermore, several students who attend class virtually require additional troubleshooting skills to access the virtual classroom. In Table 12, the observations support the students concerns. The face-to-face students had more technical questions than their online peers.

Table 11 Technical questions from MIT and EDL students.

\begin{tabular}{ll}
\hline Type of Interaction & Technical questions \\
\hline Instructor-Whole class & 1 \\
Instructor-Online & 2 \\
Instructor-Face-to-face & 10 \\
Total & 13 \\
\hline
\end{tabular}

Based on instructor preference, students attending the MIT class in the face-toface environment were expected to $\log$ into the virtual environment with their online peers. This was not an expectation for the EDL students. Face-to-face students in the EDL described technology as being a barrier based on the number of students who experienced technical difficulties. For instance, when the instructor placed the students into breakout groups, some of the students were ejected from the small group room and then were unsure of how to proceed. However, one student stated that "once they got the technology figured out and it was behaving itself, it worked out well for everybody." The face-to-face students in MIT had more experience with technology due to the expectation of logging into the virtual classroom which led to deeper connections between the faceto-face students and their online peers. One student in EDL described a connection she 
formed with her online peers as a result of actually logging into the virtual classroom and interacting with classmates. Through logging into the virtual classroom, the face-to-face students could better relate to their online peers.

Overall, the online students had a more positive experience with the BSLE.

Although the environment was new for many of the online students, they adapted to the learning environment. One student stated,

... so far I think the whole WebEx experience has been really good for me. I'm able to hear everybody and take everybody's input and add my input, and I think it makes the class ... You know even though, we're not all together at one time, I think we're able to collaborate and we're able to share ideas. I think the flow of the class is really good and so far it's been a great experience for me.

Another online student stated, "It feels more like a real environment and I don't feel so disconnected from everyone." As a group, the online students navigated the virtual environment and felt comfortable interacting with the instructor and both their online and face-to-face peers.

\section{$\underline{\text { Instructor Knowledge with Technology }}$}

There were also differences in instructor knowledge with the technologies used in the classrooms. For example, moving students into breakout groups or small groups would be considered advanced, and the instructor was able to do this with ease. The MIT instructor was cognizant of the technologies employed within the BSLE and assisted students with troubleshooting technological issues. The EDL instructor was familiar with the technologies but was unable to assist students with technology issues. She also took more time to move students into small groups within the virtual environment. She stated in class, "Breakout sessions are a step I haven't done in Blackboard in two years. So I have to remind myself how to do it . . . so bear with me and we will try our best." This 
statement also depicts the instructor's awareness of the technology tools as the Learning Management System (LMS) was Blackboard, but she was using WebEx for breakout sessions. This also could have been misspoken since she felt uncomfortable with the WebEx technology while showing her Blackboard course.

$\underline{\text { Summary for Question One }}$

By investigating students' experiences of the BSLE, the researcher concluded that comfort level with technology was a common theme among students that dictated their outlook on the educational environment. The online students who used the technology regularly, felt more connected to both their peers and the instructor whereas the face-toface students had more difficulty forming relationships with their online peers. Training and regular access to the technology for both students and the instructors could alleviate technology barriers and provide a more seamless environment for the face-to-face students. Finally, requiring the face-to-face students to $\log$ in to the virtual environment could enable them to become more comfortable with the environment and technology.

\section{Research Question Two}

The second research question was how did students describe interactions (student and instructor) within the live BSLE? To investigate this research question, data was collected through observations, faculty interviews, and student interviews. During the observations, frequencies were collected on the interactions between students and the instructor. These were coded under four categories: administrative, social, content, and technical. The frequencies were collected to validate student experiences as well as the researcher's analytic observations. A frequency table is included in the following section 
(see Table 14). Three major themes emerged from the analysis of the instructor and student interviews :

(a) Distributing attention equally among the online and face-to-face students is an important concept that requires deliberate and conscious effort.

(b) Active learning is an important concept for students to receive feedback from the instructor.

(c) Instructors need to be aware of the non-verbal cues.

\section{$\underline{\text { Attention among groups of students }}$}

According to the students from both classes, the instructors distributed their attention between the two groups, online and face-to-face, equally. Several face-to-face students stated they also tried to show respect by allowing the online students to answer some of the questions and were aware of the audio lag that can occur. They stated they held back from answering questions, so the online students had an opportunity to interact with the instructor. One student stated that by distributing equal attention among the faceto-face and online students, the instructor made "it felt as if there's not two different environments."

From the observations, the researcher noted that the instructors routinely would ask whole class questions. The MIT instructor would then call on students by their name to answer the question. Each time the instructor asked a question, she would call on different students to ensure all of them had the opportunity to answer. In the EDL class, the instructor would ask a whole class question, and either look at the face-to-face students to answer or call on the "online folks." Using this method, typically the same online people answered the question. 
The instructors used multiple methods to distribute their attention among the two groups of students to ensure they were able to interact with both the online and face-toface students. They made sure to call on the online students as well as employing the use of polling questions. From the observations, polling questions were effective when faceto-face students were required to login to WebEx as it leveled the playing field with regards on time to answer. Every student had the same opportunity and the time to answer. Throughout each class, the instructors prompted the students to participate by answering yes/no questions. This method ensured the students were actively listening and participating. In the EDL class, when this method was employed it was noted in the observations, that only the face-to-face students would participate as the instructor (1) moved through the questioning quickly and (2) did not direct the online students on how to participate in the questioning. In this case, the researcher felt the instructor was more focused on the face-to-face students, and the online students did not have an opportunity to contribute. In the MIT class, the instructor employed this same method but instructed the face-to-face students to use the yes/no buttons in the virtual classroom to participate. Once the students became accustomed to the instructor's expectations, all students participated without prompting from the instructor. This method ensured that the instructor equally distributed her attention to both the online and face-to-face students and all the students viewed each other's responses.

During class activities in which students were asked to respond to yes or no questions, the MIT instructor placed specific attention on making sure the online students were represented. During the first class session, she stated that she started with the online students to ensure they had an opportunity to participate. This same instructor called 
students out by name and specifically solicited responses from students who typically did not speak up on their own. The other instructor randomly chose between the online and face-to-face students. When addressing the online students, she did not call on the students by name but addressed the online students as a whole.

Frequency data was collected during the ten observations to determine how often the students and instructors were interacting and to determine if one group dominated the interactions (Table 13).

Table 12. Frequency of interactions by class.

\begin{tabular}{lccccc}
\hline $\begin{array}{l}\text { Class } \\
\text { observation }\end{array}$ & Administrative & Social & Content & Technical & Total \\
\hline O1 MIT & 32 & 0 & 0 & 0 & 32 \\
O2 MIT & 4 & 0 & 26 & 0 & 30 \\
O3 MIT & 6 & 0 & 46 & 0 & 52 \\
O4 MIT & 14 & 0 & 72 & 0 & 86 \\
O5 MIT & No video recording & & & & \\
O6 MIT & No video recording & & & & \\
O7 MIT & 8 & 1 & 66 & 0 & 75 \\
O1 EDL & 47 & 14 & 97 & 1 & 159 \\
O2 EDL & 43 & 7 & 123 & 9 & 74 \\
O3 EDL & 42 & 6 & 22 & 4 & \\
Total & 196 & 28 & 448 & 14 & \\
\hline
\end{tabular}

A deductive analysis was used to classify the frequency data in alignment with Rasmussen' (2003) study. The categories used were administrative, content, social, and technical. Administrative interactions are defined as exchanges dealing with matters from the syllabus, assignments, papers, tests class breaks, due dates, etc. Social interactions are defined as exchanges of a personal nature including questions and statements regarding personal events, jokes, stories, or side comments. Content interactions are those associated with course topics. Technical interactions revolved around the Learning Management System or the virtual classroom. Interactions regarding instructor to student were classified whether it was instructor to student to student to 
instructor since often there was banter between the two groups. There were a small number of students in each of the two instructional settings that alternated back and forth between participating in person and online. For example, in the MIT class, the first class session had four students who attended the session face-to-face and four students who attended the session online. As the semester progressed, more of the students who initially participated in person began participating online. Eventually only one of the eight students was still attending face-to-face. The EDL classroom experienced a similar shift. The first class started with ten students face-to-face, and by the third class session, half of those students had started attending class sessions online. As seen in Table 14, averages were determined by adding the number of students attending in each environment divided by the number of class sessions. The MIT class had an average of six students online and two face-to-face. The EDL classroom had twelve online and seven face-to-face. When both classes were combined, there was an average of eight students face-to-face, and four students online. Overall there was a majority of students attending in the online environment.

Table 13 Average number of students attending the EDL and MIT classes in the online and face-to-face environment.

\begin{tabular}{lcc}
\hline Class & Face-to-face & Online \\
\hline MIT & 2 & 6 \\
EDL & 7 & 12 \\
Combined & 4 & 8 \\
\hline
\end{tabular}

From the observations, frequencies of interactions between the instructor and students were tallied. An interaction was considered when the instructor would address 
the whole class with a question, call on a specific student, or call on a group such as the online students. The interactions were also tallied for when students from a respective group addressed either the class or the instructor specifically. Table 15 depicts the interactions that occurred in the EDL environment.

Table 14 Interactions between the instructor, class, face-to-face students and online students in the Leadership Theory class (EDL).

\begin{tabular}{|c|c|c|c|c|c|c|c|}
\hline $\begin{array}{l}\text { Type of } \\
\text { Interaction }\end{array}$ & Admin & Social & Content & Technical & Total & $\begin{array}{l}\text { Percentage } \\
\text { of } \\
\text { interaction }\end{array}$ & $\begin{array}{l}\text { Percent of } \\
\text { students in } \\
\text { online or } f 2 f\end{array}$ \\
\hline $\begin{array}{l}\text { Instructor- } \\
\text { Whole class }\end{array}$ & $\begin{array}{c}19 \\
(24 \%)\end{array}$ & $\begin{array}{c}10 \\
(12.8 \%)\end{array}$ & $\begin{array}{c}48 \\
(61.5 \%)\end{array}$ & $1(1 \%)$ & 78 & $20.4 \%$ & \\
\hline $\begin{array}{l}\text { Instructor- } \\
\text { Online }\end{array}$ & $\begin{array}{c}32 \\
(32.6 \%)\end{array}$ & $5(5 \%)$ & $\begin{array}{c}59 \\
(60 \%)\end{array}$ & $2(2 \%)$ & 98 & $25.7 \%$ & $63 \%$ \\
\hline $\begin{array}{l}\text { Instructor- } \\
\text { Face-to-face }\end{array}$ & $\begin{array}{c}69 \\
(33.6 \%)\end{array}$ & $\begin{array}{c}7 \\
(3.4 \%)\end{array}$ & $\begin{array}{c}120 \\
(58.5 \%)\end{array}$ & $9(4.3 \%)$ & 205 & $53.8 \%$ & $37 \%$ \\
\hline Total & 120 & 22 & 227 & 12 & 381 & & \\
\hline
\end{tabular}

According to the results displayed in Table 15, face-to-face students accounted for a majority of the interactions with the instructor although they made up $37 \%$ of the class. The online students composed $63 \%$ of the class yet only interacted with the instructor $25.7 \%$ of the time. The frequency data contradicted students' perceptions that the instructor divided her time equally. Students' perceptions suggested the instructors equally split their time between the face-to-face and online students by making it a priority to call on the online students individually or as a group. One student stated he moved to the online environment to have more freedom to explore related topics while class is going on. "Sometimes we may be covering something that I know well or am not 
particularly interested in so when I attend online I can direct my attention to other class related work."

Another student stated, “. . . the only thing that I prefer about the online environment is really more like a personal thing, for me to be able to collect my thoughts, rather than maybe how we're collaborating in class." From these statements, it could be inferred that some online students preferred to listen to interactions between other students and the instructor rather than actively participate in class discussions.

Table 16 illustrates the interactions from the MIT classroom. The instructor in the MIT class probed each student by asking each student at the beginning and end of class to explain their knowledge gained or questions regarding content, therefore, the interactions are more representative of the distribution of the students. On average, $75 \%$ of the students attended online and $25 \%$ attended face-to-face.

Table 15 Interactions between the instructor, class, face-to-face students and online students in the Instructional Technology class (MIT).

\begin{tabular}{|c|c|c|c|c|c|c|c|}
\hline $\begin{array}{l}\text { Type of } \\
\text { Interaction }\end{array}$ & Admin & Social & Content & Technical & Total & $\begin{array}{l}\text { Percentage } \\
\text { of } \\
\text { interactions }\end{array}$ & $\begin{array}{l}\text { Percentage of } \\
\text { students } \\
\text { attending } \\
\text { online or f } 2 \mathrm{f}\end{array}$ \\
\hline $\begin{array}{l}\text { Instructor- } \\
\text { Whole class }\end{array}$ & $\begin{array}{c}12 \\
(13.6 \%)\end{array}$ & $\begin{array}{c}0 \\
(0 \%)\end{array}$ & $\begin{array}{c}76 \\
(86.3 \%)\end{array}$ & $0(0 \%)$ & 88 & $33.5 \%$ & \\
\hline $\begin{array}{l}\text { Instructor- } \\
\text { Online }\end{array}$ & $\begin{array}{c}34 \\
(25.9 \%)\end{array}$ & $\begin{array}{c}0 \\
(0 \%)\end{array}$ & $\begin{array}{c}97 \\
(74 \%)\end{array}$ & $0(0 \%)$ & 131 & $50 \%$ & $75 \%$ \\
\hline $\begin{array}{l}\text { Instructor- } \\
\text { Face-to- } \\
\text { face }\end{array}$ & $\begin{array}{c}18 \\
(41.8 \%)\end{array}$ & $\begin{array}{c}0 \\
(0 \%)\end{array}$ & $\begin{array}{c}25 \\
(58 \%)\end{array}$ & $1(2 \%)$ & 43 & $16.4 \%$ & $25 \%$ \\
\hline Total & 64 & 0 & 198 & 1 & 262 & & \\
\hline
\end{tabular}


Although the students perceived the interaction to be distributed equally among the face-to-face and online students, the observation frequencies dispute this fact. Despite the actual interaction data that was collected and calculated by the researcher, overall, students seemed to be satisfied with the amount of attention they received from the instructors. Again, this could be due to online student's preference for anonymity and having the ability to process the information being presented and discussed.

\section{Active learning}

Both instructors engaged all students in discussion and frequently directed questions to the class as a whole. Many students enjoyed hearing the viewpoints of their peers and therefore were partial to the whole class discussion. During the whole class discussion, the interaction was primarily between the instructor and the student answering the question and rarely between students. The instructor took the stance of a facilitator of knowledge and solicited student responses. The primary reason for students' fondness for whole class discussion was the ability to hear other's viewpoints and the ability to received immediate feedback on class concepts from the instructor. Students implied that it is important to get clarification from the instructor. One student stated,

Just the sharing of ideas. . . Someone has an idea and I'm like, oh I didn't think of it that way, which would help me out in say answering a question or providing input or giving another outlook and experience that I've had. It really does help.

Another student stated, “. . . whenever I go back into the reading where I go back to some of the articles that I read and I'm like, oh this is what, you know, [student] was talking about." A third student stated,

So I think that's important to have some instructor led conversations, because if we were just left up to our own devices I don't think we'd ever know if we were on the right page. I did like how we had our chance to discuss together afterwards, 
but I think just student led discussion together all the time would be . . . I wouldn't really be sure if I was on the right path to learning.

This suggests that students gained insight and understanding from both the instructor and other students

The MIT class had an enrollment of eight students, therefore it was feasible for the instructor to have all the students give input for whole class discussion. The instructor asked each student to demonstrate their knowledge either with a yes or no question or she asked them to give an example of the concept being discussed. The instructor stated,

Then, all the time assess them, because they know that I'm not going to miss them if they're not listening. I grab them right immediately. If I know that somebody is disappearing, I'll ask them kind of questions so that they know that it's like you are right here. You [students] have to be very attentive and as much as possible.

The EDL class had nineteen students. Due to the number of students the instructor did not gather input from each student for each question. One student in the EDL class stated that she recognized the class was too big to have everyone contribute to the discussion but that she would like to figure out a better way to hear from every student.

The instructors also engaged the students in a variety of collaborative activities from whole class to small group activities. Based on interviews, students in the MIT class had group activities every class period and enjoyed discussing concepts with their group in a small informal setting without the instructor as well as it allowed them to "talk less self-consciously" and then bring their ideas back to the whole class and instructor.

\section{$\underline{\text { Instructor Nonverbal cues }}$}

During the observations, it was noted that both instructors exhibited non-verbal cues that elicited various responses from the online and face-to-face students. Some of the non-verbal cues included the instructor's eye contact when addressing the whole 
class, and the volume of the instructor's voice. These nonverbal cues seem to dictate which group of students would answer whole class discussion questions.

The EDL instructor typically faced the face-to-face students which allowed the online students to have a frontal view of the instructor since the camera was located at the back of the room. Often the instructor asked whole class questions while facing the camera. Therefore, she was facing the face-to-face students. In these instances, the faceto-face students actively engaged with the instructor. During these banters, the online students either used the hand raise tool in the virtual classroom to alert the instructor they would like to answer the question, or they typed an answer in the text chat. When the online students used the virtual hand raise, the instructor received an audio alert. If the instructor wanted to engage the online students, she faced the television screen to the left of the room and slightly raise her voice. In this instance, the online students saw her looking up and left. The face-to-face students often did not engage the instructor when she looked at the screen since she was not making eye contact with the face-to-face students. When the instructor was asked about her non-verbal cues, she stated,

I do often realize I'm talking to the screen 'cause I see them, and that makes a connection for me and then I sometimes have to force myself to look to the back of the room and talk.... That's my cue.

The MIT instructor employed similar non-verbal cues but due to the design of the room, the nonverbal cues were not as obvious. The camera was located above the screen where the online student videos were located, yet the instructor looked at the student videos on her computer monitor when conducting dialogue with the online students instead of the camera. 


\section{$\underline{\text { Summary for Question Two }}$}

Through the use of observations and interviews, students were able to describe interactions between the students and the instructors. The themes that described how the students interacted with the instructor were (a) attention among students, (b) active learning, and (c) instructor nonverbal cues. Although the students felt the instructor divided her time equally, the observation data reflected an imbalance of attention. This could be alleviated through employing a systematic method of ensuring all students have the opportunity to participate in the class discussion. The instructors used active learning through the use of probing to ensure students were actively participating and to gauge student knowledge. This allowed the students to be active participants and also hear the viewpoints of their classmates. Finally, through observations, it was noted that both instructors used nonverbal cues. Even the subtle nonverbal cues elicited reactions to which group was more likely to answer the question being asked.

\section{Research Question Three}

Research question three analyzed how students interacted with one another. Three different types of interactions, face-to-face to face-to-face, online to online, and face-toface to online were recorded and studied by the researcher. Data was collected through observations, an open-ended survey, and student interviews. During the observations, frequencies were collected on the interactions between face-to-face and online students. These were classified into four categories: administrative, social, content, and technical. The frequencies were collected to validate student experiences as well as the researcher's analytic observations. The major finding was that students did not engage with each other 
frequently. Student to student interaction was found primarily among the face-to-face students.

\section{$\underline{\text { Student interaction }}$}

Overall, participants in both courses, online and face-to-face, preferred to interact with the instructor during whole class discussions. The students wanted the immediate feedback of the instructor to confirm their knowledge. Students rarely referenced one another or engaged one another during class time. This was noted for both the online and face-to-face students.

During observations, students infrequently engaged one another during the discussion portion of the class. Students did interact with one another during group activities, but when there was a general discussion, students did not answer each other's questions nor did they answer questions that arose via text chat. For example, one student was having difficulty finding the document the instructor was referring to in class on the LMS and asked a question in the text chat on where to find it. None of the online students answered the question, and all waited for the instructor to answer the question. According to the frequencies of interaction in Tables 17, interactions among the face-to-face students is much higher than that of face-to-face to online and online to online yet faceto-face interactions are still low. Frequencies were gathered only during whole class discussion not during collaborative activities. Again a deductive analysis was applied to frequency data based on Rasmussen's (2003) study. One face-to-face student stated she already knew two of the people in the class, therefore, it was much easier to ask them questions as well as the fact that these students all were in close proximity at the same table. Another face-to-face student stated, "I usually interact mostly with the students that 
are in the same room." A third student stated, "I am definitely more conversational in my F2F [face-to-face] classes and do find a disconnect between OL [online] and class participation."

Table 16 Student interaction from both the MIT and EDL classes (10 class sessions).

\begin{tabular}{lcccccc}
\hline Type of Interaction & Admin & Social & Content & Technical & Total & Percentage \\
\hline F2F-F2F* & 11 & 5 & 14 & 1 & 31 & $67 \%$ \\
Online - Online & 0 & 1 & 1 & 0 & 2 & $4 \%$ \\
F2F- online & 1 & 0 & 3 & 2 & 6 & $13 \%$ \\
Online - whole class & 1 & 0 & 1 & 0 & 2 & $4 \%$ \\
F2F - whole class & 0 & 0 & 5 & 0 & 5 & $11 \%$ \\
Total & 13 & 6 & 24 & 3 & 46 & \\
\hline
\end{tabular}

*F2F $=$ Face to face students

Student interaction was low in both classes. The explanation for low student interaction can be seen from the following comments as the students preferred to interact with the instructor. The students from both classes sought immediate feedback from the instructor on content related questions and answers. This was validated through the oneon-one interviews. One student stated that she enjoyed the group work but felt she would not be on the right path to learning if the class focused around student-led discussions. Another student described instructor interaction as an opportunity to get clarification. When answering questions, students non-verbally engaged with the instructor making eye contact when answering the whole class. The students did not scan the class making eye contact with their peers. This indicated that the students only engaged with the instructor seeking validation for their thoughts or clarification. When students did engage with one 
another, they were more likely to engage with those in the same environment. One faceto-face student stated that he was able to get more out of a face-to-face conversation. In fact, he stated that "it's a little awkward interacting with people online." Another student wrote, "I feel an emotional connection to my peers in the face-to-face class. I do not feel the emotional connection to online peers because it is difficult to build relationships with them through a computer screen."

Online students had a different view of collaborating with their peers. Although they did not engage in conversation with their face-to-face peers during whole class discussion, the online students felt they collaborated well with others including the faceto-face peers. The online students referenced the sharing of ideas when describing their interaction with their peers. This type of interaction indicated the online students felt this was a form of collaboration. One student stated,

Just the sharing of ideas . . . Someone has an idea and I'm like, oh I didn't think of it that way, which would help me out in say answering a question or providing input or giving another outlook and experience that I've had.

Although the online students did not engage in direct discussion with one another or the face-to-face peers, they perceived the whole class discussion as student interaction.

\section{$\underline{\text { Group activities }}$}

Students did interact with one another when the instructors implemented in-class activities. One instructor used standing groups and integrated a small group activity into class session. The other instructor used random groups for small group activities and integrated a whole class collaborative activity. The instructors also used discussion boards within the Learning Management System (LMS) for student collaboration. Many of the students referenced the discussion forums as a means of collaborating with one 
another. One student referenced the blended model of having synchronous class while at the same time fostering content conversations through asynchronous discussions,

I feel that collaboration is strongly developed in the blended model with both types of peers. Introductions and initial conversations create the foundations of these relationships, while the forums allow us to really build and converse around the content. We then reconnect in the synchronous environment to discuss with those same peers.

They were able to build on each others' knowledge and then elaborated further during the synchronous sessions.

The use of collaborative activities during class also promoted the building of relationships and led to increased student interaction. The group activities need to be designed to foster collaboration and students need time to develop their thoughts and ideas. A problem based learning activities was used in one class and students were given 30-40 minutes to complete the assignment. Upon completion of the activity students were required to present their findings and describe their experience to the class. Other students commented on ensuring the activity was meant to be a collaborative activity and to ensure students have adequate time to develop ideas. One student stated, "I think I almost felt a sense of collaboration on the titan activity; however, it didn't last long enough to really delve deep." Another student said, "Often I feel as if the online collaboration is forced and ineffective." From the student comments and observations, design of the collaborative in-class activities and the amount of time allowed for students to interact can affect students' perceptions of student-to-student interaction and the effectiveness of the activity. 


\section{$\underline{\text { Research Question Three Summary }}$}

Through observations, the researcher noted that students did not actively engage with one another during class discussion. The most frequent engagement was answering one another's questions regarding administrative or content questions yet was limited to face-to-face students. Face-to-face students in the EDL class were not logged into the WebEx environment, therefore, they did not have the opportunity to engage with the online students in text format. Yet based on the interviews, online and face-to-face students had different perceptions on student interaction. Overall, face-to-face students perceived interaction as engaging in dialogue with another person whereas the online students perceived interaction as listening to discussion among the students. This is a notable difference in perception of student interaction.

From the observations the researcher noted, the type of activity and the time allowed for students to interact with one another can affect student-to-student interaction. The activity should be designed to foster collaboration where students need to interact with one another to complete the activity and be given adequate time. The in-class activities can assist with promoting student-to-student interaction if well designed and the instructor allows for time to collaborate.

\section{Research Question Four}

The fourth research question was: how do students describe designed interactions within the live BSLE environment? To investigate this question, data was collected using interviews and an open-ended survey to gain insight on how students perceived designed interactions. Observations were used to confirm student descriptions. Analysis of the data 
showed that students described two types of designed interactions: in-class collaborative activities and collaborative projects.

The in-class collaborative activities varied between the MIT and the EDL class. In the MIT class, students were assigned to predetermined at the beginning of the semester and remained in the same groups for the duration of the semester. During each class, the students would break out into team activities for approximately thirty minutes. The instructor said, "The class activities are basically mini problems that they solve during class time." Generally, the group activities consisted of each group being assigned a case to analyze. Each group was then asked to present their findings to the class at the end of each activity. For example, one group focused on $20^{\text {th }}$-century technologies while another was tasked to researching technologies from 1920-1940. Although some of the activities assigned to teams had to be completed outside of class time. She stated,

I want them to perform during the class time so that I can see how they are doings. A lot of time when they are meeting on their own I won't be able to see what they are doings. Also, I want them to really put the time to meet synchronously, because a lot of them may decide not to. ... They really can get most of the work done in class and then present their draft to the class so that they get immediate feedback rather than submitting and I will give them feedback, which would be a lad time for feedback.

The instructor would decide the groupings of the EDL students during class time and student groupings varied from class to class. Some of the collaborative activities were whole class activities, face-to-face groups with online students working individually or online and face-to-face students were grouped. The students typically had eight to ten minutes to work in their groups. The collaborative grouping typically required the students to brainstorm. As one student stated, “. . . here's my information and presentation, please consume and respond sort of interaction" Another student stated, 
We were supposed to be interacting and having a discussion, but really what it turned into was for the first thirty seconds we all assigned tasks to ourselves, and then we went and did our task. I didn't really hear another person online talk again.

Students were also teamed together to complete collaborative projects. The students were able to choose their team members based on the topic of the project. These projects typically lasted the duration of the semester and were expected to work together outside of class time. Projects examples were case studies or problem based learning scenarios. One student described the difference in the two activities as,

It is like two to four months that you are working on that [project] and then the activities are maybe in class activities where the instructor breaks you out into breakout groups and you have a scenario that you have to discuss and support and so you are collaborating together for just that hour, a short period of time.

Another student described the collaborative project as, "In my current class, I have a project that will take many weeks. The project will force my "partner" and I to interview others and will require a good amount of creativity and working together."

From the observations and interviews, students described designed interactions as collaborative activities among students where students need to engage with one another in order to achieve a common goal. The statements from students in the EDL class imply that the collaborative activities were meant to engage the students in discourse with one another yet the assignment did not lend itself to student discourse and could be completed independent of any dialogue among the students. Therefore, designed interactions should be ill-structured problems which promote student discourse. 


\section{$\underline{\text { Research Question Four Summary }}$}

Students typically referred to the in-class activities as group or team activities and the collaborative projects as projects. From the observations, the researcher noted that the team activities were short in duration and guided by the instructor and the students had expectations to debrief the class. For the collaborative projects, students were working over a span of time and primarily working independently. Designed interactions specifically engaged students in discourse.

\section{Research Question Five}

The fifth research was: How do students describe social presence within the BSLE. Social presence can be defined as the ability to project one's self (Garrison et al., 2000), but for the purpose of this study, the researcher wanted to know how students form social-emotional connections. Social-emotional connections go beyond the learners being able to project themselves and distinguish one another (Garrison et al., 2000) whereas the addition of emotion to social-emotional presence adds the expression of emotion and feeling by individuals as they relate to the course and the participants (Cleveland-Innes \& Campbell, 2012). Data from interviews and an open-ended survey were analyzed. From these data sources, students discussed a process of creating social presence with their peers beginning with the ability to distinguish their peers and identify them by name, next creating a superficial relationship with their peers, and finally developing a social relationship with their peers. These elements were identified through two interactions: use of the webcam and collaborative activities.

Despite the data from the frequencies, based on data from the interviews, a majority of the students in both classes felt that social interaction assisted with their 
learning. Working in groups was welcomed by most students, but generally, the preference for whom they worked with differed among students. One student in MIT stated, "I wouldn't want to even attempt any of her assignments individually." The MIT instructor used problem-based learning as the foundation for her pedagogical approach. Another student stated, “. . and I enjoy working with groups .... " A third student stated,

I appreciate having someone to talk to. We cry on each other's should, we complain to each other, we bitch and moan. It releases a lot of frustration, and it helps us clarify to ourselves what's wrong, are we crazy, are we really as dumb as everybody say we are?

Only one student stated that she did not enjoy the group activities. Furthermore, the same student felt that working with a group was a hindrance to her learning as that she felt it was easier to complete the projects and assignments individually. When asked if social interaction contributed to her learning, she stated, "I am very much an independent learner. I don't necessarily feel like my goal is to get in there and really create lasting relationships." One face-to-face student posted a Google form for people to fill out to get to know each other better; however, only three people completed the form. Most of them were her face-to-face peers. Based on the data from the interviews and open-ended survey, the students described social presence as a tiered format based on the type of activity (Figure 15). Table 18 contains quotes from students that support this tiered format. The following sections contain more detailed results and analysis for webcam, collaborative and collaborative projects. 


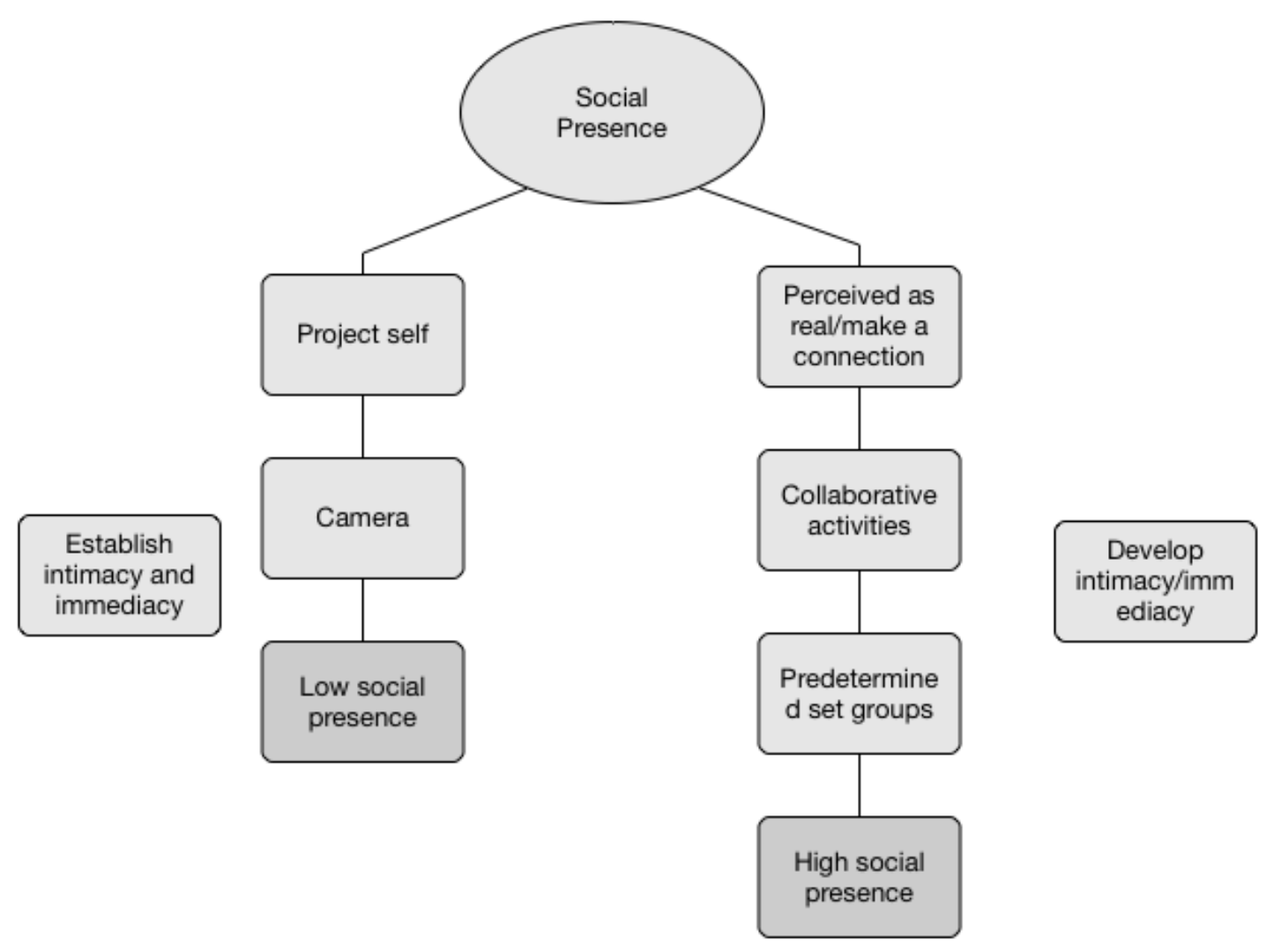

Figure 14. Social presence process as described by the students

Table 17 Student perceptions of social presence based on webcam, and collaborative activities.

\begin{tabular}{|c|c|c|}
\hline Activity & Presence & Student comments \\
\hline Use of video & Low & $\begin{array}{l}\text { - . . because then I can get those looking at the body language, non- } \\
\text { verbal cues, facial expressions, ... } \\
\text { - But, having seen someone's face, I think that's what opens the door } \\
\text { for it to be a person. } \\
\text { - . . it helps me if I can see the professor talking, and if I can see the } \\
\text { others sharing ideas. } \\
\text { - I think the class camera is very important because it simulates me } \\
\text { being there. I can see students in the class. It gives me a sense that I'm } \\
\text { kind of there. } \\
\text { - I think being able to see colleagues online via webcam and have active } \\
\text { discussions creates an emotional connection. }\end{array}$ \\
\hline
\end{tabular}


Collaborative High activities
- Having those assignment before we had to meet kind of opened the door to let us discuss together

- Honestly, I think those group activities draws us closer. I think getting to know how other people think and if there is some commonality in some of the ideas that we have. . . I think we're becoming more and more of a tight knit group.

- I think the little team activities you do in class you may just become superficial colleagues ...

- That really felt like it was more of a personalized discussion because there was only five of us and I was able to actually physically talk to my online peers.

Breakout groups within the WebEx session create the most collaboration with peers.

- We will sometimes have break-out sessions and that give me a chance to get to know the other students.

- I think [you] develop relationships when you work with someone for a long period of time on a project.

- I don't know if it will be a long-lasting relationship but I know that we're going to have some sort of bond by the end of it [project] just by the amount of work that we're going to do together.

- Each semester I have worked with another student on a project and have become friends with that student.

- She just works to make you talk and I think because she works to make you communicate with other people, and she does group work, you almost have this sense of community because we're working on a common goal.

\section{$\underline{\text { Use of Video }}$}

Students felt that the use of the web camera allowed them to develop the initial intimacy and immediacy. Although the use of video did not help the students develop social-emotional presence, the participants alluded that the use of video allowed them to begin to know each other, or as Garrison and colleagues (2000) defined, project themselves. When the online students employed the web camera other online and face-toface students could see who was speaking along with that student's name. This allowed other students to feel that they were getting to know those students through visual recognition. For instance, one online student stated that he felt he knew his online peers 
since he could see who was talking and listed their names and as he stated was able to “distinguish who they are". Another online student stated, "But, having seen someone's face, I think that's what opens the door for it to be a person." As for the face-to-face students, the same online student was unable to state their names two months into class. "I wanna build that relationship with them but I can only see like the side of their face, or like you said the back of their head." Another student stated that when their peer's web camera is not on, they often wonder if they are even there at the computer and found it "annoying" when students did not use their web camera. A third student described it as "frustrating" when they see the person's name but not their face. Although this student was a face-to-face student, she stated that she kept her web camera on because she found it "more respectful" and it made it seem "like you are all there". While another said, “But, having seen someone's face, I think that's what opens the door for it to be a person." Finally, another student stated that it "stimulates me being there" and that she "loses confirmation of what a person is saying" when it is audio only.

Due to the capabilities of the virtual classroom, only five students' cameras showed up on one screen. One student mentioned they would like to see all online students on one screen so they did not have to scroll which would make it easier to get to know the "onliners" better. The use of video was essential for students to begin to establish their presence and project themselves into the educational environment.

\section{Collaborative Activities}

Collaborative activities for the purpose of this situation are defined as class activities where students are grouped with a common problem or activity to accomplish 
during a set amount of class time. The grouping could be among or between the face-toface and online students.

One face-to-face student described relationships that are formed during collaborative activities as "superficial" where she is able to begin to learn why they are in school and her peers' backgrounds. One online student stated,

Having those assignments before we had to meet kind of opened the door to let us discuss together. Then, from there, I feel like we built relationships and we built a community and we started talking outside of that, too.

During the MIT class, students had regular collaborative activities where they had thirty minutes to work in their small groups. Students were asked how they preferred to be grouped either with peers who were attending class in the same format or having a mixed group. One student stated that she could not differentiate between who was online and who was face-to-face since they always met online in the virtual classroom for their class activities. Another student stated that they spend $80 \%$ of the time discussing content, and $20 \%$ of the time talking about "personal stuff."

\section{Grouping Students for In-Class Work}

One instructor predetermined groupings prior to class and the students remained in those groups for the duration of the semester. By determining these groups prior to class, students knew who they would be working with on a regular basis. The instructor stated that due to technology, it was best to keep the same groups for classroom activities so that the students could work out any technology issues. This would assist with making the technology less of a barrier to the learning process. Grouping students this way lends 
itself to creating social presence among the students as one student referred to her group as a "clique" and how they use a variety of technologies to complete their activities.

The other instructor did not use predetermined groupings and would place students in groups during class time. Often the grouping would be for the face-to-face students to work together in groups and the online students would work independently. It was for this reason that one student who was attending face-to-face sessions began attending online. She wanted to have time to collect her thoughts and the ability to pick and choose who she would work with or if she wanted to work with anyone at all

Based on student responses in the interviews, by placing students in groups prior to class and using the same groups throughout the duration of the semester, students were able to break through the barrier of online and face-to-face collaboration. Students who were in predetermined groups and had regular class exercises were more comfortable collaborating with one another. The same students were also more comfortable with the technology they used. Whereas the students who were not placed in predetermined groups and did have regular collaborative class activities, still felt there were two classes in one environment: online and face-to-face. The students in the predetermined groups would get to know each other better and gain a more rounded picture of each other and become more "empathic" of their teammates which creates a well-rounded team and forces each other to work harder for the team and produce better results. One online student stated,

Yeah, I like that my group is set but I like my group. .... I know that my team is really good about being there when I need them. Like, I had family coming into town one weekend, the day that an assignment was due, so I asked if we could meet a little earlier to have the project done so that I could spend time with my family. They all met and they really just rallied and supported me so that we could turn it in. 
Another students (face-to-face) stated,

Yeah, because already I feel like our team is the best team. We are the best but you just kind of wonder what are the other teams doing. You then become like a little clique among the class. ...

Predetermined set groups fostered social-emotional connections among the team members where they supported one another outside of class.

\section{$\underline{\text { Research Question Five Summary }}$}

One-on-one interviews and an open-ended survey data were collected to further investigate students' perceptions towards social presence. The students described a variety of levels of social presence which could be viewed as a process. The webcam allowed students to project their "self." Both online and face-to-face students stressed the importance of being physically seen or present. The collaborative activities allowed the students to acknowledge one another as peers regarding class content. The collaborative activities combined with predetermined groupings of students fostered relationships among the groups of students. Overall, students felt there were multiple levels of social presence depending on the situation and how that was fostered by the instructor through designed interactions.

\section{Chapter Summary}

Chapter four provided a detailed analysis of the data collected for this study. Detailed findings were analyzed from multiple data sources: observations, frequencies of interaction, an open-ended survey, and one-on-one interviews. From the data, themes of students' perceptions were generated for each research question. Multiple themes emerged from the data including student's level of comfort with technology, instructor 
pedagogy, perception of student interaction, and varied levels of social presence and how social presence was formed.

In research question one, the research showed that technology was a contributing factor to students' perceptions to the BSLE. Students who were uncomfortable with the technologies utilized in the BSLE had more difficulty connecting or interacting with their peers. The research also showed those students who had an introduction or orientation to the technologies were able to interact with their peers.

In research question two, the research revealed that active learning was a critical component for interacting with the instructor. Active learning strategies allowed the students to engage with the instructor and gave them the perception of the instructor dividing their attention among the online and face-to-face group equally. The research also revealed that instructors' nonverbal cues play a critical role in the active learning process. The nonverbal cues prompted either the face-to-face or online students to engage with their instructor.

In research question three, the research revealed that online and face-to-face students had different perceptions of what constitutes student interaction. The face-toface students described interaction as direct interaction with their peers which would include eye contact and discussion. Whereas the online students described interaction as whole class discussion and collaboration. The ability to hear their peers constituted interaction with their peers.

Research question four, students described designed interactions. Through their descriptions and observations, two types of activities emerged: in-class collaborative activities and collaborative projects. Both activities elicited student interaction in order to 
achieve a goal. The in-class activities were shorter in duration and under the supervision of the instructor whereas the collaborative projects span over a period of time and are completed independently of the instructor.

In research question five, students described social presence in terms of varying degrees depending on the activity. Students described a process for achieving high socialemotional presence beginning with the ability to see and project themselves through the use of video and ending with social-emotional presence after working in groups with other students. The in-class collaborative activities enabled students to share knowledge in a safe and trusting environment. Finally, collaborative activities allowed students to form personal relationships with one another. 


\section{CHAPTER FIVE: DISCUSSION \\ Summary of Findings}

The purpose of this case study was to explore students' perceptions of interactions within a Blended Synchronous Learning Environment (BSLE). Through the lens of the student, the researcher sought insight on interactions among the face-to-face and online learners. It was also hoped the results would build on previous research to guide instructional designers and faculty on instructional strategies for teaching within the BSLE.

The case study research used naturalistic inquiry to collect qualitative data through ten semi-structured observations, ten in-depth interviews, and deploying an openended survey to the students. Participants in the study included twenty-seven students and two instructors. Analytic memoing was used throughout the first-round coding process along with structural coding by the researcher. Pattern coding was then used to organize categories into themes (Saldaña, 2015). The study was based on the following six research questions:

\section{Central question:}

How do students perceive the various interactions that take place within the BSLE?

\section{Sub Questions:}

1. What were students' experiences within the live BSLE?

2. How did students describe interactions (student and instructor) within the live BSLE? 
3. How did students describe interactions (student and student) within the live BSLE?

4. How did students describe designed interactions within the live BSLE?

5. How did students describe social presence within the BSLE?

This chapter will discuss the implications stemming from the research findings, recommendations, best practices, conclusions and future research. In addition, any recommendations that were derived from the research will be presented. The discussion takes into consideration literature on BSLE pedagogy, interactions, and social presence. The implications of these findings are intended to augment the understanding of how students perceive interactions and the result of implementing various interactions on students perceived social presence. Finally, the chapter concludes with implications for researchers and faculty.

The central research question for this study was how student perceive various interactions that occur in the BSLE. Research surrounding the BSLE is limited, yet best practices have been recommended including implementing active learning strategies, becoming familiar with technologies utilized, and designing in-class activities to stimulate meaningful communication (Bower et al., 2015; Szeto, 2014; Szeto \& Cheng, 2014). Students also described social presence in terms of interactions that were designed specifically by the instructor to promote collaboration. Social presence was described by the students as falling on a continuum depending on the activity. 


\section{Research Question \#1: What are Students' Experiences in Within the Live BSLE?}

Online and face-to-face students had varied experiences within the BSLE. Online students had very positive attitudes towards the BSLE and the interaction that occurred within the BSLE. This could be attributed to the fact that the online students had access to education that they may not otherwise be able to obtain due to geographic location. White et al. (2010) stated that the BSLE offers advantages to students who are geographically isolated or unable to attend face-to-face to obtain equitable education. The face-to-face students had a different perspective on the BSLE. One student described the environment as "uncomfortable." Since the face-to-face students were able to attend class in a traditional format, having peers in a virtual environment with an audio lag may prove to be tedious as they had to adjust how they interacted with both the instructor and their peers. This audio lag can be a deterrent to the online and face-to-face student's ability to connect with one another (Bower et al., 2015; Szeto \& Cheng, 2014).

Technology was the main barrier for the face-to-face students when describing the BSLE environment. The ability to navigate technology inhibited some of the face-to-face students from interacting with their online peers thus affecting social presence. Although Cunningham (2014) stated participants in the BSLE environment exhibited high levels of social presence due to the immediacy and intimacy, face-to-face students preferred their face-to-face peers. A majority of the face-to-face students did not log into the virtual environment; therefore, the face-to-face students were separated from their online peers. This was based on instructor preference and knowledge regarding teaching in the BSLE. Bower et al. (2015) recommended that face-to-face students log into the virtual environment. By joining their online peers in the virtual environment, face-to-face 
students can experience the BSLE holistically with their online peers and become connected through the text chat feature. All students should also be prepared prior to class with technical requirements as well as be oriented to the technologies used for the BSLE (Cunningham, 2014; Szeto, 2014). These technology skills are referred to as digital literacy skills. Glister (1997) stated that digital literacy was a set of skills and attitudes of handling communication through a variety of technology and media. Digital skills need to be taught and take time to acquire (Ting, 2015). By requiring the face-toface students to log into the virtual environment for each class session, they will become more comfortable and familiar with the environment. This ultimately will allow them to focus more on the class concepts and interacting with their peers rather than navigating the technology (Bower et al., 2015).

The participants in general were satisfied with the BSLE. This overall satisfaction with the BSLE environment potentially could be attributed to the instructors applying many of the practices from the Blended Synchronous Learning Design Framework. Bower and colleagues (2015) conducted case study research on best practices for the BSLE that contributed to student learning and satisfaction. Table 19 lists the Blended Synchronous Learning Design Framework with the practices the instructors utilized gathered from observations, interviews and an open-ended survey. The practices utilized in this study are in bold. 
Table 18 The Blended Synchronous Learning Design Framework with the practices used in this study bolded.

\begin{tabular}{|c|c|c|c|}
\hline & Pedagogy & Technology & Logistic/setup \\
\hline Presage & $\begin{array}{l}\text { - Clearly define learning } \\
\text { outcomes } \\
\text { - Design for active } \\
\text { learning } \\
\text { - Determine whether to } \\
\text { group online with face- } \\
\text { to-face students } \\
\text { - Utilize general design } \\
\text { principles }\end{array}$ & $\begin{array}{l}\text { - Match technologies to } \\
\text { lessons } \\
\text { - Setup and test the } \\
\text { technology in advance }\end{array}$ & $\begin{array}{l}\text { - Be organized in } \\
\text { advance } \\
\text { - Prepare students } \\
\text { - Prepare self } \\
\text { - Establish a learning } \\
\text { community }\end{array}$ \\
\hline Process & $\begin{array}{l}\text { - Encourage regular } \\
\text { student contribution } \\
\text { - Distribute attention } \\
\text { between online and } \\
\text { face-to-face students } \\
\text { - Identify the focus of } \\
\text { learning and discussion } \\
\text { - Avoid duplicate } \\
\text { explanations } \\
\text { - Circulate among } \\
\text { groups } \\
\text { - Be flexible and } \\
\text { adaptive }\end{array}$ & $\begin{array}{l}\text { - Know how to use and } \\
\text { troubleshoot the } \\
\text { technologies } \\
\text { - Appropriately utilize } \\
\text { audio-visual modalities } \\
\text { - Ensure students have } \\
\text { correct permissions } \\
\text { - Advise students how } \\
\text { to use the technologies }\end{array}$ & $\begin{array}{l}\text { - Start lessons } 10 \\
\text { minutes early for } \\
\text { technology testing } \\
\text { - Apply tactics to work } \\
\text { with text chat } \\
\text { contributions } \\
\text { - Login to a second } \\
\text { computer (for student } \\
\text { view) } \\
\text { - Seek teaching } \\
\text { assistance where } \\
\text { possible }\end{array}$ \\
\hline $\begin{array}{l}\text { Product } \\
\text { (Outcomes) }\end{array}$ & \multicolumn{2}{|c|}{$\begin{array}{l}\text { - More active learning (online and face-to-face) } \\
\text { - Enhanced sense of community } \\
\text { - } \quad \text { More flexible access to learning } \\
\text { - Increased student satisfaction }\end{array}$} & \\
\hline
\end{tabular}

Both instructors designed the class for active learning which included discussions, group report back activities, collaboration problem solving activities, and collaborative design tasks, all which required student participation. Bower et al. (2015) stated the overall premise for the framework is to compile practices for collaborative learning. 
Implementing these practices before and during facilitating class can optimize the student experience.

\section{Research Question \#2: How Do Students Describe Interactions (Student and Instructor) Within the Live BSLE?}

The primary interaction that occurred in the BSLE was between the instructor and the students. This was due to the active learning strategies the instructors employed during the class. Through the use of probing the instructors continually monitored the students' engagement while distributing their attention between the online and face-toface students. Bower et al. (2015) highly recommended employing active learning strategies while equally distributing the attention among students as part of the blended synchronous learning design framework.

Both Szeto (2015) and Rasmussen (2003) found an unequal distribution of attention from the instructor to either the online group or the face-to-face group similar to this case study. Unlike this case study, the students in Szeto (2014) and Rasmussen's (2003) studies felt there was an unequal distribution of attention from the instructor. In Szeto (2014), the instructor over compensated his attention towards the online students. The face-to-face students felt the instructor spent too much time focused on additional explanations specifically for the online students. Rasmussen (2003) found the opposite where the instructor focused his attention towards the face-to-face students. In this case study, although the frequency of interactions between the instructor and face-to-face students was higher, overall, the students felt the attention of the instructor was distributed equally. One instructor used a systematic practice of calling on students by name. The other instructor typically called on students by group: online or face-to-face. 
The face-to-face students were more apt to answer the instructors' questions and then continued to engage in the discussion. Whereas one or two online students would answer the question without continuing to engage the instructor in the dialog. This could be one possible reason for the imbalance of interactions. As long as the instructors identified both groups for each question, the students perceived they were being acknowledged.

One notable finding was the instructor's nonverbal cues. One instructor was unaware that she was using her body language and eye contact to elicit responses from specific groups of students. Instructors in the BSLE should be aware of their body language to ensure both groups of students are included in the verbal and nonverbal conversation. Bower et al. (2015) found that instructors may experience cognitive overload while managing students in two environments. Adding the nonverbal awareness could contribute to additional cognitive overload for instructors. To overcome this additional awareness task, instructors need to employ a systematic method for interacting with students such as calling on individual students by name. This would ensure the attention is distributed among all students, employ a method of active learning, and assist instructors with their nonverbal cues.

Overall, students were satisfied with the active learning strategies employed in the classroom. Active learning is a teaching method that supports learning which uses techniques such as writing reflections, discussion, and problem solving activities (Chickering \& Gamson, 1987). These types of activities promote analysis and synthesis of course content that guides students to achieve the intended learning objectives (Morrison, 2015). The instructors in this study used group report activities, collaborative problem solving activities, and class discussions. The collaborative activities allowed the 
students to engage with the instructor and receive immediate feedback which contributed to their learning goals (Bower et al., 2015).

\section{Research Question \#3: How Do Students Describe Interactions (Student and Student) Within the Live BSLE?}

Interactions can be described as reciprocal engagement between persons (Parker et al., 2013). Students described interactions with their peers through a broad variety of collaborations. Some students felt that interactions consisted of engaging their peer in conversation which included eye contact and nonverbal cues. Other students described interactions with their peers as a form of listening to others' views. Overall, student to student interaction has been shown to support learning (Bower et al., 2015; Swan, 2002).

Similar to Ramussen (2003) and Szeto and Cheng (2014), there were a low number of interactions between the online and face-to-face students. Face-to-face students preferred to interact with those in their immediate vicinity whereas online students who had questions chose to engage with the instructor rather than fellow classmates. This suggests that students perceived each other in two separate educational environments rather than in one class. Many of the face-to-face students were enrolled in the Educational Leadership (EDL) class where they were not required to log into the virtual environment with their online peers. A majority of face-to-face students, primarily EDL students, stated they had difficulty connecting with their online peers. This was also evident in Szeto and Cheng's (2014) study. Despite the environment where the face-toface students can see physical attributes of the online students including nonverbal facial expressions, it cannot be assumed that students in the two environments will interact. The lack of connection could be attributed to the fact that many of the face-to-face students 
were not required to $\log$ into the virtual environment with their online peers. Since the face-to-face students were not in the virtual environment, they did not have the opportunity to interact with the online students via text chat. Although in Ramussen's (2003) and Szeto and Cheng's (2014) studies, the online and face-to-face students were connected in the virtual environment, they still had low interactions. Szeto and Cheng (2014) recommended instructors cultivate quality interactions to enhance student interactions among groups.

Bower et al. (2015) recommended a blended synchronous framework that includes strategies such as all students have access to the virtual environment and by carefully designing active learning activities. One suggestion was to pair an online student with a face-to-face student so the face-to-face student could articulate any concerns or issues the online student was facing. This strategy could also assist with facilitating communication between the two groups and allow for a relationship to develop among the pairs of students. It was also suggested that online students need preparation in terms of technological setup, technology skills, and expectations. From the current case study, it is suggested that all students including the face-to-face students participate in an orientation to ensure all students have the technology skills that are required to participate with the instructor and other students.

In conclusion, based on previous and current research, there are many suggestions instructors can incorporate into their instruction to promote interaction among the faceto-face and online students. First, an orientation to ensure all students have the basic skills to navigate the technology utilized in the BSLE (Bower et al., 2015; Cunningham, 2014). Second, pair online and face-to-face students (Bower et al., 2015). Finally, design 
group activities that fosters communication among group members (Szeto \& Cheng, 2014). By employing a combination of these suggestions, the instructor will ensure the students are technologically prepared and able to participate in discourse will all students.

\section{Research Question \#4: How Do Students Describe Designed Interactions Within the Live BSLE?}

Collaborative learning is defined as working in a group to achieve a common goal (McInnerney \& Robert, 2004). Students in this study described designed interactions as instructor created activities where two or more individuals worked together to achieve a common goal. These in class activities were defined as team activities where the students acknowledged the limited time frame to work together to form their thoughts and ideas. Students did not include whole class discussions as an example of designed interaction even though they stated it was a form of collaboration. Oyarzun (2016) described two types of interaction: designed and contextual. She stated designed interactions are intentionally designed and implemented to provide students an opportunity to collaborate. Contextual interactions provide students with the opportunity to interact yet have no instructional intent. In this study, whole class discussions could be considered contextual interactions which allowed the students to collaborate; yet, students were not working towards an instructional goal.

Oyarzun (2016) stated that designed interaction should include the following characteristics: (a) positive interdependence; (b) individual and group accountability; (c) promotive interactions, and (d) elaborate explanations. Positive interdependence is when the group perceives a need for one another to achieve a common goal. Students may complete tasks individually but need to synthesize the information together in order to 
complete the given task. Individual and group accountability refers to group members assessing one another's contributions both individually and as a group. Promotive interaction refers to students supporting one another both academically and personally (Johnson \& Johnson, 2009). Elaborate explanations refer to collaboration with a focus on encouraging understanding (Oyarzun, 2016).

Based on the experiences from the Master of Instructional Technology (MIT) students, the collaborative activities exhibited positive interdependence, individual and group accountability, promotive interactions, and elaborate explanations. The students had to work together to solve an ill-structured problem. Although they may have worked individually on sections of the problem, there was a need to regroup and synthesize the information found individually to provide the instructor with elaborate explanations. The complexity and design of the activity created positive interdependence, required individual and group accountability, and elaborate explanations which led to promotive interactions among the group members and in turn the group members became a more cohesive group. In contrast, the EDL students implied the collaborative activities did not have positive interdependence and individual or group accountability. For this reason, students did not have to rely on one another to complete a common goal; therefore, they did not exhibit promotive interactions. It can be inferred that the positive interdependence is the underlying characteristic of designed interactions which enables students to have accountability, elaborate on the explanations, and create promotive interactions.

Szeto and Cheng (2014) stated that inter- and intra-group interactions should be taken into consideration when designing blended learning activities. Szeto (2015) also stated that the instructor stimulated these types of activities through moderations of the 
learning activities. The designed interactions should be well explained by the instructor and stimulate students to create positive interdependence. Based on the data from this case study, the instructor needs to allow for enough time for the activities to allow the students to delve deep into the content. A well-designed interaction activity that includes positive interdependence, clear instructor moderation, and time will allow students to build interpersonal relationships while working towards a common goal.

\section{Research question \#5: How Do Students Describe Social Presence Among the Face- to-Face and Online Students Within The BSLE?}

One finding was how students described various degrees of social presence in terms of how they collaborate and the types of designed interactions. Students consistently referred to the webcam and collaborative activities when referencing how they develop relationships with their peers. Throughout the years, researchers have postulated a variety of definitions of social presence (Gunawardena, 1995; Gunawardena \& Zittle, 1995; Richardson \& Swan, 2003). Yet the students in this study illustrated degrees of social presence depending on the activities with the use of video allowing the students to project themselves and working in teams which then established socialemotional presence. When referencing use of video, students felt they were able to project themselves or perceive others as real (Garrison et al., 2000). On the opposite end of the spectrum, students felt an emotional connection to their peers during and after working on a long-term collaborative project. Lowenthal (2009) stated that definitions of social presence fall on a continuum. In this study, students' descriptions suggest a process of moving from low social presence to high social-emotional presence depending on the type of activity. Kreijns et al., (2011) referred to social presence as the "degree of illusion 
that others appear to be a 'real' physical person ... "(p. 366). For this study, the researcher refers to low social presence as the perception of the student to recognize and distinguish other students, yet the students acknowledged there is no relationship with the other students. The students felt they either projected their 'self' or their peers projected their 'self.' Whereas high social-emotional presence is referring to students' perceptions of bringing in an element of emotion such as fear, happiness, or excitement and building a relationship with their peers (Kreijns et al., 2011; Tu, 2000). Cleveland-Innes and Campbell (2012) discussed the emotional element as a separate element yet acknowledged that it exists as a part of social presence. They defined emotional presence as an outward expression of emotion among learners as they interact with the content, students, and instructor.

Social presence is defined by an individual's' perceived sense of interpersonal relationships through interactions (Short et al., 1976). Social presence was stated to be important to the learning process by a majority of the students in this study thus confirming social presence is important to student satisfaction (Gunawardena, 1995; Gunawardena \& Zittle, 1995; Richardson \& Swan, 2003). Bandura (1986) stated that environmental events can influence personal perceptions which in turn influence individual behaviors. The environmental factors in this study were the types of interactions delineated by the instructor. By requiring the students to use their webcams, students were able to project themselves into the physical classroom and thus be perceived as real by their peers. In turn, the design of small group activities also influenced student perceptions of social presence. When activities were designed to ensure students relied upon one another to achieve a common goal, students perceived 
higher social presence than when they did not have to rely upon one another. In accordance with Kreijns et al. (2014), it was not the technology that assisted with students building high social presence but the design of the activities or the designed interactions that facilitated creating social presence among the students.

Student's sense of social presence is influenced by online education features and strategies employed by the instructor (Sung \& Mayer, 2012). Sung and Mayer (2012) stated the instructor and students should share personal experiences which allow students to view each other as humans. The students in this study expressed social presence in a similar format. Through the webcam video, they were able to physically distinguish one another during class discussions. As they collaborated on in class activities, which promoted the sharing of different viewpoints, they were able to not only see one another but also share personal experiences as it related to class material. When they worked on collaborative activities, they shared content viewpoints as well as personal stories thus developing a more emotional presence with one another. As one student stated, when they met to discuss collaborative projects, $80 \%$ of the discussion was focused on course content, and the other $20 \%$ of the conversation was on non-course content. Through these discussions, the students were able to go beyond identifying one another through visual recognition and develop a relationship with their peers based on emotional connections. These emotional connections formed through sharing of personal information. For instance, one online student shared her excitement for her family coming to visit. The students in her group not only met around her schedule yet also shared in her excitement. These findings reinforce Pallof and Pratt's (2007) notion of recognizing the importance of intentionally designed activities to facilitate social presence among students. 
Visual cues are an important aspect for establishing social presence (Borup, West, \& Graham, 2012; Garrison et al., 2000). Borup and colleagues (2012) found the use of video helped students perceive their peers as real people. Social climates created in a virtual environment are different from a traditional face-to-face environment even with the use of interactive audio and video (Gunawardena, 1995). Therefore, it is important for students in the BSLE to all be logged into the virtual room and activate the webcam. Students in the study stated that the video assisted with forming bonds among peers and establishing a presence of the person attending virtually. The ability to see the other students and their visual cues is helpful for negotiating meaning and to build a learning community (Wang, 2006). Although students cannot see nonverbal cues such as body language through the camera, the immediacy assists with the facilitation of communication (Pinsk et al., 2009). Yamada and Akahori (2007) found similar results to this study where students had a better perception of presence when there was an image combined with the audio transmission. Ko (2012) also found social presence was higher when students used a combination of the web camera and audio. The availability of nonverbal cues, peers' immediacy and the feeling of being 'real' were the three factors that influenced students' perception of social presence. As this study also suggested, the use of the video influences students' perceptions of social presence and is an important aspect of beginning to develop a community of learners (Pinsk et al., 2014).

Research suggests that there is a relationship between collaborative learning and social presence (Kreijns et al., 2014; So \& Brush, 2008). The relationship is confirmed through this study since many of the students noted that in-class collaborative activities helped to establish a connection between the one another. As a result of the study 
conducted, the researcher found that the collaborative in-class activities assisted in creating trust and interdependence between the students which in turn created a higher level of social presence (Garner \& Rouse, 2016). The class activities allowed the students to exchange information relating to course content in a supportive environment thus encouraging reciprocal discourse and establishing interdependence. This recognition and acknowledgement of each other's contributions are important in the BSLE. This study also corroborated Garner and Rouse (2016) who found in class activities assisted with creating social presence among students.

Many of the students stated that the in-class activities opened the line of communication which served to create high social-emotional presence. The inclusion of the in-class collaborative activities is an important aspect in the development of social presence as Sato and Kageto (2015) also stated. This study suggests that for students to move from low to high social presence, the building of relationships and trust needs be established among students. This establishment of relationships could be accomplished through carefully designed and scaffolded collaboration activities throughout the duration of the course.

Students reported social presence in terms of various type of activities as well as different levels of social presence. This suggests that social presence can be created through intentionally designed interactions. Students stated the importance of the web camera to allow them to begin to distinguish one another and enabled students to project themselves (Garrison et al., 2000). The in-class collaborative activities allowed students to be perceived as real by others while discussing class concepts (Gunawardena, 1995) and enabling the students to become emotionally connected and form personal 
relationships (Tu, 2000). This suggests that students perceive social presence on a continuum and that intentionally designed interactions can move students from low social presence to high social presence.

\section{Implications for Practice}

The Blended Synchronous Framework developed by Bower et al. (2015) offers suggestions and strategies for teaching in the BSLE. This study corroborated the following strategies within the framework: technology preparation for instructor and students, active learning, distribute attention between online and face-to-face students, and determine student groupings ahead of time for student satisfaction. The following sections will elaborate on implications for instructors based on the Blended Synchronous Framework and social presence theory and add additional practices based on this case study project.

\section{Blended Synchronous Framework}

Technology can contribute to or counteract from the students' educational experiences. Bower et al. (2015) summarized the following technology practices: match technologies to lesson requirements, setup and test technology in advance, prepare students and instructor, advise students on how to use the technologies and have the ability to troubleshoot the technologies. Szeto (2015) recommended that both students and instructors receive professional development. Although the students in the EDL did not receive professional development or training regarding the technology, it was stated by one student that an orientation would assist with the comfort level. The research in this case study coincides with the recommendations from the Blended Synchronous 
Framework as experience and familiarity with the technology used in the BSLE can affect the overall student experience.

All students should have access and be logged into the virtual environment. This enables the face-to-face and online students to have access to one another via text chat as well as through audio. By requiring all students to be in the virtual environment, the instructor can use various polling features available in the virtual environments which can level the playing field and engage the class holistically. Requiring all students to be logged into the virtual environment, the instructor is also able to distribute attention equally through the use of polling questions.

Active learning contributes to students' educational experience through various forms of participation such as discussions and small group activities. Instructors need to design their lessons to include student participation. During discussions, distributing attention among and between the face-to-face and online students is essential. Bower et al., (2015) stated that attention needs to be distributed among the face-to-face and online groups but does not offer suggestions on implementing this practice. One strategy that surfaced out of this particular study was a systematic practice of calling on individual students. The instructor could use the class roster and make a note when a student is called upon to answer a question. Therefore, all students have an opportunity to participate, and this helps to reduce cognitive overload for the instructor. By referencing a class roster, the instructor can visually identify who has and who has not yet participated. To reduce cognitive overload, instructors should assign a student to monitor the text chat (Bower et al., 2015; Szeto \& Cheng, 2014). This ensures students can communicate in a method other than audio and still feel they are acknowledged. 
Another strategy that surfaced from this study was predetermined groupings for in-class collaborative activities. The instructor should determine groups prior to class and maintain the same groups throughout the duration of the course. This allows students to work through any technology issues and then be able to focus on course content not trying to learn about and familiarize themselves with one another. Maintaining the same groups throughout the duration of the semester also allows the students to build strong relationships.

\section{$\underline{\text { Social Presence }}$}

Instructors need to design activities that can facilitate the social presence process to create a community among students (Bower et al., 2015; Szeto, 2015; Szeto \& Cheng, 2014). By enforcing the webcam and calling on students by name, the instructor reinforces the notion that everyone is a distinct individual not just part of the online or face-to-face group. Designed interactions may be able to facilitate the process of creating high social-emotional relationships among students.

Logistics of the room design and setup also needs to be considered. In the EDL distance room, the online students had a frontal view of the instructor yet were only able to see the back of the face-to-face students' heads. This created a barrier for the online students to be able to identify their face-to-face peers. As one online student suggested, he was able to name and remember what his online peers looked like since he saw their faces yet stated he did not know the names of the face-to-face students because he could not visually remember them. Therefore, the instructor needs to take into account the design of the room when planning for instruction. 
Use of active learning strategies when designing collaborative activities that foster reciprocal relationships are an important concept for instructors (Garner \& Rouse, 2016). The design of the activities should foster reciprocal relationships among the students. Case studies and ill-structured problems serve as examples of collaborative activities that force students to collaborate and discuss. Instructors should also guide the students on communication strategies when grouping online and face-to-face students.

Finally, carefully designing collaborative activities to include positive interdependence. Positive interdependence ensures students collaborate together and work towards a common interest. Through positive interdependence, students have individual and group accountability to provide elaborate explanations to the instructor. These characteristics of a designed interaction will eventually lead to promotive interactions where students are supportive of one another both academically and personally.

\section{Additional Practices Based on this Case Study Project}

This case study garnered student perceptions on interactions within the BSLE. From this research, additional suggestions for instructors and instructional designers emerged (Table 20). Prior to class, the instructor should determine student groupings ahead of time. If teams include both online and face-to-face students, consider maintaining the same groups throughout the semester. Provide technology orientation to all students and ensure the instructor also is proficient with the technologies. Finally, design collaborative activities with intent. At the beginning of class, assign a face-to-face student to assist with moderating the chat feature and require all students to log into the 
virtual class room. During class time, encourage regular student contribution by calling

on students by name.

Table 19 The Blended Synchronous Design Framework with additional recommendations from this case study research project. Additional recommendations are in bold.

\begin{tabular}{|c|c|c|c|}
\hline & Pedagogy & Technology & Logistic/setup \\
\hline Presage & $\begin{array}{l}\text { - Clearly define learning } \\
\text { outcomes } \\
\text { - Design for active } \\
\text { learning } \\
\text { - Determine whether to } \\
\text { group online with face-to- } \\
\text { face students } \\
\text { - Determine groups } \\
\text { ahead of time and keep } \\
\text { groups for duration of } \\
\text { class } \\
\text { - Utilize general design } \\
\text { principles }\end{array}$ & $\begin{array}{l}\text { - Match technologies to } \\
\text { lessons } \\
\text { - Setup and test the } \\
\text { technology in advance } \\
\text { - Provide orientation } \\
\text { to technologies }\end{array}$ & $\begin{array}{l}\text { - Be organized in } \\
\text { advance } \\
\text { - Prepare students } \\
\text { - Prepare self } \\
\text { - Establish a learning } \\
\text { community } \\
\text { - Ensure interactions } \\
\text { are designed with } \\
\text { intent }\end{array}$ \\
\hline Process & $\begin{array}{l}\text { - Encourage regular } \\
\text { student contribution by } \\
\text { calling on students by } \\
\text { name } \\
\text { - Distribute attention } \\
\text { between online and face- } \\
\text { to-face students } \\
\text { - Identify the focus of } \\
\text { learning and discussion } \\
\text { - Avoid duplicate } \\
\text { explanations } \\
\text { - Circulate among groups } \\
\text { - Be flexible and adaptive } \\
\text { - Assign student to } \\
\text { moderate text chat }\end{array}$ & $\begin{array}{l}\text { - Know how to use and } \\
\text { troubleshoot the } \\
\text { technologies } \\
\text { - Appropriately utilize } \\
\text { audio-visual modalities } \\
\text { - Ensure students have } \\
\text { correct permissions } \\
\text { - Require all students } \\
\text { to log into the virtual } \\
\text { classroom }\end{array}$ & $\begin{array}{l}\text { - Start lessons } 10 \\
\text { minutes early for } \\
\text { technology testing } \\
\text { - Apply tactics to work } \\
\text { with text chat } \\
\text { contributions } \\
\text { - Login to a second } \\
\text { computer (for student } \\
\text { view) } \\
\text { - Seek teaching } \\
\text { assistance where } \\
\text { possible }\end{array}$ \\
\hline $\begin{array}{l}\text { Product } \\
\text { (Outcomes) }\end{array}$ & \multicolumn{2}{|c|}{$\begin{array}{l}\text { - } \quad \text { More active learning (online and face-to-face) } \\
\text { - } \quad \text { Enhanced sense of community } \\
\text { - } \quad \text { More flexible access to learning } \\
\text { - Increased student satisfaction }\end{array}$} & \\
\hline
\end{tabular}


During the presage, the instructor can prepare for class by determining student groupings for any collaborative activities. Preparation ahead of time will allow more class time for collaborative activities. Maintain the groups for the duration of the semester. This strategy will allow the group members to "norm". The groups will then be able to focus on the content rather than any technology and/or personality issues. The collaborative activities need to be designed to promote collaboration through positive interdependence. Collaborative activities should not be designed for the sake of collaboration only. Finally, require students to participate in an orientation to the technologies used for the BSLE. This can be accomplished through a live orientation or a Computer Based Training (CBT). Through careful planning and preparation, the students will be able to focus on the instructional content.

During the process stage, require all students to log into the virtual classroom. All students in the virtual classroom serve multiple purposes. Face-to-face and online students will be connected through the chat feature. The instructor can pair face-to-face with online student easily, and the face-to-face students become familiar with the technology. Also, the instructor can use polling features within virtual classes to ask whole class questions and garner participation from all students using one method (e.g. text chat, polling features). At the beginning of class, assign a face-to-face student to assist with moderating the chat. The instructor can then focus on the instructional content, and the student will alert the instructor to any issues or comments from the online students. Finally, distribute attention equally among the online and face-to-face students by calling on students by name. This ensures all students have a voice and there is equal participation from all students. Using these strategies throughout class sessions can assist 
the instructor with his/her awareness of the two groups of students and reduce cognitive overload.

\section{Implications for Research}

The current study was conducted to explore students' perceptions of interactions in the BSLE. Future research can build on the findings to investigate how types of designed interactions shape students' perceptions of social presence and whether these types of interactions guide students through the social presence process from low to high social presence.

In addition, there is a need for further work to understand how various degrees of social presence contributes to student learning and satisfaction in the BSLE. This study examined student perceptions of interactions and social presence but not the effect of social presence on learning and student satisfaction. Students were asked if they felt social interaction contributed to their learning but to what degree is social presence necessary for students to achieve course learning outcomes was not identified. Also, Walther (1996) suggested participants will form social relationships over time, yet can social presence be fostered within a given time frame with intentionally designed interactions (Johansen, Vallee \& Spangler, 1988)? Further research on intentionally designed collaborative activities could determine how students form relationships.

Finally, this study confirmed many of the suggestions from the Blended Synchronous Design Framework (Bower et al., 2015) yet additional research should be conducted to validate the framework. This study examined classes within the BSLE. Future research should continue to examine each class as a case to corroborate instructional and technological strategies set forth by the Blended Synchronous Design 
Framework and continue to expand upon the framework to serve as a guide for those teaching within the BSLE in the future.

\section{Limitations of the Study}

This study as with most studies is subject to limitations. First, as with all qualitative research, the product is a result of the reflection of the researcher. The researcher is alumni of the MIT program and was more aware of the instructor's teaching strategies. The research also had some bias towards the BSLE. This study began its inception as a potential study when I was a participant in a workshop with a facilitator who was an instructor in the BSLE. During this workshop, the facilitator dismissed the online participants during the introductions by allowing the face-to-face participants to introduce themselves and then generally introduced the online participants generally. After the online participants were informally introduced, there was no effort on the part of the instructor to engage the online participants, and we were treated more like observers than participants. My concern at that point was that students taking classes may have the same experience. This concern was reaffirmed during the pilot study when one student commented that the feeling was when a student chose to attend online, that student was choosing to be an observer and not a participant.

To prevent bias interpretations of subjective information, multiple sources of data was obtained particularly in the form of multiple interviews from students with diverse backgrounds. Second, a cross-case analysis of this study could be completed to pinpoint the differences in student perceptions based on instructional style. Both instructors had teaching experience within the BSLE yet their instructional and preparation styles differed. These instructional styles could be analyzed further to ascertain in the 
differences among the specific classes and analyze each class as a case. This was not done as the researcher wanted to gain a holistic view of the BSLE and overall student perceptions. Third, the current study was limited by its context, and there was a small number of students participating in the study. The researcher recruited volunteers for the interviews through email. Therefore, the majority of students who volunteered may have had similar outlooks on the BSLE. The findings of this study may be suggestive for similar groups yet may not be generalizable to other groups such as undergraduate programs or other institutions. Particularly since students in these programs had the option to attend online or face-to-face and they took advantage of this freedom. This mobility of the students may have led to their positive experiences.

\section{Conclusions}

The BSLE is a unique environment since it incorporates both face-to-face and online students simultaneously. Research in distance education is overwhelming yet, there are limited studies examining the BSLE and student perceptions in order to refine best pedagogical practices. The purpose of this qualitative case study was to explore students' perceptions toward the BSLE and the interactions that take place. This study aimed to answer one central research question how do students perceive the various interactions that take place within the BSLE? The findings of this study expanded the work of previous researchers in the area of BSLEs including Moore's Transactional Distance, social presence theory, and the Blended Synchronous Design Framework. The interactions were framed within the context of Moore's Transactional Distance: learnerlearner, learner-instructor, and learner-content. Social presence theory was applied to 
students' experiences to garner the level of social presence. Finally, the pedagogical suggestions from Blended Synchronous Design Framework were applied.

The results corroborated Bower and colleague's (2015) Blended Synchronous Design Framework suggestions for designing and implementing instruction such as designing for (a) active learning, (b) determining grouping strategies ahead of time, and (c) becoming proficient with the technology. Additional suggestions of including technology orientation for students, assigning a student moderator, and requiring all students to log into the virtual classroom were added to this framework based on the evidence from this study. Although the results of this study corroborate Szeto and Cheng (2014) and Ramussen (2003) studies with low student-to-student interaction, students in this study were still able to form emotional connections with other students due to designed interactions

Designed interactions by the instructors were small group ill-structured problems that had the following characteristics: (a) positive interdependence, (b) individual and group accountability, (c) promotive interactions, and (d) elaborate explanations (Oyarzun, 2016). Positive interdependence was a key characteristic to promote interaction among the students and thus build relationships. The need to rely on one another to achieve a common goal allowed students to support one another (promotive interactions) and provide elaborate explanations.

Results also suggested students perceive various degrees of social presence. The degree of social presence students perceived was based on the type of interaction. Social presence has been determined to affect student learning outcomes and satisfaction; therefore, implementing interactions designed for collaboration is essential 
(Gunawardena, 1995; Richardson \& Swan, 2003). Contextual interactions such as whole class discussion where the students are physically seen by all created a "presence" where students could distinguish one another (low social presence). Thus leading to students projecting themselves. Designed interactions such as small group activities can be implemented to facilitate collaboration and move students from low social presence to high social-emotional presence. Additional research regarding student perceptions of levels of social presence based on designed interactions should be conducted to further ascertain how students move from low to high social-emotional presence. 


\section{REFERENCES}

Allen, I. E., \& Seaman, J. (2015). Grade level: Tracking online education in the United States. Babson Park, MA: Babson Survey Research Group and Quahog Research Group. Retrieved from http://www.onlinelearningsurvey.com/reports/gradelevel.pdf

Akyol, Z., \& Garrison, D. R. (2008). The development of a community of inquiry over time in an online course: Understanding the progression and integration of social, cognitive and teaching presence. Journal of Asynchronous Learning Networks, 12, 3-22.

Akyol, Z., Garrison, D. R., \& Ozden, M. Y. (2009). Online and blended communities of inquiry: Exploring the developmental and perceptual differences. International Review of Research in Open and Distance Learning, 10(6), 65-83.

Anderson, T., Rourke, L., Garrison, D. R., \& Archer, W. (2001). Assessing teacher presence in a computer conferencing context. Journal of Asynchronous Learning Networks, 5(2), 1-7.

Arbaugh, J. B., \& Benbunan-Fich, R. (2006). An investigation of epistemological and social dimensions of teaching in online learning environments. Academy of Management Learning \& Education, 5(4), 435-447.

Baker, C. (2010). The impact of instructor immediacy and presence for online student affective learning, cognition, and motivation. Journal of Educators Online, 7(1), $1-30$.

Bandura, A. (1986) Social foundations of thought and action: A social cognitive theory. Englewood Cliffs, NJ: Prentice Hall.

Bernard, R. M., Abrami, P. C., Borokhovski, E., Wade, C. A., Tamim, R. M., Surkes, M. A., \& Bethel, E. C. (2009). A meta-analysis of three types of interaction 
treatments in distance education. Review of Educational Research, 79(3), 12431289.

Bielawski, L., \& Metcalf, D. (2005). Blended Elearning: Integrating knowledge, performance support and online learning. Amherst, MA: HRD Press.

Borup, J., West, R. E., \& Graham, C. R. (2012). Improving online social presence through asynchronous video. The Internet and Higher Education, 15(3), 195-203.

Bower, M., Dalgarno, B., Kennedy, G., Lee, M. J., \& Kenney, J. A. (2014). Handbook for Educators. Retrieved from https://blendsync.org/handbook

Bower, M., Dalgarno, B., Kennedy, G. E., Lee, M. J., \& Kenney, J. (2015). Design and implementation factors in blended synchronous learning environments: Outcomes from a cross-case analysis. Computers \& Education, 86, 1-17.

Bower, M., Cram, M., \& Groom, D. (2010) Blended reality: Issues and potential in combining virtual worlds and face-to-face classes. In C.H. Steel, M.J. Keppell, P. Gerbic \& S. Housego (Eds), Curriculm, technology \& transformation for an unknown future. Proceedings ascilite Sydney 2010 (pp. 129-140). Brisbane: The University of Queensland.

Chen, N. S., Ko, H. C., Kinshuk, \& Lin, T. (2005). A model for synchronous learning using the Internet. Innovations in Education and Teaching International. 42(2), 181-194.

Chickering, A.W., \& Gamson, Z. F. (1987). Seven principles for good practice in undergraduate education. American Association for Higher Education Bulletin, 39, 3-7.

Christensen, L., \& Evamy, S. (2011). MAPs to success: Improving the first year experience of alternative entry mature age students. The International Journal of the First Year in Higher Education, 2(2), 35-48.

Cleveland-Innes, M., \& Campbell, P. (2012). Emotional presence, learning, and the online learning environment. The International Review of Research in Open and Distributed Learning, 13(4), 269-292. 
Conklin, S., Barreto, D., Rabidoux, S., \& Oyarzun, B. (2016). Blended synchronous learning environment: Students’ Perspective. Manuscript submitted for publication.

Creswell, J. W. (2012). Qualitative inquiry and research design: Choosing among five approaches. Los Angeles, CA: Sage.

Cunningham, U. (2014). Teaching the disembodied: Othering and activity systems in a blended synchronous learning situation. The International Review of Research in Open and Distributed Learning, 15(6). Retrieved from http://www.irrodl.org/index.php/irrodl/article/view/ 1793/3175

Dewey, J (1938). Experience and education. New York: Collier Books.

Eisenhardt, K. M., \& Graebner, M. E. (2007). Theory building from cases: Opportunities and challenges. Academy of Management Journal, 50(1), 25-32.

Ezzy, D. (2002). Qualitative analysis: Practice and innovation. London: Routledge.

Foddy, W. (1994). Constructing questions for interviews and questionnaires: Theory and practice in social research. Cambridge, UK: Cambridge University Press.

Garner, R., \& Rouse, E. (2016). Social presence-connecting pre-service teachers as learners using a blended learning model. Student Success, 7(1), 25-36.

Garrison, D. R. (2009). Communities of inquiry in online learning. In P.L Rogers, Berg. G. A., Boettcher, J. V., Howard, C., Justice, L., \& Schenk, K. D. (Eds.), Encyclopedia of distance learning (2nd ed., pp. 352-355). Hershey, PA: IGI Global.

Garrison, D. R. (2011). E-Learning in the 21st Century: A Framework for Research and Practice. London: Routledge/Falmer Retrieved from http://www.eblib.com.

Garrison, D. R., \& Arbaugh, J. B. (2007). Researching the community of inquiry framework: Review, issues, and future directions. The Internet and higher Education, 10(3), 157-172. 
Garrison, D. R., Anderson, T., \& Archer, W. (2000). Critical inquiry in a text-based environment: Computer conferencing in higher education. Internet and Higher Education, 2(2-3), 87-105.

Garrison, D. R., \& Kanuka, H. (2004). Blended learning: Uncovering its transformative potential in higher education. The Internet and Higher Education, 7(2), 95-105.

Garrison, D. R., \& Cleveland-Innes, M. (2003, September). Critical factors in student satisfaction and success: Facilitating student role adjustment in online communities of inquiry. Invited paper presented to the Sloan Consortium Asynchronous Learning Network Invitational Workshop, Boston, MA.

Garrison, D. R., \& Anderson, T. (1993). An analysis of the control construct in selfdirected learning. In H. Long (Ed.), Emerging perspectives of self-directed learning (pp. 27-44). Norman, OK: Research Center for Continuing Professional and Higher Education of the University of Oklahoma.

Garrison, D. R., \& Anderson, T. (2003). E-learning in the 21st century: A framework for research and practice. New York, NY: Taylor \& Francis.

Garrison, D. R., \& Akyol, Z. (2013). The Community of Inquiry theoretical framework. In M. G. Moore (Ed.), Handbook of Distance Education (3rd ed., pp. 104-119). New York, NY: Routledge.

Gilster, P. (1997). Digital literacy. New York, NY: John Wiley

Gunawardena, C. N. (1995). Social presence theory and implications for interaction and collaborative learning in computer conferences. International journal of educational telecommunications, 1(2), 147-166.

Gunawardena, C. N., \& Zittle, F. J. (1997). Social presence as a predictor of satisfaction within a computer-mediated conferencing environment. American journal of distance education, 11(3), 8-26.

Hastie, M., Hung, I. C., Chen, N. S., \& Kinshuk. (2010). A blended synchronous learning model for educational international collaboration. Innovations in Education and Teaching International, 47(1), 9-24. 
Ice, P., Curtis, R., Phillips, P., \& Wells, J., (2007). Using asynchronous audio feedback to enhance teaching presence and students' sense of community. Journal of Asynchronous Learning Networks, 11(2), 3-25.

Johansen, R., Vallee, J., \& Spangler, K. (1988). Teleconferencing: Electronic group communication. In R. S. Cathcart \& L. A. Samover (Eds.), Small group communication: A reader (5th ed., pp. 140-154). Dubuque, IA: William C. Brown.

Johnson, D. W., \& Johnson, R. T. (2009). An educational psychology success story: Social interdependence theory and cooperative learning. Educational Researcher, 38(5), 365-379. http://dx.doi.org/10.3102/0013189X09339057

Keppell, M., Souter, K., \& Riddle, M. (Eds). (2012) Physical and virtual learning spaces in higher education: Concepts for the modern earning Environment. Hershey, PA: Information Science Reference.

Ko, C. J. (2012). A case study of language learners' social presence in synchronous CMC. ReCALL, 24(1), 66-84.

Kreijns, K., Kirschner, P.A., Jochems, W. Van Buuren, H. (2011). Measuring perceived social presence in distributed learning groups. Education and Information Technologies, 16(4), 165-182.

Kreijns, K., Van Acker, F., Vermeulen, M., \& Van Buuren, H. (2014). Community of Inquiry: social presence revisited. E-Learning and Digital Media, 11(1), 5-18.

Lehman, R., \& Conceicao, S. (2010). Creating a sense of presence in online teaching: How to "be there" for distance learning. San Francisco, CA: John Wiley \& Sons.

Lincoln, Y. S., \& Guba, E.G. (1985). Naturalistic inquiry. Newbury Park, CA: Sage.

Lowenthal, P. R. (2009). The evolution and influence of social presence theory on online learning. In T. T. Kidd (Ed.), Online education and adult learning: New frontiers for teaching practices (124-139). Hershey, PA: IGI Global.

Lowenthal, P. R., \& Dunlap, J. C. (2014). Problems measuring social presence in a community of inquiry. E-Learning and Digital Media, 11(1), 19-30. 
Marjanovic, O. (1999). Learning and teaching in a synchronous collaborative environment. Journal of Computer Assisted Learning, 15(2), 129-138.

McCue, L. S., \& Scales, G. R. (2007). Embracing the middle ground: engaging on- and off-campus students within the same 'classroom'. In B. B. Thomas (Ed.), Proceedings of the 2007 ASEE Southeastern Section Annual Conference and Meeting Washington, DC: American Society for Engineering Education.

McInnerney, J., \& Robert, T. S. (2004). Collaborative or cooperative learning? In T. S. Roberts (Ed.), Online collaborative learning: Theory and practice. (pp. 203-214). Hershey, PA: Information Science Publishing.

Medeiros Vieira, L. M., Ferasso, M., \& Schröeder, C. D. S. (2014). Connecting multiple intelligences through open and distance learning: Going Towards a Collective Intelligence? European Journal of Open, Distance and E-Learning, 17(1), 108117.

Merriam, S. B. (2009). Qualitative research: A guide to design and implementation. San Francisco, CA: John Wiley \& Sons.

Merriam, S. B., \& Tisdell, E. J. (2015). Qualitative research: A guide to design and implementation. San Francisco, CA: John Wiley \& Sons.

Miles, M. B., \& Huberman, A. M. (1994). Qualitative data analysis: An expanded sourcebook. Thousand Oaks, CA: Sage.

Moore, M. G. (1989). Editorial: Three types of interaction. The American Journal of Distance Education, 3(2), 1-7.

Moore, M. G. (1993). Theory of transactional distance. In D. Keegan (Ed.), Theoretical principles of distance education (p. 22-38).London: Routledge.

Moore, M. G. (Ed.) (2013). Theory of transactional distance. In Handbook of distance education (pp. 66-85). New York, NY: Routledge.

Morrison, D. (2015, September 2). Four-step strategy to create active learning in any learning space - Online, F2F or blended. Retrieved from 
https://onlinelearninginsights.wordpress.com/tag/active-learning-strategies-foronline/

Norberg, A. (2012). Blended learning and new education logistics in Northern Sweden. In D. G. Oblinger (Ed..), Game changers: Education and information technologies (pp. 327-330). Boulder, CO: EDUCAUSE.

O’Malley, J., \& McGraw, H. (1999). Student perceptions of distance education, online learning, and the traditional classroom. Online Journal of Distance Education Administration, 2(4). Retrieved from http://www.westga.edu/ distance/omalley24.html

Osguthorpe, R. T., \& Graham, C. R. (2003). Blended learning environments: Definitions and directions. Quarterly Review of Distance Education, 4(3), 227-33.

Oyarzun, S. E. A. (2016). Effects of learner-to-learner interactions on social presence, achievement and satisfaction (Order No. 10127567). Available from ProQuest Dissertations \& Theses Global. (1808509711). Retrieved from http://libproxy.boisestate.edu/login?url=http://search.proquest.com.libproxy.boise state.edu/docview/1808509711 ?accountid=9649

Oyarzun, B., \& Martin, F. (2013). A case study on multi-modal course delivery and social learning opportunities. Bulletin of the IEEE Technical Committee on Learning Technology, 15(1), 25-27.

Palloff, R. M., \& Pratt, K. (2007). Online learning communities in perspective. In R. Luppicini (Ed.), Online Learning Communities, (pp. 3-16), Greenwich: Information Age Publishing.

Park, Y. J., \& Bonk, C. J. (2007). Is online life a breeze? A case study for promoting synchronous learning in a blended graduate course. Journal of Online Learning and Teaching, 3(3), 307-323.

Parker, J., Maor, D., \& Herrington, J. (2013). Authentic online learning: Aligning learner needs, pedagogy and technology. Issues in Educational Research, 23(2), 227-241.

Patton, M. Q. (2002). Qualitative evaluation and research methods. Thousand Oaks, CA: Sage. 
Pelliccione, L., \& Broadley, T. (2010). R U there yet? Using virtual classrooms to transform teaching practice. In Steel, C., Keppell, M., Gerbic, P. \& Housego, S. (Eds.), Curriculum, technology \& transformation for an unknown future (pp. 749760) ASCILITE Conference Proceedings 2010, 5-8 December 2010, Sydney, Australia. Retrieved from http://espace.library.curtin.edu.au/cgibin/espace.pdf?file=/2011/02/18/file_1/152536

Picciano, A. (2002). Beyond student perceptions: Issues of interaction, presence, and performance in an online course. Journal of Asynchronous Learning Networks, 6(1), 21-40.

Picciano, A. G. (2006). Blended learning: Implications for growth and access. Journal of Asynchronous Learning Networks, 10(3), 85-91.

Pinsk, R., Curran, M., Poirier, R., \& Coulson, G. (2014). Student perceptions of the use of student generated video in online discussions as a mechanism to establish social presence for nontraditional students: A case study. Issues in Information Systems, 15(1), 267-276.

Porter, D. (Ed.) (1994). New directions in distance learning: Interim report. (Available: David Porter, Manager, Schools Curriculum Programs, 4355 Mathissi Place, Burnaby, BC, Canada V5G 4S8).

Quinn, D., Amer, Y., Lonie, A., Blackmore, K., Thompson, L., \& Pettigrove, M. (2012). Leading change: Applying change management approaches to engage students in blended learning. Australasian Journal of Educational Technology, 28(1), 16-29.

Rasmussen, R. C. (2003). The quantity and quality of human interaction in a synchronous blended learning environment. (Doctoral dissertation, Brigham Young University) Available from ProQuest Dissertations \& theses. (UMI No. 305345928)

Ravenna, G., Foster, C., \& Bishop, C. (2012). Increasing student interaction online: A review of the literature in teacher education programs. Journal of Technology and Teacher Education, 20(2), 177-203. 
Reece, M., \& Lockee, B. (2005). Improving training outcomes through blended learning. Journal of Asynchronous Learning Networks, 9(4), 49-57.

Ritcdhhart, R., Church, M., \& Morrison, K. (2011). Making thinking visible: How to promote engagement, understanding, and independence for all learners. San Francisco, CA: Jossey-Bass.

Richardson, J., \& Swan, K. (2003). Examining social presence in online courses in relation to students' perceived learning and satisfaction. Journal of Asynchronous Learning Networks, 7(1), 68-88.

Rourke, L., Anderson, T., Garrison, R., \& Archer, W. (2001). Methodological issues in the content analysis of computer conference transcripts. International Journal of Artificial Intelligence in Education, 12(1), 8-22.

Runeson, P., \& Höst, M. (2009). Guidelines for conducting and reporting case study research in software engineering. Empirical Software Engineering, 14(2), 131164.

Saldaña, J. (2015). The coding manual for qualitative researchers. Los Angeles, CA: Sage.

Sahin, I., \& Shelley, M. C. (2008). Considering Students' Perceptions: The distance education student satisfaction model. Educational Technology \& Society, 11(3), 216-223.

Sato, S., \& Kageto, M. (2015). Analysis of an international project-based learning collaboration using the Community of Inquiry framework. International Journal, 9(1), 16-24.

Schornack, G. R., \& Beck, C. E. (2016). Maximizing the distance education learning environment: Using technology for mind expansion. Retrieved from http://commons.erau.edu/cgi/viewcontent.cgi?article=1127\&context=bollingerrosado

Shea, P., Li, C. S., \& Pickett, A. (2006). A study of teaching presence and student sense of learning community in fully online and web-enhanced college courses. The Internet and Higher Education, 9(3), 175-190. 
Shea, P. J., Fredericksen, E., Pickett, A., Pelz, W., \& Swan, K. (2001). Measures of learning effectiveness in the SUNY learning network. In J. Bourne \& J.C. Moore (Eds.) Online education, volume 2: Learning effectiveness, faculty satisfaction, and cost effectiveness (pp. 31-54). Needham, MA: SCOLE.

Short, J., Williams, E., \& Christie, B. (1976). The social psychology of telecommunications. London: Wiley.

Singh, H., \& Reed, C. (2001). A white paper: Achieving success with blended learning. Centra software, Retrieved from http://www.centra. com/download/whitepapers/blendedlearning.pdf

Simonson, M., Smaldino, S., Albright, M., \& Zvacek, S. (2014). Teaching and learning at a distance. Upper Saddle River, NJ: Information Age Publishing.

So, H., \& Brush, T. (2008). Student perceptions of collaborative learning, social presence, and satisfaction in a blended learning environment: Relationships and critical factors. Computers \& Education, 51(1), 318-336. Doi:

10.1016/j.compuedu.2007.05.009

Stake, R. E. (1995). The art of case study research. Los Angeles, CA: Sage.

Stewart, A. R., Harlow, D. B., \& DeBacco, K. (2011). Students' experience of synchronous learning in distributed environments. Distance Education, 32(3), 357-381.

Strauss, A., \& Corbin, J. (1990). Basics of qualitative research. Newbury Park, CA: Sage.

Sung, E., \& Mayer, R. E. (2012). Five facets of social presence in online distance education. Computers in Human Behavior, 28(5), 1738-1747.

Swan, K. (2002). Building learning communities in online courses: The importance of interaction. Education, Communication \& Information, 2(1), 23-49.

Swan, K. (2004). Relationships between interactions and learning in online environment. Retrieved from The Sloan Consortium http://sloanconsortium.org/publications/books/pdf/interactions.pdf. 
Swan, K., \& Shih, L. F. (2005). On the nature and development of social presence in online course discussions. Journal of Asynchronous Learning Networks, 9(3), 115-136.

Szeto, E. (2015). Community of inquiry as an instructional approach: What effects of teaching, social and cognitive presences are there in blended synchronous learning and teaching? Computers \& Education, 81, 191-201.

Szeto, E., \& Cheng, A. Y. (2014). Towards a framework of interactions in a blended synchronous learning environment: what effects are there on students' social presence experience? Interactive Learning Environments, 1-17. doi:10.1080/104948 20.2014.881391

Teng, D. C. E., Chen, N. S., \& Leo, T. (2012). Exploring students' learning experience in an international online research seminar in the synchronous cyber classroom. Computers \& Education, 58(3), 918-930.

Thorne, K. (2003). Blended learning: How to integrate online and traditional learning. London: Korgan Page.

Ting, Y. L. (2015). Tapping into students' digital literacy and designing negotiated learning to promote learner autonomy. The Internet and Higher Education, 26, 25-32.

Treanor, F. (2010). Structured observation - An assessment of methodological strengths and weaknesses from two epistemological perspectives. Retrieved from http://www.academia.edu/5256389/Structured_Observation_as_Research_Method _in_Education_-_a_Critical_Assessment

Tu, C. H. (2000). On-line learning migration: from social learning theory to social presence theory in a CMC environment. Journal of network and computer applications, 23(1), 27-37.

Wagner, E. D. (1994). In support of a functional definition of interaction. American Journal of Distance Education, 8(2), 6-29.

Wang, Y. (2006). Negotiation of meaning in desktop videoconferencing - supported distance language learning. ReCall, 18(1), 122-146. 
Walther, J. B. (1996). Computer-mediated communication: Impersonal, interpersonal, and hyperpersonal interaction. Communication Research, 23(1), 3-43.

Wise, A., Chang, J., Duffy, T., \& del Valle, R. (2004). The effects of teacher social presence on student satisfaction, engagement, and learning. Journal of Educational Computing Research, 31(3), 247-271.

White, C. P., Ramirez, R., Smith, J. G., \& Plonowski, L. (2010). Simultaneous delivery of a face-to-face course to on-campus and remote off-campus students. TechTrends, 54(4), 34-40.

Yamada, M., \& Akahori, K. (2007). Social presence in synchronous CMC-based language learning: How does it affect the productive performance and consciousness of learning objectives? Computer Assisted Language Learning, 20(1), 37-65.

Yamada, M. (2009). The role of social presence in learner-centered communicative language learning using synchronous computer-mediated communication: Experimental study. Computers \& Education, 52, 820-833.

Yin, R. K. (2014). Case study research: Design and methods (5th ed.). Thousand Oaks, CA: Sage.

Zayapragassarazan, Z., \& Kumar, S. (2012) Active learning methods. NTTC Bulletin, 29(1), 75-81. 
APPENDIX A 


\section{Letter of Consent (Student)}

Hello,

I am conducting research study on how interactions between students and instructors can affect the student experience in the blended synchronous learning environments. The blended synchronous learning environment is defined as a live environment with an instructor where the students can attend class either face-to-face or virtually from a virtual classroom such as Cisco WebEx. Many of these classes are offered in Distance Education classrooms.

The research study will be conducted on two summer classes. Students will be asked to fill out an anonymous survey which will be sent to the class by the researcher. Students will also be asked to volunteer to for one-on-one interviews. The survey will take 10-15 minutes and the interview will last approximately 30 minutes

All forms have been approved by the Human Subjects Research Committee. If you have any questions about this project, you can contact Sheri Anderson (910) 9623929 or Dr. Candance Gauthier (910) 962-3558.

Print Name 
APPENDIX B 


\section{Survey from Pilot Study}

Instructions: This questionnaire is designed to measure your learning environment satisfaction and your level of social presence (e.g. your interaction with your face-to-face, online peers, and instructor) in the Blended Synchronous Learning Environment (BSLE). The BSLE is when you can attend class either in the classroom on campus or join virtually via WebEx. Your participation is entirely voluntary and will in no way affect your grade in your course. We will use the information you provide to add to our understanding of online learning from the student perspective. All your answers will be kept confidential. It should take you about 5-10 minutes to complete the survey.

\section{Demographic Information}

1. Select your age range.

a. Under 20

b. 20-29

c. $\quad 30-39$

d. $40-49$

e. $\quad 50-59$

f. Over 60

2. Select your gender.

a. Male

b. Female

3. How many semesters have you taken classes in the Blended Synchronous Learning Environment
a. 1
b. 2
c. 3
d. 4
e. More than 5

4. What is your school status?

a) Part-time student (undergraduate less than 12 credits, graduate less than 9 credits)

b) Full-time student (undergraduate more than 12 credits, graduate more than 9 credits)

7. Identify your major

(open ended) 
8. What is your preferred mode for attending classes in the BSLE.

a. Online in WebEx

b. Face-to-Face on campus

c. I prefer to alternate between face-to-face and online

Social - Likert scale 1 Strongly disagree, $2=$ strongly disagree, $3=$ uncertain, 4=agree, $5=$ strongly agree

1. BSLE is an excellent medium for social interaction.

2. I felt comfortable conversing with both online and face-to-face peers through this medium.

3. I felt comfortable introducing myself in this environment.

4. The introductions enabled me to form a sense of community

5. I felt comfortable participating in discussions.

6. The instructors created a feeling of a community.

7. The instructors facilitated discussions.

8. Discussions in the BSLE were impersonal.**

9. Discussions are more impersonal in this environment. **

10. I felt comfortable interacting with other participants.

11. I felt my viewpoint was acknowledged by other participants.

12. I was able to form distinct individual impressions of other participants.

13. (Open ended) Please write any comments regarding how you interact with your faceto-face and online peers.

Instructor Scale of 1-5 (Strongly Disagree, Disagree, Neutral, Agree, Strongly Agree)

14. My Instructor is a caring person with the students.

15. My Instructor is a "real person" with the students.

16. My Instructor is professional with the students.

17. My Instructor is humble with the students.

18. My instructor provides open communication.

19. My instructor creates unity.

20. My instructor creates an attitude of sharing.

21. My instructor creates an attitude of group encouragement.

22. My instructor draws the class together.

23. My instructor grades my performance fairly.

24. (Open ended) Please write any comments regarding how you interact with your instructor.

Satisfaction Scale of 1-5 (Strongly Disagree, Disagree, Neutral, Agree, Strongly Agree) 25. I found success in the BSLE

26. I enjoyed discussions in the BSLE

27. As a result of my experience in a BSLE, I would participate in more classes using this environment. 
28. I felt the instruction was student-centered (meaning student engagement was part of the course structure.

29. BSLE allows me to allocate my time better.

30. BSLE allows me to work at home comfortably.

31. In terms of time and location, BSLE is flexible.

32. BSLE is appropriate to students with different learning capabilities.

33. (Open ended) Please write any comments regarding the BSLE 
APPENDIX C 


\section{Survey for Case Study (Students)}

Instructions: This questionnaire is designed to gain insight on how you interact with your peers in the Blended Synchronous Learning Environment (BSLE). The BSLE is when you can attend class either in the classroom on campus or join virtually via WebEx. Your participation is entirely voluntary and will in no way affect your grade in your course. The information you provide will add to understanding online learning from the student perspective. All your answers will be kept confidential. It should take you about 5-10 minutes to complete the survey.

\section{Demographic Information}

1. Select your age range.
a. Under 20
b. 20-29
c. 30-39
d. 40-49
e. 50-59
f. Over 60

2. Select your gender.

a. Male

b. Female

3. Please indicate your degree program

a. Master of Instructional Technology

b. Doctorate of Educational Leadership

4. Where are you located (geographically) (open ended) 
5. What is your school status?

a) Part-time student (less than 9 credits)

b) Full-time student (more than 9 credits)

6. What is your preferred mode for attending classes in the BSLE.
a. Online in WebEx
b. Face-to-Face on campus
c. I prefer to alternate between face-to-face and online
7. How many classes in the BSLE have you taken?

\section{Survey Questions}

8. Please identify how you typically attend and then describe how you interact with your face-to-face and online peers.

9. Do you feel an emotional connection to your peers?

10. Do you feel you are able to develop a sense of collaboration with your peers? Describe a situation and whether it is with peers in a similar environment as you (either face-to-face or online) or in the opposite environment or both.

11. Do you backchannel (text chat with peers without instructor knowledge) with your peers, if so, are they your face-to-face peers, online, or both. Describe some of your typical conversations. Are they regarding content, class questions, social (e.g. kids, family work) or technical assistance? 
APPENDIX D 


\section{Observation Protocol for Semi-Structure Observations}

Description of classroom (e.g. use of webcams, computers, number of student f2f, number of students online):

\begin{tabular}{|c|c|c|c|c|c|c|}
\hline Type & $\begin{array}{l}\text { Sub- } \\
\text { Type }\end{array}$ & Admin & Social & Content & Tech & Description/Notes \\
\hline \multicolumn{7}{|l|}{ S-S } \\
\hline & $S^{f}-S^{f}$ & & & & & \\
\hline & $\mathbf{S}^{\mathbf{0}}-\mathbf{S}^{\mathbf{O}}$ & & & & & \\
\hline & $\mathbf{S}^{\mathrm{F}}-\mathbf{S}^{\mathbf{O}}$ & & & & & \\
\hline & $\mathbf{S}^{\mathbf{O}}-\mathbf{S}^{\mathrm{C}}$ & & & & & \\
\hline & $\mathbf{S}^{\mathrm{F}}-\mathrm{S}^{\mathrm{C}}$ & & & & & \\
\hline \multicolumn{7}{|l|}{ I-S } \\
\hline & $\mathbf{I}-\mathbf{S}^{\mathbf{C}}$ & & & & & \\
\hline & $\mathbf{I}-\mathrm{S}^{\mathbf{O}}$ & & & & & \\
\hline & $\mathbf{I}-\mathbf{S}^{\mathrm{F}}$ & & & & & \\
\hline
\end{tabular}

Legend:

$S^{F}-$ Face to face student

$\mathrm{S}^{\mathrm{O}}-$ Online student

$\mathrm{S}^{\mathrm{C}}-$ Whole class 
APPENDIX E 
Blended Learning Framework Observation Form for Analytic Memoing

\begin{tabular}{|l|l|l|}
\hline $\begin{array}{l}\text { Blended Synchronous } \\
\text { Framework construct }\end{array}$ & Present & Notes \\
\hline $\begin{array}{l}\text { Encourage regular student } \\
\text { contribution }\end{array}$ & & \\
\hline $\begin{array}{l}\text { Distribute attention between } \\
\text { remote and face-to-face students }\end{array}$ & & \\
\hline Identify the focus of discussion & & \\
\hline $\begin{array}{l}\text { Avoid duplication of } \\
\text { explanations }\end{array}$ & & \\
\hline
\end{tabular}


APPENDIX F 


\section{Interview Consent Form}

Thank you for agreeing to participate. We are very interested to hear your valuable opinion on Blended Synchronous Learning Environments.

- The purpose of this study is to learn more about interactivity and relationships that are formed in the blended synchronous learning environment including strategies that create a community of learners as well as best practices for studentcontent interaction that we can share with instructors who will be teaching in this type of environment in the future.

- The information you give us is completely confidential, and we will not associate your name with anything you say during the interview.

- Interviews will be recorded so that I can be sure to capture the thoughts, opinions, and ideas correctly. No names will be attached to the interviews and the recording will be deleted as soon as it is transcribed.

- You may refuse to answer any question or withdraw from the study anytime.

- I understand how important it is that this information is kept private and confidential

- If you have any questions now or after you have completed the interview, you can always contact me.

- Please sign (electronically) to show you agree to participate in this interview.

Print Name

Signature

Date 
APPENDIX G 


\section{Student Interview Questions}

1. Describe your class experience with your peers.

2. Have you disclosed information about life outside of class to others? Have others to you? What was the context for the conversation?

3. Were you able to develop a sense of collaboration with your peers? Describe how this was done and with which peers?

4. How do you typically interact with your peers? How do you prefer to interact with your peers?

5. When completing group work, how do you prefer to be grouped and why? How are your typically grouped? 
APPENDIX H 
Instructor Interview Questions

1. How long have you been teaching in the BSLE and/or have you conducted research in this area or professional development? Please tell me about your previous experience.

2. How do you handle technology difficulties? How would you describe your experience?

3. Describe how you prepare for class?

4. How do you determine grouping strategies and what is the reasoning?

5. Describe how you facilitate in class discussion. Is this based on any frameworks or instructional strategies?

6. Do you use active learning strategies, please describe and why do you use this strategy(s)? If none, describe your pedagogy for teaching in this environment. 
APPENDIX I 
This research was conducted under the approval of the Institutional Review Board, UNCW, protocol \#16-0385. 